UNIVERSIDADE DE SÃO PAULO

ESCOLA DE ENFERMAGEM

CHRISTIANE BORGES DO NASCIMENTO

CONHECIMENTO E USO DA ANTICONCEPÇÃO DE EMERGÊNCIA ENTRE ADOLESCENTES ESTUDANTES DO ENSINO MÉDIO

São Paulo 
CHRISTIANE BORGES DO NASCIMENTO

\section{CONHECIMENTO E USO DA ANTICONCEPÇÃO DE EMERGÊNCIA ENTRE ADOLESCENTES ESTUDANTES DO ENSINO MÉDIO}

Dissertação apresentada à Escola de Enfermagem da Universidade de São Paulo para obtenção do título de Mestre em Ciências

Área de concentração:

Cuidados em Saúde

Orientadora:

Prof ${ }^{a}$. Dra . Ana Luiza Vilela Borges

São Paulo 
AUTORIZO A REPRODUÇÃO E DIVULGAÇÃO TOTAL OU PARCIAL DESTE TRABALHO, POR QUALQUER MEIO CONVENCIONAL OU ELETRÔNICO, PARA FINS DE ESTUDO E PESQUISA, DESDE QUE CITADA A FONTE.

Assinatura:

Data:

Escola de Enfermagem da Universidade de São Paulo

Nascimento, Christiane Borges do

Conhecimento e uso da anticoncepção de emergência entre adolescentes estudantes do ensino médio / Christiane Borges do Nascimento. - São Paulo, 2012.

$131 \mathrm{p}$.

Dissertação (Mestrado) - Escola de Enfermagem da Universidade de São Paulo.

Orientadora: $\operatorname{Prof}^{\mathrm{a}} \mathrm{Dr}^{\mathrm{a}}$ Ana Luiza Vilela Borges

Área de concentração: Cuidados em saúde

1. Saúde reprodutiva 2. Anticoncepção 3. Dispositivos anticoncepcionais femininos 4. Saúde do adolescente I. Título. 
Nome: Christiane Borges do Nascimento

Título: Conhecimento e uso da anticoncepção de emergência entre adolescentes estudantes do ensino médio

Dissertação apresentada à Escola de Enfermagem da Universidade de São Paulo para obtenção do título de Mestre em Ciências.

Aprovado em:

Banca Examinadora

Prof ${ }^{a} . \mathrm{Dr}^{\mathrm{a}}$.

Instituição:

Julgamento:

Assinatura:

Prof $\stackrel{\text { a }}{\text { Dr }} \stackrel{\text { a }}{ }$

Instituição:

Julgamento:

Assinatura:

Prof ${ }^{\mathrm{a}}$. Dr ${ }^{\mathrm{a}}$.

Instituição:

Julgamento:

Assinatura: 


\section{DEDICATÓRIA}

Ao meu querido marido Carlos José Chofakian, por ter permanecido ao meu lado com todo amor, carinho e paciência, me apoiando e incentivando

a percorrer este caminho. Sempre se fazendo presente na minha vida e sendo meu melhor amigo em todos os momentos, contribuindo decisivamente para que esta dissertação pudesse ser concluída. 


\section{AGRADECIMENTOS}

Primeiramente, agradeço a Deus, pela oportunidade de realização de um grande sonho e por ter me dado coragem e persistência no desenvolvimento deste estudo.

À minha dedicada orientadora Ana Luiza, que, além da excelente orientação, me ofereceu sua amizade no momento que mais precisei. Muito obrigada pelas palavras de incentivo, pela confiança, pela disponibilidade dispensada em todas as situações e, acima de tudo, pelas contribuições e sugestões que colaboraram para qualidade deste projeto. Seus valiosos ensinamentos foram fundamentais para o meu crescimento pessoal e acadêmico.

À Prof $^{a}$ Dr $^{\mathrm{a}}$ Luiza Akiko Komura Hoga e à Prof ${ }^{\mathrm{a}} \mathrm{Dr}^{\mathrm{a}}$ Néia Schor, pelas contribuições e observações pertinentes apresentadas por ocasião do Exame de Qualificação.

À Prof ${ }^{-}$Dr $^{\text {a }}$ Elizabeth Fujimori, pelo carinho, pelo apoio e pelos valiosos ensinamentos na disciplina de pós-graduação, que colaboraram para a realização deste projeto.

À memória da minha querida mãe, exemplo de força e superação, que me ensinou o significado e a importância da determinação na busca dos objetivos e na superação dos obstáculos. Ao meu pai e amigo Sergio, que, mais do que me proporcionar uma boa vida acadêmica, formou os fundamentos do meu caráter e esteve sempre presente na minha vida de uma forma indispensável.

À minha irmã Tatiana, por ser a minha referência de tantas maneiras e por vibrar com cada vitória minha, mesmo separadas por tantos quilômetros. Sua presença comigo alguns dias e mesmo quando longe, suas palavras, emails, lágrimas e orações cruzando metade do país, vieram principalmente 
quando mais precisei e foram essenciais para mim: obrigada por esse amor incondicional.

À minha irmã Simone, que, por ser a primogênita, é aquela em quem enxergo as mesmas raízes que me alimentam. Exemplo de luta e coragem, obrigada pelo apoio e pelos ensinamentos que foram imprescindíveis nessa trajetória.

Em especial, agradeço aos meus sogros Ana Maria e Karekin Chofakian, pelo carinho e pelo apoio desde o início do mestrado e, posteriormente, por me acolherem como filha em sua casa. Obrigada pela companhia constante e tão querida, sacrifício ilimitado em todos os sentidos; pelas palavras e pelos abraços que aliviaram minhas horas mais difíceis, me alimentando de certezas, forças e alegrias.

À Fundação de Amparo à Pesquisa do Estado de São Paulo (FAPESP), pelo apoio financeiro e institucional concedido na forma de bolsa de mestrado.

A todos do grupo de pesquisa NEPESC, pelas sugestões apresentadas para a melhoria do projeto e pelo importante aprendizado compartilhado durante as reuniões.

Às minhas amigas Sayuri, Osmara e Raissa, agradeço particularmente a troca de experiências, o carinho e o incentivo que me deram em todos os momentos.

Às escolas que autorizaram e aos adolescentes que participaram da pesquisa.

A todos que não estão aqui mencionados, mas que, de alguma forma, apoiaram a realização desta pesquisa. 


\section{EPÍGRAFE}

"A fé inabalável é somente aquela que pode encarar a razão face a face, em todas as épocas da humanidade".

(Allan Kardec, 1864) 


\section{RESUMO}

Nascimento CB. Conhecimento e uso da anticoncepção de emergência entre adolescentes estudantes do ensino médio [dissertação]. São Paulo: Escola de Enfermagem, Universidade de São Paulo; 2012.

As práticas contraceptivas na adolescência apresentam dinâmica própria, em que as decisões acerca do uso de algum método variam em função de uma série de elementos, como o conhecimento sobre anticoncepção, a experiência sexual e o relacionamento vigente. Por conta de serem essencialmente solteiros, os adolescentes alternam os métodos de acordo com o tipo de relacionamento, seja ocasional ou estável, bem como ao longo deste. E justamente nos momentos de alternâncias e descontinuidades no uso de métodos que a anticoncepção de emergência pode surgir como opção para a prevenção da gravidez não planejada. Mesmo que já esteja disponível em alguns serviços da rede pública de saúde no país, pouco se sabe sobre o seu conhecimento e uso. Assim, este estudo teve como objetivo analisar o nível do conhecimento e o uso da anticoncepção de emergência entre adolescentes estudantes do ensino médio. Para isto, foi conduzido um estudo quantitativo do tipo transversal. A população de estudo constou de estudantes solteiros de 15 a 19 anos de idade que estavam matriculados em escolas públicas e privadas do município de Arujá, São Paulo. Os estudantes foram selecionados considerando a amostragem probabilística por conglomerado, realizado em duas etapas (estratificação por escola e sistemática por turma) $(n=669)$. Os dados foram coletados por meio de um questionário autoaplicado, no qual as variáveis dependentes foram o conhecimento sobre a anticoncepção de emergência (incluindo apenas aqueles que a conheciam) e o uso da anticoncepção de emergência (incluindo apenas aqueles que iniciaram a vida sexual). As variáveis independentes dizem respeito às características sociodemográficas e ao comportamento sexual e contraceptivo. A análise de regressão linear múltipla identificou como variáveis associadas ao nível do conhecimento da anticoncepção de emergência o tipo de escola, o ano escolar, o sexo, a relação sexual e conhecer alguém que já usou o método. Por sua vez, a análise de regressão logística múltipla identificou como variáveis associadas ao uso da anticoncepção de emergência a religião, o namoro atual e conhecer alguém que já usou 0 método. Os resultados obtidos demonstraram que os adolescentes de ambos os tipos de escola sabem pouco sobre a anticoncepção de emergência, apesar de uma parcela significativa ter usado este método. Demonstraram, também, que o nível de conhecimento da anticoncepção de emergência não afetou o uso deste método.

Palavras-chave: Saúde Sexual e Reprodutiva; Anticoncepção; Anticoncepção Pós-Coito; Saúde do Adolescente. 


\begin{abstract}
Nascimento CB. Knowledge and use of emergency contraception among adolescent students of the high school [dissertation]. São Paulo: Escola de Enfermagem, Universidade de São Paulo; 2012.

Contraceptive practices in adolescence present specific dynamics, in which decisions about the use of a method vary upon contraception knowledge, sexual experience and dating. As adolescents are mostly single, they alternate the use of contraceptive methods according to their relationships, whether occasional or permanent, as well as along it. Whenever there are alternations and discontinuities in the use of regular methods, emergency contraception may emerge as an option to prevent an unplanned pregnancy. Even though it is already available in some primary health services, little is known about adolescents knowledge and use. This study aimed to analyze the level of knowledge and use of emergency contraception among high school adolescent students. So we conducted a cross-sectional quantitative study. The study population was single students from 15 to 19 years of age enrolled in public and private high schools in the city of Arujá, São Paulo, Brazil. Students were selected based on a cluster sampling, conducted in two stages (stratificatied sampling by school and systematic sampling by class) ( $n=669$ ). Data were collected through a self-administered questionnaire, in which the dependent variables were knowledge about emergency contraception and the use of emergency contraception (considering only those who reported sexual initiation). Independent variables were sociodemographic characteristics and sexual and contraceptive behavior. From multiple logistic regression analysis, data showed that associated variables to the level of knowledge of emergency contraception were school type, school year, sex/gender, sexual intercourse and knowledge of someone who has used the method. On the other hand, variables associated with the use of emergency contraception were religion, current dating and knowledge of someone who has used the method. Results showed that adolescents from both schools know little about emergency contraception, although more than a half have used this method. Level of knowledge of emergency contraception did not affect the use of this method.
\end{abstract}

Keywords: Sexual and Reproductive Health; Contraception; Postcoital Contraception; Adolescent Health. 


\section{LISTA DE ILUSTRAÇÕES}

Figura 1 - Estrutura organizacional dos adolescentes entrevistados segundo experiência sexual, conhecimento e uso da anticoncepção de emergência, Arujá - 2011 .53

Figura 2 - Distribuição dos adolescentes entrevistados segundo o início da vida sexual, por tipo de escola, Arujá - 2011

Figura 3 - Distribuição dos adolescentes entrevistados segundo a participação de palestras sobre a anticoncepção de emergência, por tipo de escola, Arujá - 2011. .59 


\section{LISTA DE QUADROS}

Quadro 1 - Relação dos alunos matriculados por classe e ano segundo as unidades escolares, Arujá - 2011 . 38

Quadro 2 - Listagem das escolas e das turmas selecionadas do Ensino Médio, Arujá - 2011 .. .44

Quadro 3 - Listagem das escolas e das turmas do Ensino Médio de Arujá que participaram da pesquisa, Arujá - 2011 . .47 


\section{LISTA DE TABELAS}

Tabela 1 - Número e proporção de adolescentes entrevistados segundo as características sociodemográficas, por tipo de escola, Arujá - 2011

Tabela 2 - Número e proporção de adolescentes entrevistados segundo as fontes de informação sobre a anticoncepção de emergência, por tipo de escola, Arujá - 2011 .58

Tabela 3 - Número e proporção de adolescentes entrevistados segundo as questões de conhecimento da anticoncepção de emergência, por tipo de escola, Arujá - 2011 61

Tabela 4 - Número e proporção de adolescentes segundo as questões de conhecimento da anticoncepção de emergência separadas por "Sabe" e "Não sabe", por tipo de escola, Arujá - 2011 63

Tabela 5- Análise de regressão linear simples e múltipla do nível do conhecimento da anticoncepção de emergência segundo as características sociodemográficas, de comportamento amoroso e sexual e fontes de informação, Arujá - 2011 65

Tabela 6 - Número e proporção de adolescentes entrevistados segundo as características de uso da anticoncepção de emergência, por tipo de escola, Arujá - 2011 69

Tabela 7- Número e proporção de adolescentes entrevistados, sexualmente experientes segundo as características sociodemográficas, experiências amorosas/sexuais e fontes de informação, por uso da anticoncepção de emergência, Arujá - 2011 71

Tabela 8 - Análise de regressão logística univariada e múltipla segundo os fatores associados ao uso da anticoncepção de

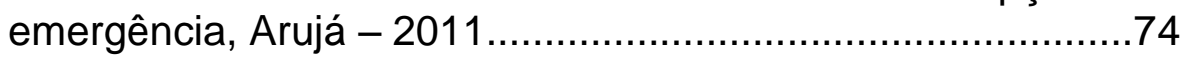




\section{LISTA DE SIGLAS}

AE

AIDS

CCR

CLAE

DST

ECA

FDA

FEBRASGO

IDH

IBGE

ICEC

IPVS

LNG

MAC

OMS

ONU

PNDS

PNUD

SBP

SEADE

SECOM

SPSS

TCLE

UNFPA

USP

WHO
Anticoncepção de Emergência

Síndrome da imunodeficiência adquirida

Comissão de Cidadania e Reprodução

Consórcio Latino-Americano de Anticoncepção de

Emergência

Doenças Sexualmente Transmissíveis

Estatuto da Criança e do Adolescente

Agência de Drogas e Medicamentos

Federação Brasileira das Sociedades de

Ginecologia e Obstetrícia

Índice de Desenvolvimento Humano

Instituto Brasileiro de Geografia e Estatística

Consórcio Internacional de Anticoncepção de

Emergência

Índice Paulista de Vulnerabilidade Social

Levonorgestrel

Métodos contraceptivos

Organização Mundial de Saúde

Organização das Nações Unidas

Pesquisa Nacional de Demografia e Saúde

Programa das Nações Unidas para o Desenvolvimento

Sociedade Brasileira de Pediatria

Fundação Sistema Estadual de Análise de Dados

Secretaria Municipal de Comunicação

Statistical Package of Social Sciences

Termo de Consentimento Livre e Esclarecido

Fundo de População das Nações Unidas

Universidade de São Paulo

World Health Organization 


\section{SUMÁRIO}

1

INTRODUÇÃO.

1.1 ADOLESCÊNCIA NO BRASIL.................................................. 17

1.2 DIREITOS SEXUAIS E REPRODUTIVOS........................................ 20

1.3 CONHECIMENTO E USO DE MÉTODOS ANTICONCEPCIONAIS NA ADOLESCÊNCIA.

1.4 ANTICONCEPÇÃO DE EMERGÊNCIA ......................................... 26

1.4.1 Uso da anticoncepção de emergência na adolescência................ 29

1.4.2 Conhecimento da anticoncepção de emergência na adolescência.

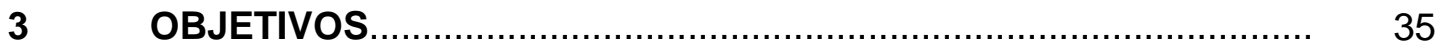

$4 \quad$ MATERIAIS E MÉTODOS....................................................... 36

4.1 DELINEMANTO DO ESTUDO..................................................... 36

4.2 POPULAÇÃO DE ESTUDO......................................................... 36

4.3 CENÁRIO DO ESTUDO............................................................ 38

$4.4 \quad$ PLANO AMOSTRAL......................................................................... 39

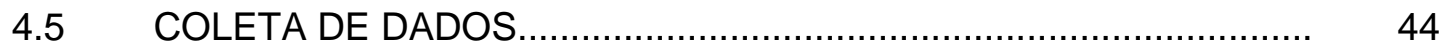

$4.6 \quad$ INSTRUMENTO ...................................................................... 48

4.7 VARIÁVEIS DO ESTUDO........................................................ 49

$4.8 \quad$ ANÁLISE DOS DADOS .......................................................... 51

4.9 CONSIDERAÇÕES ÉTICAS .................................................... 54

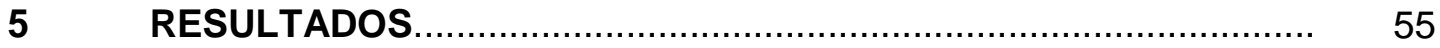

5.1 CARACTERÍSTICAS SOCIODEMOGRÁFICAS DOS

$5.2 \quad$ INÍCIO DA VIDA SEXUAL........................................................ 57

5.3 CONHECIMENTO DA ANTICONCEPÇÃO DE EMERGÊNCIA.......... 57

5.4 NÍVEL DO CONHECIMENTO DA ANTICONCEPÇÃO DE EMERGÊNCIA

5.4.1 Questões sobre anticoncepção de emergência: respostas "Falso", "Verdadeiro" e "Não sei"...

5.4.2 Questões sobre anticoncepção de emergência: "Sabe" e "Não sabe".

5.5 DETERMINANTES DO NÍVEL DO CONHECIMENTO DA ANTICONCEPÇÃO DE EMERGÊNCIA.

5.6 USO DA ANTICONCEPÇÃO DE EMERGÊNCIA............................ 68 
5.7 DETERMINANTES DO USO DA ANTICONCEPÇÃO DE EMERGÊNCIA.

5.7.1 Modelo final de regressão logística múltipla para o uso da anticoncepção de emergência.

6.1 DIFICULDADES E LIMITAÇÕES DO ESTUDO.

6.2 CARACTERIZAÇÃO SOCIODEMOGRÁFICA DOS ADOLESCENTES

6.3 COMPORTAMENTO SEXUAL: DIFERENÇAS ENTRE ESTUDANTES DE ESCOLAS PÚBLICAS E PRIVADAS

6.4 CONHECIMENTO DA ANTICONCEPÇÃO DE EMERGÊNCIA.......... 80

6.4.1 Nível do conhecimento da anticoncepção de emergência............. 83

6.4.2 Determinantes do nível do conhecimento da anticoncepção de emergência.

6.5 USO DA ANTICONCEPÇÃO DE EMERGÊNCIA ............................. 88

6.5.1 Perfil do uso da anticoncepção de emergência............................. 88

6.5.2 Determinantes do uso da anticoncepção de emergência.............. 93

$7 \quad$ CONCLUSÕES

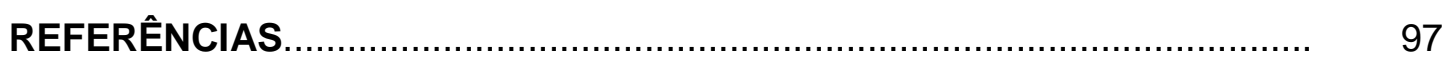

APÊNDICE 1 - TERMO DE CONSENTIMENTO LIVRE E ESCLARECIDO.

APÊNDICE 2 - QUESTIONÁRIO SOBRE O COMPORTAMENTO SEXUAL E CONTRACEPTIVO.

APÊNDICE 3 - CONSTRUÇÃO DOS MODELOS DE REGRESSÃO LINEAR.

APÊNDICE 4 - CONSTRUÇÃO DOS MODELOS DE REGRESSÃO LOGÍSTICA MÚLTIPLA.

ANEXO 1 - INFORMAÇÕES ADICIONAIS SOBRE A ANTICONCEPÇÃO DE EMERGÊNCIA..

ANEXO 2 - MAPA DO MUNICÍPIO DE ARUJÁ, SÃO PAULO..

ANEXO 3 - APROVAÇÃO DO COMITÊ DE ÉTICA EM PESQUISA.

ANEXO 4 - AUTORIZAÇÃO DA COORDENADORIA DE ENSINO DO INTERIOR. 


\section{INTRODUÇÃO}

\subsection{ADOLESCÊNCIA NO BRASIL}

O conceito de adolescência foi definido pela Organização Mundial de Saúde (OMS), em 1974, na Reunião sobre Gravidez e Aborto na Adolescência (Who, 1975), como o período que compreende a segunda década de vida, ou seja, dos 10 aos 19 anos de idade, 11 meses e 29 dias, no intuito de abranger as mudanças sociais, psicológicas e físicas (Brasil, 2010). Este conceito caracteriza os estudos que abordam a questão, a partir do paradigma biomédico (ou médico-biológico). Segundo esta tendência, a adolescência é considerada uma etapa de transição entre a infância e a idade adulta, tendo como base as transformações puberais, de caráter biológico, que, por sua vez, desencadeariam mudanças psicológicas e sociais, até atingir a maturidade (Peres, Rosenburg, 1998).

Contudo, ao delimitar o início e o fim dessa transição, segundo o critério cronológico, supõe-se que o processo de "amadurecimento" se complete como um todo, permitindo concluir que existe equivalência e sincronia dos tempos (biológico, psicológico e social). Esta é uma afirmação contraditória até mesmo do ponto de vista do paradigma biomédico, como os próprios adeptos desse paradigma reconhecem, pois as condições reais de existência em sociedades vêm demonstrando a existência de diferenças e disparidades entre os tempos biológico, psicológico e social, de forma cada vez mais acentuada (Peres, Rosenburg, 1998).

Assim, ao se demarcar a faixa etária como o tempo da adolescência, surge uma ampla discussão a respeito da sua significação. Evidencia-se, portanto, uma concepção de adolescência com diferentes significados segundo a classe social, a religião, a etnia, o gênero - impedindo o consenso quanto à sua definição e propiciando uma variedade de conceitos.

De acordo com Oliveira (1997), a adolescência é geralmente demarcada por critérios biológicos que admitem que possam variar em 
diferentes culturas, o que leva à falta de uniformidade na definição do seu início e fim. Ademais, segundo a autora, a adolescência não é apenas uma fase estanque do desenvolvimento, mas um fenômeno psicossocial e cultural, um tempo, uma forma de viver e de ser no mundo; daí a impossibilidade da adoção de critérios cronológicos de demarcação ou da utilização de um padrão uniforme e universal para a adolescência.

Dentro deste contexto, existe a vertente sociológica, que afirma que o conceito da adolescência tem suas origens nas sociedades industrializadas, nas quais são identificadas diferenças nas formas de estruturação da adolescência, conforme as posições sociais em uma sociedade em um dado momento histórico (Oliveira, 1997). Em resumo, ao analisar a adolescência a partir do referencial teórico das ciências sociais, a consideramos como uma categoria sociocultural, de origem histórica e destituída do sentido de universalidade.

Para Peres e Rosenburg (1997), quando afirmamos a universalidade do fenômeno "adolescência", a partir do fenômeno biológico, cremos numa visão reducionista da questão, pois indagamos como seria possível analisar o biológico (ou o psicológico), destacando-o de suas interconexões, visto que o ser humano nasce e se desenvolve a partir das relações sociais em um dado contexto sócio-histórico. Assim, para estes autores, o conceito biomédico ignora as especificidades das sociedades e dos grupos sociais distintos, encobrindo as diferenças e as desigualdades sociais dos sujeitos em seu processo de desenvolvimento; com isso, homogeneíza as condições de existência dos mesmos, dentro de uma concepção de igualdade abstrata e universal.

Isto não significa dizer que deixamos de reconhecer a importância das transformações biológicas deste período de vida, mas sim que existem outros valores, conceitos e contextos a serem analisados e interpretados.

Desse modo, verifica-se que não há um tipo de adolescente, mas vários, podendo este ser classificado como um grupo heterogêneo de indivíduos, que impossibilitam generalizações que levem a homogeneizá-los.

Neste cenário, observa-se a dificuldade de estabelecer critérios precisos de demarcação para a adolescência, havendo a impossibilidade de 
uma definição universal, genericamente aplicável a todos os adolescentes (Oliveira, 1997). Logo, não parece tratar-se apenas de uma questão semântica - o uso de um ou outro termo -, mas de uma questão muito mais relacionada ao referencial teórico: de um lado, o da biologia e o da psicologia e, de outro, o da sociologia (Rosenbrug, Peres, 1998).

De acordo com o Censo de 2000, o grupo de indivíduos que tinha entre 10 e 19 anos de idade havia ultrapassado os 35 milhões, o que representava, aproximadamente, $21 \%$ da população do Brasil (IBGE, 2000). Já, o Censo de 2010 revelou que a população adolescente no Brasil corresponde, atualmente, a cerca de 34 milhões de indivíduos, que representam, no entanto, 18\% da população nacional (IBGE, 2010a). Essa diminuição na porcentagem de adolescentes significa que o ritmo de crescimento deste segmento está menor. Esse fenômeno ocorre devido à queda nas taxas de mortalidade e fecundidade, concomitantemente ao aumento na expectativa média de vida da população brasileira (Borges, Fujimori, 2009). Contudo, embora tenha havido pequeno decréscimo da porcentagem da população adolescente no Brasil, este grupo ainda representa parcela significativa da população brasileira.

Assim, a magnitude do grupo adolescente em relação à população total e o fato desse segmento vivenciar um processo de passagem para a vida adulta, em que vigoram certos marcos no sentido de aquisição de autonomias - inclusive no âmbito das práticas sexuais - tornam-no de grande interesse e relevância para o campo da saúde coletiva, especialmente no que se refere à saúde sexual e reprodutiva, porquanto esta é uma fase em que as práticas sexuais assumem um caráter específico, dentre as quais se destaca a iniciação sexual (Borges, 2009).

Segundo a Pesquisa Nacional de Demografia e Saúde de 2006 (PNDS 2006) (Brasil, 2008), aproximadamente 55\% das adolescentes entre 15 e 19 anos de idade já iniciaram a vida sexual, o que significa que o início da vida sexual é um evento que ocorre majoritariamente na adolescência, ou seja, antes dos 19 anos de idade (Borges, Schor, 2005).

Contudo, ao mesmo tempo em que o início da vida sexual é um importante marco de passagem para a vida adulta, também insere o 
adolescente, de forma mais intensa, no grupo vulnerável às doenças sexualmente transmissíveis (DST) e AIDS, à gestação não planejada, ao aborto, entre outros problemas (Borges, 2004).

Assim, estas descontinuidades próprias do desenvolvimento do adolescente, caracterizadas pelos ritos de passagem, constituem um período crítico, por se tratar de momento de definições de identidade, que gera "crises", caracterizado num quadro típico da adolescência, conhecido como "síndrome da adolescência normal" (Reis, 1993; Peres, 1995). Tais crises são fruto das alterações psicossociais e culturais, da mudança comportamental e do questionamento dos valores vigentes, próprios do período vivenciado (Oliveira, 1997). Em frente a esse ser adolescente, constitui um período de extrema vulnerabilidade, sobretudo ao que diz respeito à sexualidade, associada ao conceito de risco.

Certamente, tais questões sobre vulnerabilidade e comportamentos de risco não tomariam a dimensão que têm para os adolescentes e os adultos se os direitos sexuais e reprodutivos fossem respeitados, incluindo informação e acesso aos métodos contraceptivos.

Considerando esse contexto de início da vida sexual na adolescência como rito de passagem para vida adulta, a oferta de informação e insumos contraceptivos é umas das possibilidades de efetivação dos direitos sexuais e reprodutivos.

\subsection{DIREITOS SEXUAIS E REPRODUTIVOS}

A adolescência é uma fase com necessidades, potencialidades e vivências presentes em todos os aspectos da vida social, inclusive na sexualidade, na reprodução e na saúde, que devem ser vividas de forma plena, com todos os direitos e responsabilidades inerentes a ela (Brasil, 2006). No entanto, a história nos mostra que até há pouco tempo havia uma lacuna na sociedade com relação aos adolescentes, pois não existia 
legislação a respeito dos direitos ou dos deveres dessa faixa etária (Minas Gerais, 2006).

O termo "direito reprodutivo" surgiu com a criação da Rede Mundial pela Defesa dos Direitos Reprodutivos das Mulheres, em 1979 (Tonelli, 2004). Mas, este termo foi aprofundado e consolidado nas conferências organizadas pela ONU, na década de 1990: a Conferência Internacional de População e Desenvolvimento, realizada no Cairo, em 1994, e a IV Conferência Mundial Sobre a Mulher, realizada em Pequim, em 1995 (Brasil, 2005a). Tais conferências internacionais tematizaram as questões relacionadas à saúde e aos direitos sexuais e reprodutivos, dando destaque, sobretudo, aos adolescentes como indivíduos a serem priorizados pelas políticas públicas de saúde (ONU, 1994; ONU, 1995).

Concomitantemente, no Brasil, foi criado o Estatuto da Criança e do Adolescente (ECA) em 1990. Por meio do ECA, os adolescentes brasileiros passaram a ser considerados sujeitos de direitos, possuindo direito à educação sexual, ao sigilo sobre a atividade sexual e ao acesso à orientação sobre todos os métodos anticoncepcionais (Brasil, 2006).

Contudo, apesar destas recentes transformações no que se refere à legislação e à atenção à saúde do adolescente, persistem no Brasil e em outros países dificuldades para aplicar e interpretar adequadamente a legislação específica, especialmente ao se tratar da sexualidade e da reprodução na adolescência. Uma primeira dificuldade é que tanto os instrumentos legais nacionais quanto os documentos internacionais enfatizam aspectos patológicos relacionados à sexualidade e à reprodução, tais como abuso, violência, exploração sexual, e não se voltam expressamente aos aspectos positivos do exercício da sexualidade e da reprodução nesta faixa etária (Ventura, Corrêa, 2006).

Outra barreira em relação à saúde sexual e reprodutiva dos adolescentes refere-se ao acesso aos métodos contraceptivos. Segundo uma pesquisa realizada em escolas públicas do ensino médio da cidade de São Paulo, alguns métodos contraceptivos, como, por exemplo, a anticoncepção de emerg6encia (AE), são adquiridos, em $70 \%$ dos casos, em farmácias, devido à falta de disponibilização do método na rede pública de 
saúde de alguns municípios (Figueiredo et al., 2008). Isto revela que os adolescentes enfrentam dificuldades no acesso a alguns métodos contraceptivos, indicando uma lacuna na efetivação dos direitos dos adolescentes à prevenção da gravidez não planejada.

Estudiosos da área de saúde sexual e reprodutiva têm refletido sobre até que ponto os adolescentes têm sido realmente portadores do interesse e das ações de políticas públicas, tendo em vista a ausência de práticas, condutas e ações voltadas para a inclusão de adolescentes no atendimento relacionado à anticoncepção, à gravidez e aos demais campos da saúde sexual e saúde reprodutiva, especialmente na atenção básica (Brasil, 2006; Arilha, Berquó, 2009).

Em síntese, é preciso considerar que a população adolescente, tal como a adulta, tem vida sexual e que as problemáticas de exposição à gravidez não planejada e às doenças sexualmente transmissíveis são inerentes e, por isso, é necessário que haja efetivamente atenção em saúde sexual e reprodutiva, sobretudo à atenção contraceptiva (Figueiredo, 2010).

Vale ainda ressaltar que as práticas contraceptivas se diferenciam para homens e mulheres em relação à primeira relação sexual e ao tipo de vínculo com o primeiro parceiro (Borges, 2007). Verifica-se que as mulheres iniciam-se sexualmente em relacionamentos com maior estabilidade, ao passo que os homens iniciam-se sexualmente em um relacionamento eventual. Por conseguinte, observa-se que a prática contraceptiva varia conforme o tipo de relacionamento, ocasional ou estável, acarretando a não utilização de métodos contraceptivos por muitos adolescentes quando iniciam sua vida sexual (Borges, Schor, 2005).

Desse modo, a atenção contraceptiva é essencial para o grupo adolescente, visto que as práticas contraceptivas neste período têm sido descritas como dinâmicas e em constantes transformações, sendo que seus perfis podem acarretar impacto importante na vida reprodutiva dos adolescentes (Borges, Schor, 2005). 


\subsection{CONHECIMENTO E USO DE MÉTODOS ANTICONCEPCIONAIS NA ADOLESCÊNCIA}

A anticoncepção na adolescência reveste-se de grande importância para a saúde coletiva, visto que os adolescentes são sujeitos de direitos sexuais e reprodutivos e que apresentam peculiaridades em relação ao uso e ao conhecimento dos métodos anticonceptivos.

O conhecimento sobre anticoncepção, embora seja relatado amplamente por adolescentes, é muitas vezes considerado insuficiente. De fato, segundo Mendonça e Araújo (2009), citar espontaneamente os métodos não significa necessariamente conhecê-los, ou seja, ter adquirido informações suficientes sobre vantagens, desvantagens, formas de acesso e modo de usar. Embora alguns autores considerem só o conhecimento da anticoncepção entre os adolescentes como adequado, baseando-se na citação espontânea dos métodos contraceptivos existentes, recentemente diversos autores têm avaliado também a qualidade do conhecimento, ou seja, por meio de um escore, avaliam e quantificam as respostas corretas sobre os métodos anticoncepcionais, para classificá-lo como adequado ou não.

Entre os estudos que avaliaram o conhecimento por meio da citação espontânea de métodos contraceptivos, destaca-se a PNDS 2006. Segundo esta pesquisa, o número de métodos contraceptivos citados espontaneamente pelos adolescentes de 15 a 19 anos situa-se em torno de três, sendo o preservativo, a pílula oral e a camisinha feminina os mais citados. Para a PNDS 2006, caso o adolescente citasse espontaneamente no mínimo três métodos contraceptivos, no momento da entrevista, o nível de conhecimento seria considerado adequado. Assim sendo, observou-se que $65 \%$ das adolescentes brasileiras sexualmente ativas tinham conhecimento adequado sobre os métodos contraceptivos (Perpétuo, 2010).

Do mesmo modo, estudo realizado com adolescentes estudantes de escolas públicas da Bahia verificou que apenas $50 \%$ dos adolescentes citaram espontaneamente de 4 a 6 métodos contraceptivos (para os autores 
do estudo, caso o adolescente citasse espontaneamente no mínimo quatro métodos, o conhecimento seria considerado adequado). Dessa forma, os autores consideraram que apenas metade dos adolescentes tinha conhecimento adequado sobre métodos contraceptivos (Almeida et al., 2003).

Em comparação, estudo realizado com adolescentes estudantes de escolas públicas e privadas de São Paulo permitiu observar que os adolescentes referiram conhecer vários métodos anticoncepcionais. Contudo, ao avaliar as respostas corretas sobre o uso dos métodos contraceptivos, ou seja, a qualidade do conhecimento, os autores observaram que os adolescentes de ambas as escolas tinham conhecimento insatisfatório, sendo o conhecimento dos alunos de escolas privadas um pouco maior (Martins et al., 2006).

Vale ressaltar que o conhecimento satisfatório e adequado sobre a contracepção varia principalmente em função do sexo, da idade, das condições socioeconômicas e da escolaridade. Segundo Martins et al. (2006), os fatores associados ao conhecimento adequado de métodos contraceptivos foram ter nível socioeconômico elevado, ter experiência sexual, ser mais velho, estudar em escola privada e ser do sexo feminino (Mendonça, Araújo, 2009). Este último aspecto pode revelar, ainda, que a responsabilidade quanto às práticas de contracepção é atribuída à mulher.

É importante destacar que o conhecimento sobre os métodos anticoncepcionais não determina o seu uso. De fato, Almeida et al. (2003), ao analisarem os fatores associados ao uso de contraceptivos, constataram a ausência de associações estatisticamente significativas entre 0 conhecimento sobre métodos contraceptivos e seu uso entre adolescentes, revelando que outros fatores fazem-se mais presentes na determinação do uso da anticoncepção. Logo, o conhecimento de métodos contraceptivos não está necessariamente relacionado ao uso consistente e adequado.

A prevalência de uso de métodos anticoncepcionais pelos adolescentes pode ser considerada alta no Brasil. De acordo com a PNDS 2006, 97,3\% das adolescentes entre 15 e 19 anos de idade já usaram algum método anticoncepcional anteriormente, sendo o preservativo masculino, a 
pílula oral e a injeção contraceptiva os métodos mais citados (Perpétuo, 2010).

Da mesma forma, um estudo realizado com adolescentes estudantes de escolas públicas de São Paulo verificou que 85,9\% dos adolescentes já haviam utilizado algum método anticoncepcional anteriormente, sendo o preservativo masculino e a pílula oral os métodos mais citados pelos adolescentes (Figueiredo, Pupo, Segri, 2008).

O uso varia em função de uma série de elementos, tais como a idade da primeira relação sexual, o tempo de experiência sexual, o acesso aos métodos contraceptivos, à objeção feita (ou pelo parceiro ou pela parceira) ao uso de métodos contraceptivos, o desejo de engravidar, a troca de parceiros, o envolvimento afetivo e a estabilidade relacional (Almeida et al., 2003).

Considerando a estabilidade relacional, é possível supor que esta propicie maior tempo para a negociação de uso de contracepção entre os parceiros. Todavia, entre as adolescentes, observa-se a tendência à flexibilização do uso do preservativo masculino e dos demais métodos, quando o parceiro é conhecido e o relacionamento torna-se estável, ou seja, os adolescentes tendem a ser menos vigilantes quando estão inseridos em relacionamentos mais duradouros, como o namoro (Almeida et al., 2003; Brandão, 2004). Em concordância, segundo Pirotta (2002), o preservativo masculino é usado somente nas relações casuais e no início dos relacionamentos sexuais com uma nova parceria. Além disso, os adolescentes negligenciam o preservativo masculino no contexto do namoro, substituindo-o pela pílula.

Aparentemente, ainda que o uso de contraceptivos na adolescência esteja aumentando, é um evento inconsistente, justamente porque o comportamento contraceptivo nessa fase é, essencialmente, definido pelo envolvimento afetivo (Borges, Schor, 2005). Isso significa que, devido à dinamicidade e à duração dos envolvimentos afetivos na adolescência, a adoção de medidas contraceptivas ou de proteção às DST pode variar, resultando no uso inconsistente de métodos contraceptivos (Brandão, 2004). 
Em virtude da descontinuidade, dos erros e dos esquecimentos no uso de métodos contraceptivos pelos adolescentes é que a $A E$ se torna fundamental neste período, sendo de grande importância por ser o único método que pode ser utilizado após as relações sexuais para prevenir a gestação não planejada.

Propiciar acesso à $A E$ aos adolescentes é uma forma a mais de garantir os direitos sexuais e reprodutivos dessa população, promovendo o pleno exercício do direito fundamental à saúde. No entanto, apesar da $A E$ constatar nas Normas de Planejamento Familiar do Ministério da Saúde (de 1996) e estar disponível no mercado brasileiro já há alguns anos (Figueiredo, 2004), há ainda poucos trabalhos nacionais sobre o seu conhecimento e os determinantes de seu uso entre os adolescentes. Ademais, trabalhos com adolescentes estudantes de escolas privadas são escassos, provavelmente porque estas instituições devem ser mais resistentes em relação à condução de pesquisas com seus alunos.

Diante da importância que o uso de métodos contraceptivos, em especial a $A E$, adquire no perfil da saúde sexual e reprodutiva dos adolescentes e da carência de estudos nacionais sobre este tema, é que se torna relevante pesquisar o nível de conhecimento sobre a $A E$ e seu uso neste grupo.

\subsection{ANTICONCEPÇÃO DE EMERGÊNCIA}

A origem do uso da $A E$ remonta à década de 1920, quando pesquisadores demonstraram que a utilização de extratos ovarianos de estrogênios provocava interferência na gravidez de mamíferos. Desde 1940, a literatura médica tem descrito relatos de casos esporádicos do uso de estrogênio pós-coito em seres humanos. O primeiro caso documentado foi publicado em meados da década de 1960, quando médicos holandeses relataram o uso do estrogênio pós-coito para uma adolescente de 13 anos vítima de violência sexual (Chinaglia, Aldrighi, Petta, 2005). 
Já em 1974, o ginecologista canadense Albert Yuzpe utilizou altas doses das pílulas de contraceptivos de uso regular, combinando estrógeno e progesterona, como um método pós-coito, conhecido posteriormente como método Yuzpe (ANEXO 1), como forma de reduzir substancialmente o risco de gravidez não planejada (Practice Committee, 2004).

No Brasil, a AE pelo método Yuzpe passou a constar nas Normas de Planejamento Familiar do Ministério da Saúde desde 1997 (Brasil, 2005b). Contudo, em 1999, a AE passou a ser disponibilizada no mercado brasileiro na forma de dose única, com apresentação em dois comprimidos de levornogestrel (LNG). Assim, o Ministério da Saúde começou sua aquisição em 2000, distribuindo-a, inicialmente, em serviços de atendimento às mulheres vítimas de violência e, logo em seguida (2002), como item dos contraceptivos disponibilizados para alguns municípios pelo Programa de Planejamento Familiar (Figueiredo, 2004).

A propósito, neste mesmo período, em outubro de 2000, ocorreu a Conferência de Quito, responsável pela garantia ao acesso da $A E$ como direito sexual e reprodutivo. Durante esta conferência, os países da América Latina e os Estados Unidos constituíram o Consórcio Latino-Americano de Anticoncepção de Emergência (CLAE), com o objetivo de expandir as ações de $A E$, por meio da defesa, da promoção, da difusão e do acesso a esse método, o que se constituiu também em um marco dos direitos sexuais e reprodutivos (Díaz et al., 2003). Dois anos mais tarde, em 2002, no fórum "Adolescência, contracepção e ética", que deu origem às Diretrizes da Anticoncepção na Adolescência, propostas pela Sociedade Brasileira de Pediatria (SBP) e pela Federação Brasileira das Sociedades de Ginecologia e Obstetrícia (FEBRASGO), a AE foi reconhecida como parte integrante e relevante da atenção à saúde dos adolescentes no Brasil (SBP, 2004).

Atualmente, a $A E$ representa um meio seguro e econômico para se evitar gravidezes não planejadas. Entre as principais indicações da $\mathrm{AE}$, estão a relação sexual sem uso de método anticonceptivo, por razão de violência sexual, a falha conhecida ou presumida do método em uso de rotina e o uso inadequado do anticonceptivo. Já entre as falhas dos anticonceptivos, pode-se citar 0 rompimento do preservativo e o 
deslocamento do diafragma. O esquecimento prolongado do anticonceptivo oral, o atraso na data do injetável mensal, o cálculo incorreto do período fértil, o erro no período de abstinência e a interpretação equivocada da temperatura basal são algumas circunstâncias que consistem no uso inadequado do método e expõem ao risco de gravidez (Brasil, 2011).

Embora a $A E$ seja eficaz, este método nem sempre é disponibilizado pela rede pública de saúde, sobretudo, para adolescentes. Conforme uma pesquisa realizada em municípios do estado de São Paulo, havia poucas cidades que ofertavam este método para adolescentes. Essa pesquisa revelou que, dos 101 municípios que confirmaram recebimento de estoques da $A E$, apenas 17 afirmaram distribuir o método nos serviços específicos de atenção aos adolescentes. Ademais, foi observado que há municípios que criam empecilhos para o acesso do método ao adolescente, restringindo explicitamente a entrega, definindo faixas etárias aleatórias (a partir de 13, 15 ou outros, conforme o serviço), restringindo o fornecimento para menores de 18 anos, ou exigindo autorizações ou presença de responsáveis para que seja prescrito. Esses resultados demonstram que a baixa oferta da $A E$ na rede pública, em geral, leva ao uso do método por automedicação em farmácias e aumenta o risco de uso do método de forma incorreta, abusiva, repetitiva e sem orientação (Figueiredo, Bastos, 2008). Inegavelmente, a restrição da oferta da $\mathrm{AE}$ para as principais situações de risco que os adolescentes enfrentam constitui-se violação dos direitos sexuais e reprodutivos deste público.

Neste ínterim, conhecer as situações e a forma de utilização deste método na adolescência, isto é, o perfil do uso da AE entre os adolescentes, assim como mensurar o nível de conhecimento que eles têm sobre esta medicação, podem contribuir para vislumbrar seu real comportamento contraceptivo e os seus determinantes. 


\subsubsection{Uso da anticoncepção de emergência na adolescência}

De acordo com a PNDS 2006, 18,9\% das adolescentes brasileiras entre 15 e 19 anos de idade já utilizaram alguma vez na vida a $A E$, sendo a região Centro-Oeste a que apresentou maior prevalência de uso (31,7\%), seguida pela região Sudeste (30,9\%) (Perpétuo, 2010). Em contrapartida, em Portugal, verificou-se que o uso da $A E$ foi da ordem de $20 \%$ entre adolescentes (Castro, Rodrigues, 2009).

Embora estudos de abrangência nacional tenham mostrado que apenas uma parcela dos adolescentes utilizou a AE anteriormente, alguns opositores da $A E$ afirmam que deveria haver maior controle no uso do método, visto que este contraceptivo impulsionaria as relações sexuais desprotegidas e que haveria tendência entre as adolescentes de banalizar sua adoção, utilizando-a rotineiramente (Perpétuo, 2010).

Diversos estudos (Belzer e at., 2003; Figueiredo, 2004; Raine et al., 2005, Figueiredo et al., 2008) já confirmaram que a $A E$ não incrementou as relações sexuais desprotegidas, visto que não propiciou ameaça de abandono dos métodos contraceptivos usados regularmente, inclusive preservativos. Segundo Figueiredo et al. (2008), entre os adolescentes que usaram a $A E$ alguma vez na vida, a maioria (85\%) adotava o preservativo masculino no momento da entrevista.

Ademais, estudos internacionais revelam que a taxa de uso repetido na faixa etária dos adolescentes é de apenas 2,5 por pessoa e que a $A E$ não ameaça o uso da contracepção regular (Ahern et al., 2010; Hensley Alford et al., 2010).

Apesar da adoção da $A E$ não ser um evento repetitivo entre os adolescentes, estudos nacionais e internacionais revelaram que seu uso pode propiciar gestação ectópica. Um dos mecanismos de ação da AE é a diminuição da motilidade tubária e da função ciliar (batimentos das fímbrias); assim, este medicamento, ao prejudicar o peristaltismo das trompas, pode contribuir para a chegada atrasada do ovo na cavidade endomentrial, um fato que leva à implantação do óvulo fecundado nas trompas (Marions et al, 
2011). Zucchi et al (2004) relataram um caso ocorrido em São Paulo, de uma paciente de 27 anos que apresentou gravidez ectópica, de localização tubária, após o uso da AE. No ano seguinte, foram constatados outros dois novos casos de gravidez ectópica em São Paulo, após o uso da AE próximo ao período ovulatório (Pereira et al, 2010). Da mesma forma, foi verificado, na revisão Cochrane, o relato de cinco casos de gravidez ectópica entre 45.842 mulheres, não associadas a qualquer regime em particular (Cheng et al, 2005). Igualmente, Kaymak et al (2010) relataram um caso de gravidez ectópica na Turquia após o uso da AE. Em oposição, documento elaborado com o apoio do Fundo de População das Nações Unidas (UNFPA), do Consórcio Latino-Americano de Anticoncepção de Emergência (CLAE) e do Consórcio Internacional de Anticoncepção de Emergência (ICEC), afirma que o uso da AE não aumenta o risco de gravidez ectópica (Bergallo, 2011).

Em geral, os determinantes do uso da AE no Brasil são ser do sexo feminino, ter escolaridade elevada e pertencer a grupos sociais favorecidos. Além disso, a AE é mais utilizada pelas adolescentes que têm maior controle da reprodução, como as que nunca ficaram grávidas, as que planejaram a gravidez e, principalmente, as que possuem parceria fixa (Perpétuo, 2010).

Estudo realizado com adolescentes estudantes do ensino médio de escolas públicas de São Paulo constatou que a parceria fixa é um dos principais aspectos associados ao uso da $A E$ na adolescência. Este estudo relatou que o uso da $\mathrm{AE}$ é maior entre as adolescentes em relacionamentos fixos do que entre as que não estão neste tipo de relacionamento. Isso ocorre porque, nos relacionamentos estáveis, há a flexibilização no uso dos métodos contraceptivos, propiciando, portanto, a opção pela AE (Figueiredo, Pupo, Segri, 2008).

Entre as razões relatadas para o uso, este mesmo estudo revelou que os adolescentes o fizeram principalmente por conta do não uso de preservativo $(39,3 \%)$, mas também pelo rompimento de preservativos $(22,8 \%)$ e pela falha no coito interrompido $(12,5 \%)$, casos estes nos quais o uso da $A E$ é indicado pelo Ministério da Saúde. Dessa forma, verifica-se que a utilização da $A E$ deve-se, principalmente, às falhas no uso de métodos contraceptivos (Figueiredo, Pupo, Segri, 2008). 
Apesar dos adolescentes usarem a $\mathrm{AE}$, mesmo que a aquisição ocorra em farmácias privadas (Figueiredo et al., 2008), nem sempre eles têm o conhecimento adequado sobre este método.

Segundo Castro e Rodrigues (2009), a maior parte das adolescentes que utilizam este método não tem conhecimento efetivo e adequado sobre o que é a $A E$ e o que pode acarretar seu uso incorreto. Já foi demonstrado que adolescentes estudantes de escolas públicas de Pernambuco fizeram uso incorreto do método, não o utilizando no prazo adequado após a relação sexual desprotegida (Araújo, Costa, 2009). Em suma, o inadequado conhecimento sobre a $A E$ pode ser um elemento que agrega mais chance ao uso inadequado deste método.

\subsubsection{Conhecimento da anticoncepção de emergência na adolescência}

Embora a $A E$ seja um método eficaz para prevenção da gravidez não planejada e já seja institucionalizada em alguns municípios pela rede pública de saúde, o conhecimento insuficiente ou inadequado sobre este método tem sido referido em diversas pesquisas.

De acordo com a PNDS 2006, apenas 6\% das adolescentes citaram espontaneamente a $\mathrm{AE}$ quando indagadas sobre quais métodos contraceptivos elas conheciam. Ao se considerar o conhecimento por meio de pergunta estimulada, a parcela de adolescentes que afirmaram já ter ouvido falar sobre a AE correspondia a $69 \%$ das adolescentes (Brasil, 2008). Similarmente, estudo realizado com adolescentes estudantes de escolas públicas de São Paulo observou que $59 \%$ dos adolescentes citaram (respostas espontâneas e estimuladas) a AE como método contraceptivo (Figueiredo, Andalaft Neto, 2005).

Costa et al. (2006), com o objetivo de avaliar a qualidade do conhecimento da $A E$, investigaram 135 adolescentes do sexo feminino do ensino médio de escolas públicas da cidade do Rio de Janeiro. Estes autores observaram que $32,6 \%$ haviam usado a $A E$. Destes, $43,2 \%$ não 
souberam responder adequadamente as questões referentes ao uso, à indicação e aos mecanismos de ação do medicamento. Outro estudo realizado com estudantes universitários de São Paulo, Santa Catarina, Goiás e Rio Grande do Norte, relatou que apenas um quinto deles conhecia precisamente todas as situações nas quais a $A E$ está indicada e menos da metade dos estudantes conhecia a real efetividade da $A E$ quando comparada aos anticoncepcionais orais hormonais. Além do mais, nenhum estudante respondeu que 120 horas é o tempo máximo que a $A E$ pode ser utilizada após o intercurso sexual desprotegido, como se preconiza atualmente (Fisberg et al., 2010).

A propósito, da mesma forma como ocorre no Brasil, outros autores também identificaram o conhecimento inadequado da $A E$ entre adolescentes de outros países, como em Portugal (Castro, Rodrigues, 2009), onde foi realizado um estudo com alunos do ensino médio e foi observado que, num primeiro momento, a maioria dos adolescentes entrevistados (83,4\%) afirmou ter alguma informação acerca da $A E$ e, num segundo momento, por meio da avaliação da qualidade do conhecimento, verificou-se que apenas $10,5 \%$ possuíam de fato o conhecimento efetivo.

Romo et al. (2004), investigando 69 adolescentes latino-americanas residentes no Texas, Estados Unidos, verificaram que $24,6 \%$ das adolescentes citaram espontaneamente conhecer a $\mathrm{AE}$ como método contraceptivo, mas, ao avaliarem a qualidade do conhecimento, apenas $12 \%$ delas responderam adequadamente sobre o uso correto deste método.

Do mesmo modo, estudo conduzido com adolescentes na Califórnia revelou que $68 \%$ dos adolescentes tinham ouvido falar da $\mathrm{AE}$. No entanto, apenas $15 \%$ responderam corretamente as perguntas sobre a $A E$, caracterizando como inadequado o conhecimento dos adolescentes sobre 0 método (Raine et al., 2000). Também Leyva-López et al. (2010), avaliando a qualidade do conhecimento da $\mathrm{AE}$ entre adolescentes mexicanos, constataram que $60 \%$ ouviram falar alguma vez sobre o método, mas apenas $45 \%$ dos adolescentes responderam corretamente as questões sobre este medicamento. 
O conhecimento da $\mathrm{AE}$ é maior entre adolescentes "mais experientes", ou seja, o conhecimento da AE pode ser considerado maior entre adolescentes que têm experiência sexual e entre aqueles que já tiveram experiência de uso de métodos contraceptivos (Figueiredo et al., 2008). Isso significa dizer que o conhecimento sobre o método melhora com a experiência sexual, o que agrega mais chances do uso adequado por este grupo.

Outro fator relevante em relação à $A E$ é a diferença do conhecimento deste método entre adolescentes dos sexos feminino e masculino. De fato, segundo uma pesquisa realizada com adolescentes estudantes de escolas públicas de Pernambuco, houve associação significativa entre 0 conhecimento da $\mathrm{AE}$ e a variável sexo, sendo que as adolescentes referiram espontaneamente conhecer mais este método do que os adolescentes do sexo masculino (Araújo, Costa, 2009), da mesma forma que adolescentes mexicanas (Leyva-López, 2010).

Em síntese, verifica-se que o nível de conhecimento sobre a $A E$ entre adolescentes é ainda escasso, tanto no Brasil como em outros países. Vale ressaltar que a informação sobre a $A E$ tem origem, majoritariamente, no contato com amigos ou conhecidos $(65,2 \%)$, indicando que pode ser, portanto, incorreta ou incompleta. Por isso, verifica-se que, apesar da maior parte dos adolescentes ter ouvido falar da $\mathrm{AE}, 41,4 \%$ revelaram não saber como utilizá-la e que existem adolescentes (16,9\%) com informação distorcida sobre esse método. Ademais, as escolas pouco informam sobre a $A E$, enquanto muitos adolescentes apontam que desejam mais informações sobre o método nestes espaços (Figueiredo et al., 2008).

Considerando, pois, o conhecimento escasso, o acesso precário à $A E$ e as falhas e descontinuidades no uso de métodos contraceptivos, presumese que esteja havendo um vivência da sexualidade confrontada com práticas inseguras, acarretando, portanto, na vulnerabilidade contraceptiva. 


\section{HIPÓTESE}

O conhecimento e o uso da anticoncepção de emergência na adolescência estão diretamente relacionados ao sexo, à experiência sexual, à idade, ao namoro atual e ao tipo de escola em que estuda (pública ou privada). 


\section{OBJETIVOS}

1) Caracterizar o nível do conhecimento sobre a anticoncepção de emergência e o uso deste método entre adolescentes estudantes do ensino médio de escolas públicas e privadas.

2) Analisar o nível do conhecimento e o uso da anticoncepção de emergência entre adolescentes estudantes do ensino médio de escolas públicas e privadas. 


\section{MATERIAIS E MÉTODOS}

\subsection{DELINEAMENTO DO ESTUDO}

Foi realizado um estudo quantitativo, do tipo transversal, no intuito de caracterizar o comportamento contraceptivo dos adolescentes, em especial o uso e o conhecimento da anticoncepção de emergência. A intenção foi estimar a magnitude do evento, analisar as características dos sujeitos e explorar os determinantes do fenômeno investigado.

\subsection{POPULAÇÃO DE ESTUDO}

A população de estudo foi constituída por adolescentes, de ambos os sexos, estudantes do ensino médio de escolas públicas e privadas do município de Arujá, São Paulo.

Este estudo adotou os seguintes critérios de elegibilidade:

- Matrícula regular no ensino médio no município de Arujá, São Paulo, em 2011. Vale ressaltar que foram considerados apenas os alunos matriculados no período matutino, visto que os alunos que estavam matriculados no período noturno correspondiam predominantemente à faixa etária entre 18 e 22 anos de idade, segundo informação da Diretoria de Ensino da Região de Jacareí, responsável pela área que inclui Arujá.

- Idade entre 15 e 19 anos (é nesta faixa etária que se encontram razoáveis proporções de adolescentes que já iniciaram a vida sexual tanto quanto de adolescentes que ainda não a iniciaram, o que possibilita comparações em relação ao comportamento contraceptivo e ao conhecimento sobre a AE). 
- Estado civil: solteiro (as experiências amorosas, sexuais e afetivas, bem como a autonomia, dos adolescentes unidos são muito diversas daqueles não unidos, ou solteiros, e sua análise em conjunto poderia acarretar viés nos achados).

Além disto, o estudo foi delimitado pelos seguintes critérios:

- Aceitação verbal do adolescente em participar do estudo, ressaltando que não poderiam participar da pesquisa adolescentes menores de 18 anos, cujos pais ou responsáveis não concordassem com a participação do aluno na pesquisa, ou seja, não assinando o Termo de Consentimento Livre e Esclarecido.

- Cooperação prévia da Secretaria de Educação do Município, das diretorias e dos professores dos colégios selecionados.

Arujá é um município do Estado de São Paulo, localizado na região metropolitana da capital paulista (mapa no ANEXO 2). Segundo os dados do Censo de 2010, sua população corresponde a 74.818, ocupando uma área de $97,45 \mathrm{~km}^{2}$, o que resulta numa densidade demográfica de $767,76 \mathrm{hab} / \mathrm{km}^{2}$ (IBGE, 2010a; SEADE, 2010). Além disso, a taxa de alfabetização do município é de $92,1 \%$ e o Índice de Desenvolvimento Humano relacionado à Educação (IDH Educação - indicador de nível educacional) é de 0,893, ou seja, o município de Arujá tem baixo índice de analfabetismo de pessoas de 15 anos ou mais e alta taxa bruta de matrículas em todos os níveis de ensino (fundamental, médio e superior) em relação à população de 7 a 22 anos de idade (PNUD, 2000).

Arujá é o município mais rico da Região do Alto Tietê, de acordo com a Fundação SEADE. Mesmo assim, seu Índice de Vulnerabilidade Social (IPVS) revelou que 59,6\% de seus habitantes vivem em situação média, alta ou de muito alta vulnerabilidade social (SEADE, 2009), sugerindo que se trata de município com grandes desigualdades sociais, o que justifica a condução deste estudo em escolas tanto públicas quanto privadas, no intuito 
de possibilitar a comparação do conhecimento e do uso da $\mathrm{AE}$ em relação ao grupo social dos participantes.

A escolha por conduzir o projeto nas escolas de ensino médio públicas e privadas de Arujá justifica-se pelo fato da pesquisadora, na época do início do mestrado, residir na cidade e pela carência de estudos que avaliam o comportamento contraceptivo dos adolescentes residentes neste município.

\subsection{CENÁRIO DO ESTUDO}

A rede de escolas públicas e privadas do ensino médio do município de Arujá era composta por 16 escolas (dados de maio de 2011). Contudo, duas escolas foram excluídas por apresentarem turmas somente no período noturno. Assim, a relação de escolas públicas e privadas foi composta, no total, por 14 escolas, conforme Quadro 1.

Quadro 1 - Relação dos alunos matriculados por classe e ano, segundo as unidades escolares, Arujá - 2011

\begin{tabular}{|c|c|c|c|c|c|c|c|c|}
\hline \multirow{2}{*}{$\begin{array}{l}\text { UNIDADES ESCOLARES } \\
\text { (ESCOLAS PÚBLICAS) }\end{array}$} & \multirow{2}{*}{$\begin{array}{l}\text { ESCOLAS } \\
\text { PÚBLICAS }\end{array}$} & \multicolumn{2}{|c|}{ 1 ANO } & \multicolumn{2}{|c|}{ 20 ANO } & \multicolumn{2}{|c|}{30 ANO } & \multirow[t]{2}{*}{ TOTAL } \\
\hline & & classe $^{*}$ & alunos & classe $^{*}$ & alunos & classe* $^{*}$ & alunos & \\
\hline EE "Amadeu Rodrigues Norte" & Escola 1 & 1 & 39 & 1 & 30 & 1 & 55 & 124 \\
\hline $\begin{array}{l}\text { EE "Profa Ana } \\
\text { Carvalho Pereira" }\end{array}$ & Escola 2 & 1 & 72 & 0 & 0 & 0 & 0 & 72 \\
\hline $\begin{array}{lll}\text { EE "Profa. } & \text { Edir } & \text { Paulino } \\
\text { Albuquerque" } & & \\
\end{array}$ & Escola 3 & 7 & 253 & 7 & 221 & 3 & 125 & 599 \\
\hline EE "Prof. Esli Garcia Diniz" & Escola 4 & 8 & 308 & 5 & 170 & 5 & 145 & 623 \\
\hline $\begin{array}{l}\text { EE "Prefeito Geraldo Barbosa } \\
\text { de Almeida" }\end{array}$ & Escola 5 & 2 & 70 & 1 & 31 & 0 & 0 & 101 \\
\hline $\begin{array}{l}\text { EE "Profa Maria Isabel Neves } \\
\text { Bastos" }\end{array}$ & Escola 6 & 2 & 82 & 1 & 45 & 1 & 40 & 167 \\
\hline EE "República Dominicana" & Escola 7 & 1 & 41 & 2 & 62 & 1 & 37 & 140 \\
\hline $\begin{array}{l}\text { EE "Dr. Washington Luiz } \\
\text { Pereira de Souza" }\end{array}$ & Escola 8 & 3 & 110 & 3 & 126 & 0 & 0 & 236 \\
\hline TOTAL & 8 escolas & 25 & 975 & 20 & 685 & 11 & 402 & 2.062 \\
\hline
\end{tabular}

(Continua) 
Quadro 1 (Continuação) - Relação dos alunos matriculados por classe e ano segundo as unidades escolares, Arujá - 2011

\begin{tabular}{|c|c|c|c|c|c|c|c|c|}
\hline \multirow{2}{*}{$\begin{array}{l}\text { UNIDADES ESCOLARES } \\
\text { (ESCOLAS PRIVADAS) }\end{array}$} & \multirow{2}{*}{$\begin{array}{l}\text { ESCOLAS } \\
\text { PRIVADAS }\end{array}$} & \multicolumn{2}{|c|}{ 1 ANO } & \multicolumn{2}{|c|}{ 20 ANO } & \multicolumn{2}{|c|}{$3=$ ANO } & \multirow[b]{2}{*}{ TOTAL } \\
\hline & & classe $^{*}$ & alunos & classe $^{*}$ & alunos & classe $^{*}$ & alunos & \\
\hline Alpha EIFM Colégio & Escola 1 & 1 & 22 & 1 & 15 & 1 & 29 & 66 \\
\hline $\begin{array}{l}\text { Cidade Natureza Inst. de } \\
\text { Ensino Colégio Objetivo }\end{array}$ & Escola 2 & 1 & 20 & 1 & 26 & 1 & 20 & 66 \\
\hline IPE Colégio & Escola 3 & 1 & 26 & 1 & 27 & 1 & 23 & 76 \\
\hline J R Instituto Educacional & Escola 4 & 1 & 42 & 1 & 33 & 1 & 30 & 105 \\
\hline Jean Piaget Colégio & Escola 5 & 1 & 24 & 1 & 22 & 1 & 23 & 69 \\
\hline Sion Colégio & Escola 6 & 2 & 33 & 1 & 18 & 1 & 12 & 63 \\
\hline TOTAL & 6 escolas & 7 & 167 & 6 & 141 & 6 & 137 & 445 \\
\hline
\end{tabular}

Fonte: D.E.R. JACAREÍ, 02/05/2011 (Diretoria de Ensino da Região de Jacareí, SP).

* Classes referentes ao período matutino.

\subsection{PLANO AMOSTRAL}

Utilizou-se a técnica de amostragem probabilística (Silva, 1998) com a qual, a partir de uma amostra, podem-se generalizar as características da população e expandir os dados para o conjunto dos estudantes adolescentes do ensino médio do município de Arujá.

Tendo em vista a finalidade do estudo, para o dimensionamento do tamanho da amostra (n), optou-se por utilizar como parâmetro a variável "uso da anticoncepção de emergência", com a finalidade de se estimar a porcentagem de adolescentes de 15 a 19 anos de idade que já utilizaram a $A E$ e, portanto, que iniciaram a vida sexual e que conheciam a $A E$.

Considerando-se a variável escolhida, calculou-se o tamanho da amostra por meio da fórmula (Silva, 1998):

$$
n=\frac{z^{2} \cdot p \cdot q \cdot N}{d^{2}(N-1)+z^{2} \cdot p \cdot q}
$$


Em que:

$\mathrm{p}=$ estimativa da proporção de um dos níveis da variável escolhida. No caso, proporção esperada de adolescentes entre 15 e 19 anos que já utilizaram a AE alguma vez na vida na região do Sudeste, de acordo com a PNDS (2006)

$\mathrm{q}=1-\mathrm{p}$

$\mathrm{Z}=$ abscissa da curva normal padrão, tendo sido assumido o nível de confiança $95 \%$

d= erro máximo em valor absoluto

$\mathrm{N}=$ tamanho da população

Considerando $p=30,9 \%$ (Perpétuo, 2010) e $d=3 \%$, com uma população total de 2.507 estudantes matriculados no período matutino nas escolas públicas e privadas de Arujá, têm-se:

$$
\text { n = } 669 \text { indivíduos }
$$

Considerando a possibilidade de perdas (por conta de recusas e ausências), foram acrescidos $20 \%$ para que não houvesse redução do tamanho da amostra, que constou, finalmente, de 803 indivíduos.

Para a seleção dos indivíduos, foi utilizado o método de amostragem por conglomerado, realizado em duas etapas (Berquó, Souza, Gotlieb, 1981). No primeiro momento, as escolas foram estratificadas, para que as subpopulações de cada escola (pública e particular) fossem representadas na amostra com a mesma proporcionalidade com que compõem a população total (Berquó, Souza, Gotlieb, 1981). No segundo momento, foi conduzida uma amostragem sistemática por turma, no qual se utilizou a ordenação das turmas de cada escola, por série.

\section{Ou seja:}


Primeira etapa (amostragem por estratos): estratificação por escola

A população é composta de 2 estratos (pública e privada). Segundo (Berquó, Souza, Gotlieb, 1981), tem-se:

$$
n_{h=N_{h}} \cdot \frac{n}{N}
$$

Em que:

$\mathrm{N}=$ tamanho da população

$\mathrm{n}=$ tamanho total da amostra

$\mathrm{n}_{\mathrm{h}}=$ tamanho da amostra em cada estrato

$\mathrm{N}_{\mathrm{h}}=$ tamanho de cada estrato populacional

Dessa forma, nas escolas públicas, tem-se:

$$
n_{h=2062 \times \frac{803}{2507}=660 \text { alunos a serem entrevistados }}
$$

Já, nas escolas privadas:

$$
n_{h=445 \times \frac{803}{2507}=143 \text { alunos a serem entrevistados }}
$$

Segunda etapa (amostragem sistemática): sistemática por turma

Primeiramente, calculou-se a média dos alunos matriculados por turma. Segundo (Berquó, Souza, Gotlieb, 1981), tem-se:

$$
\bar{x}=\frac{n}{N}
$$


Em que:

$\overline{\mathrm{x}}=$ média aritmética da quantidade de alunos por turma

$\mathrm{n}=$ total de alunos por escola

$\mathrm{N}=$ total das turmas

a) Escolas Públicas:

$\bar{x}=\frac{2062}{56}=37$ alunos por turma

b) Escolas Privadas:

$\bar{x}=\frac{445}{19}=23$ alunos por turma

Posteriormente, calculou-se, a partir da média de alunos por turma, quantas turmas seriam pesquisadas em cada estrato. Segundo (Berquó, Souza, Gotlieb, 1981), tem-se:

$$
\bar{y}=\frac{n_{h}}{\bar{x}}
$$

Em que:

$\bar{y}=$ média aritmética da quantidade de turmas a serem sorteadas em cada estrato

$\mathrm{n}_{\mathrm{h}}=$ tamanho da amostra em cada estrato

$\overline{\mathrm{x}}=$ média aritmética da quantidade de alunos por turma

a) Escolas Públicas:

$\bar{y}=\frac{660}{37}=18$ turmas 
b) Escolas Privadas:

$\bar{y}=\frac{143}{23}=6$ turmas

Por fim, foi calculado o intervalo de amostragem. Segundo (Berquó, Souza, Gotlieb, 1981), tem-se:

Em que:

$$
k=\frac{N}{\bar{y}}
$$

$\mathrm{k}$ = intervalo de amostragem

$\mathrm{N}=$ total das turmas

$\overline{\mathrm{y}}=$ média aritmética das turmas

a) Escolas Públicas:

$$
k=\frac{56}{18}=3
$$

b) Escolas Privadas:

$$
k=\frac{19}{6}=3
$$

Vale ressaltar que todos os cálculos foram arredondados para o inteiro mais próximo, segundo Berquó, Souza e Gotlieb (1981) preconizam.

Em resumo, foi realizada a listagem das escolas por ordem alfabética (separadamente, por pública e privada), com suas respectivas turmas. Assim, após o início casual (Berquó, Souza, Gotlieb, 1981), a cada intervalo de amostragem $(k=3)$, uma turma foi selecionada.

O quadro 2 mostra a listagem das escolas públicas e privadas com as respectivas turmas selecionadas, de acordo com a amostragem sistemática. 
Quadro 2 - Listagem das escolas e das turmas selecionadas do Ensino Médio, Arujá - 2011

\begin{tabular}{|c|c|}
\hline Escolas Públicas & Turmas Selecionadas \\
\hline Escola 3 & $1 \mathrm{~A} / 1 \mathrm{D} / 1 \mathrm{G} / 2 \mathrm{C} / 2 \mathrm{~F} / 3 \mathrm{~B}$ \\
\hline Escola 4 & $1 \mathrm{~B} / 1 \mathrm{E} / 1 \mathrm{H} / 2 \mathrm{C} / 3 \mathrm{~A} / 3 \mathrm{D}$ \\
\hline Escola 5 & $1 \mathrm{~B}$ \\
\hline Escola 6 & $1 \mathrm{~B}$ \\
\hline Escola 7 & $1 \mathrm{~A} / 3 \mathrm{~A}$ \\
\hline Escola 8 & $1 \mathrm{C} / 2 \mathrm{C}$ \\
\hline Total & 18 turmas \\
\hline Escolas Privadas & Turmas Selecionadas \\
\hline Escola 1 & $3 \mathrm{~A}$ \\
\hline Escola 2 & $3 \mathrm{~A}$ \\
\hline Escola 3 & $3 \mathrm{~A}$ \\
\hline Escola 4 & $3 \mathrm{~A}$ \\
\hline Escola 5 & $3 \mathrm{~A}$ \\
\hline Escola 6 & $2 \mathrm{~A}$ \\
\hline Total & $\mathbf{6}$ turmas \\
\hline
\end{tabular}

\subsection{COLETA DE DADOS}

A coleta de dados foi realizada após da aprovação deste projeto pelo Comitê de Ética em Pesquisa da Escola de Enfermagem da Universidade de São Paulo (Processo $n^{\circ}$ 1056/2011) (ANEXO 3) e da autorização da Coordenadoria de Ensino do Interior e da Diretoria de Ensino da Região de Jacareí, responsável pela área que inclui Arujá (ANEXO 4). A obtenção das autorizações atrasou devido à dificuldade de comunicação com a Coordenadoria de Ensino do Interior, sendo obtida somente em 25 de agosto de 2011. 
Vale ressaltar que o ofício da autorização da pesquisa, fornecido pela Diretoria de Ensino de Jacareí, descreve apenas os alunos do Ensino Médio das escolas públicas de Arujá, uma vez que as escolas privadas têm seu próprio regimento interno, não necessitando, portanto, de autorização da Diretoria de Ensino.

Apenas no final de agosto de 2011, foi iniciada a coleta de dados. Inicialmente, foi feito contato com os coordenadores e diretores das escolas sorteadas, a fim de fornecer orientações sobre o projeto. Conforme descrito no item 4.4, a pesquisa deveria ser realizada em seis escolas públicas e seis escolas privadas.

Nas escolas públicas, o contato inicial e o acesso à direção foram obtidos com facilidade e prontamente em todas as escolas. Nestas, foi estabelecido contato com os professores, coordenadores e diretores. Assim sendo, o projeto foi exposto à direção e aos professores em reuniões préagendadas pela coordenação, sendo autorizado o projeto em todas as escolas públicas sorteadas.

No entanto, nas escolas privadas, houve dificuldade no acesso aos diretores das escolas. Logo, foi estabelecido contato somente com os coordenadores do Ensino Médio, exceto em uma escola, devido à falta de disponibilidade dos diretores. Esta dificuldade de acesso à direção das escolas privadas pode ter sido um dos fatores que contribuiu para a não aceitação da pesquisa em algumas destas instituições. Vale ressaltar que o primeiro contato em algumas das escolas privadas foi dificultoso, sendo primeiramente enviado o projeto via e-mail e, somente após muitas tentativas e insistências, é que foi possível marcar alguns encontros com a coordenação das escolas para apresentação do projeto.

Em relação à autorização do projeto nas escolas privadas, das seis escolas selecionadas, apenas três autorizaram a realização do projeto de pesquisa. Os motivos da recusa do projeto nas escolas privadas foram: a escola 2 informou que somente autorizaria a pesquisa caso fosse desenvolvido um projeto sobre a temática em conjunto com a escola e que isto só seria possível em 2013; a escola 3 informou que, no passado, houve uma pesquisa sobre métodos contraceptivos e que muitos pais reclamaram, 
pois achavam que a escola estava incentivando o sexo; e a escola 6 justificou a recusa por se tratar de uma escola administrada por padres. Das escolas privadas que permitiram a realização da pesquisa, apenas a escola 4 autorizou a pesquisa com turmas dos $1^{\circ}, 2^{\circ}$ e $3^{\circ}$ anos. A escola 1 somente permitiu a pesquisa com alunos do $3^{\circ}$ ano e a escola 5 permitiu a pesquisa com alunos do $2^{\circ}$ e do $3^{\circ}$ anos. As escolas 1 e 5 alegaram que os alunos das turmas não autorizadas eram muito novos para participar da pesquisa e que os pais poderiam reclamar com a direção da escola.

Em seguida, após autorização, a pesquisadora foi até as escolas (setembro e outubro de 2011), fez o convite aos alunos, durante uma aula, nas turmas sorteadas, conforme acordado com o corpo docente e com 0 diretor da escola, e distribuiu o Termo de Consentimento Livre e Esclarecido (TCLE) (modelo no APÊNDICE 1) para os alunos. Neste momento, foi enfatizado que os adolescentes que tivessem menos que 18 anos de idade deveriam entregar o TCLE aos pais ou responsável. Caso os pais ou o responsável aceitassem sua participação na pesquisa, estes deveriam assinar as duas cópias do TCLE, ficar com uma e entregar a outra ao aluno, que deveria devolver à pesquisadora no dia seguinte, quando fossem distribuídos os questionários. Caso o TCLE não fosse assinado pelos pais ou responsáveis pelo aluno que tivesse menos que 18 anos de idade, 0 estudante não poderia participar da pesquisa. Para os alunos que tinham mais que 18 anos de idade, se quisessem participar, deveriam assinar as duas cópias do TCLE, ficar com uma e devolver a outra para a pesquisadora no dia seguinte.

No dia posterior à entrega do TCLE, ocorreu a distribuição do instrumento. Após seu preenchimento, este foi depositado pelo estudante numa urna que ficou disponível na frente da sala. Os questionários foram distribuídos simultaneamente nas turmas selecionadas em cada escola, já que as perguntas que versam sobre o conhecimento não deveriam ser compartilhadas entre os participantes antes que o questionário fosse preenchido.

Assim, foram entrevistados 723 adolescentes no total. Contudo, conforme o critério de elegibilidade, optou-se por excluir os adolescentes 
unidos e aqueles que tinham 14 anos de idade. Logo, foram excluídos 18 adolescentes das escolas públicas por terem 14 anos de idade e/ou por serem casados ou por estarem morando com o parceiro. Portanto, a população de estudo foi finalmente constituída de 705 adolescentes solteiros entre 15 e 19 anos de idade.

Quadro 3 - Listagem das escolas e das turmas do Ensino Médio de Arujá que participaram da pesquisa, Arujá - 2011

\begin{tabular}{|c|c|c|}
\hline Escolas Públicas & $\begin{array}{c}\text { Turmas } \\
\text { participantes } \\
\text { Escola 3 e 1E } \\
2 \mathrm{~A} \mathrm{e} \mathrm{2D} \\
3 \mathrm{~A} \mathrm{e} \mathrm{3B}\end{array}$ & $\begin{array}{c}\text { Quantidade de alunos que } \\
\text { responderam a pesquisa }\end{array}$ \\
\hline Escola 4 & $\begin{array}{c}\text { 1F e 1H } \\
2 \mathrm{C} \mathrm{e} \mathrm{2E} \\
3 \mathrm{~A} \mathrm{e} \mathrm{3E}\end{array}$ & 246 \\
\hline Escola 5 & $1 \mathrm{~B}$ & 183 \\
\hline Escola 6 & $1 \mathrm{~B}$ & 23 \\
\hline Escola 7 & $1 \mathrm{~A} \mathrm{e} \mathrm{3A}$ & 40 \\
\hline Escola 8 & $1 \mathrm{C} \mathrm{E} \mathrm{2C}$ & 55 \\
\hline Total & 18 turmas & 555 \\
\hline Escolas Privadas & $\begin{array}{c}\text { Turmas } \\
\text { participantes }\end{array}$ & $\begin{array}{c}\text { Quantidade de alunos que } \\
\text { responderam a pesquisa }\end{array}$ \\
\hline Escola 1 & $3 \mathrm{~A}$ & 24 \\
\hline Escola 4 & $1 \mathrm{~A} / 2 \mathrm{~A} / 3 \mathrm{~A}$ & 106 \\
\hline Escola 5 & $2 \mathrm{~A}$ e 3A & 38 \\
\hline Total & 6 turmas & 168 \\
\hline
\end{tabular}

Vale destacar que algumas turmas sorteadas das escolas públicas não puderam participar da pesquisa, pois os alunos não estavam presentes no momento da entrega do instrumento (participação em outra atividade fora da escola, recesso escolar, reunião de pais, entre outros). Logo, foram 
selecionadas as turmas posteriores da listagem das escolas. Da mesma forma, as turmas sorteadas das escolas privadas, que não autorizaram a pesquisa, foram substituídas pelas turmas subsequentes das escolas que autorizaram a pesquisa.

Houve 6 recusas: seis adolescentes recusaram a pesquisa, sendo duas recusas da escola privada 5 , duas recusas da escola pública 3 e duas recusas da escola pública 4 .

O total de perdas $(0,9 \%)$ foi considerado adequado ao esperado pelo plano amostral. Vale ressaltar que houve excelente receptividade e entusiasmo por parte dos adolescentes das turmas selecionadas. Os adolescentes mostraram-se interessados e questionaram sobre a $A E$ no decorrer da aplicação do questionário. Dessa forma, foram agendadas datas com a coordenadoria da escola nas quais foram realizadas oficinas sobre métodos contraceptivos, em especial sobre a $A E$, para os adolescentes. As oficinas sobre métodos contraceptivos foram realizadas nas escolas públicas 3, 4, 6, 7 e 8 e na escola privada 4. Na maioria das escolas, a oficina foi dirigida a todos os alunos e não somente para aqueles que participaram da pesquisa. Ademais, nas escolas públicas 3, 4 e 8, a oficina foi administrada também para os professores, pois a direção da escola relatou que muitos alunos dividiam suas dúvidas com os professores e que estes muitas vezes não tinham o conhecimento adequado para responder tais perguntas. Nas oficinas, tanto os alunos quanto os professores se mostraram interessados, participaram ativamente e fizeram perguntas relevantes ao tema.

\subsection{INSTRUMENTO}

O instrumento foi elaborado com base nos estudos de Figueiredo et al. (2008), Araújo e Costa (2009) e Borges et al. (2010). O questionário foi estruturado, pré-codificado e autoaplicado (APÊNDICE 2). O questionário foi pré-testado no mês de agosto de 2011 com adolescentes de 15 a 19 anos de idade da escola EE Profạ. Ana Maria de Carvalho Pereira - escola não 
sorteada para participar da pesquisa. No pré-teste, os estudantes relataram que o questionário era de fácil compreensão e nenhum deles teve dúvidas quanto ao preenchimento do questionário. Assim, não foram necessárias modificações no instrumento.

O instrumento foi dividido em quatro partes:

1 - Informações sociodemográficas dos adolescentes.

2 - Conhecimento sobre a anticoncepção de emergência.

3 - Comportamento sexual e contraceptivo.

4 - Uso da anticoncepção de emergência.

\subsection{VARIÁVEIS DO ESTUDO}

No presente estudo, as variáveis dependentes foram duas: o conhecimento sobre a anticoncepção de emergência e 0 uso da anticoncepção de emergência.

As variáveis independentes compreenderam:

a) Perfil sociodemográfico dos adolescentes:

- Tipo de escola (optou-se por usar o tipo de escola - pública e privada - como um indicador do grupo social)

- Escolaridade

- Idade

- Sexo

- Estado civil

- Religião

- Coabitação 


\section{b) Comportamento sexual:}

- Namoro atual

- Relação sexual

- Idade em que teve a primeira relação sexual

- Utilização de algum método contraceptivo na última relação sexual

- Número de parceiros sexuais

c) Conhecimento sobre a anticoncepção de emergência entre os adolescentes:

- Conhecimento da AE

- Pessoas ou locais onde o adolescente obteve informações sobre a $A E$

- Participação de palestras sobre AE na escola

- Conhecimento de alguém que já usou AE

- Em relação ao nível de conhecimento sobre a $A E$ : foram elaboradas dez questões, no qual houve escores e cujas opções de resposta foram "falso", "verdadeiro" e "não sei responder".

d) Uso da anticoncepção de emergência entre os adolescentes:

- Uso anterior da AE

- Motivos pelo qual utilizou a AE na última vez

- Tipo de relacionamento vigente quando utilizou a $A E$ pela última vez

- Métodos contraceptivos usados concomitantemente com a AE

- Aquisição da $A E$ com receita médica

- Pessoas ou locais onde o adolescente obteve a AE

- Tempo de uso da AE após a relação sexual desprotegida

- Número de vezes que já utilizou a $A E$ no último ano 


\subsection{ANÁLISE DOS DADOS}

A digitação duplicada do banco de dados foi realizada utilizando o software EPIINFO 3.5.1. Todas as análises foram realizadas utilizando o software SPSS para Windows versão 17.0. A análise dos resultados foi dividida em três etapas:

1) A caracterização sociodemográfica e do comportamento sexual e contraceptivo dos adolescentes, bem como o uso e o conhecimento da $A E$, realizado por meio de proporções e médias, desvio-padrão e medianas. A diferença entre as proporções foram testadas pelo teste de Qui-quadrado ou Exato de Fisher. As médias foram comparadas por meio do teste t-student e a colinearidade pelo coeficiente de correlação de Pearson.

2) A análise dos determinantes do nível do conhecimento da $A E$ foi realizada por meio da análise de regressão linear simples e múltipla, incluindo apenas os adolescentes que conheciam a AE. Com a finalidade de avaliar o nível do conhecimento da $A E$, foram elaboradas 10 questões específicas, que deram origem ao escore de conhecimento. $\mathrm{O}$ escore de conhecimento foi obtido pelo número de respostas corretas, com peso igual para cada pergunta (1 ponto). Desse modo, a pontuação total de escore variou de 0 (quando nenhuma questão foi acertada) a 10 (quando todas as questões foram respondidas corretamente). $\mathrm{Na}$ análise de regressão linear, foram analisadas as médias dos escores de conhecimento da AE.

3) A análise dos determinantes do uso da $A E$ foi realizada por meio da análise de regressão logística univariada e múltipla, incluindo apenas os adolescentes que já iniciaram a vida sexual (336 adolescentes). Cabe destacar que, dentre estes, 29 adolescentes do sexo masculino responderam que não sabiam se a parceira havia usado a $A E$ e foram 
excluídos da análise, que passou a consistir, portanto, de 307 adolescentes. Sete relataram não conhecer a $A E$, mas foram mantidos na análise e considerados na categoria dos que não usaram este método contraceptivo (Ver figura 1).

O levantamento dos aspectos que predispuseram o adolescente a ter maior média do escore de conhecimento (regressão linear múltipla) ou maior chance de usar a $\mathrm{AE}$ (regressão logística múltipla), foi elaborado mediante os seguintes passos:

a- Foram construídos modelos univariados, sendo elegíveis as variáveis que mostraram associação $(p<0,20)$ pelo teste $H_{0}: \beta=0$ para regressão linear e pelo teste do Qui-quadrado para regressão logística.

b- As variáveis referentes ao conhecimento e ao uso da $A E$ que mostraram alguma associação $(p<0,20)$ passaram para a etapa seguinte da regressão linear múltipla e da regressão logística múltipla, respectivamente. $\mathrm{Na}$ análise de regressão linear múltipla para o nível do conhecimento da $\mathrm{AE}$, foram considerados elementos que predispõem à menor média do escore de conhecimento as categorias com coeficiente de $\beta$ menores que 0 (zero) e foram considerados elementos que predispõem à maior média do escore de conhecimento as categorias com coeficiente de $\beta$ maiores que 0 (zero). Já na regressão logística múltipla para o uso da $\mathrm{AE}$, foram considerados fatores que predispõem ao risco as categorias com odds ratio (OR) maiores que 1,0 e foram considerados fatores de proteção as categorias com OR menores que 1,0. As construções dos modelos finais da regressão linear múltipla e da regressão logística múltipla são apresentadas nos APÊNDICES 3 e 4, respectivamente. 
Figura 1 - Estrutura organizacional dos adolescentes entrevistados, segundo experiência sexual, conhecimento e uso da anticoncepção de emergência, Arujá - 2011

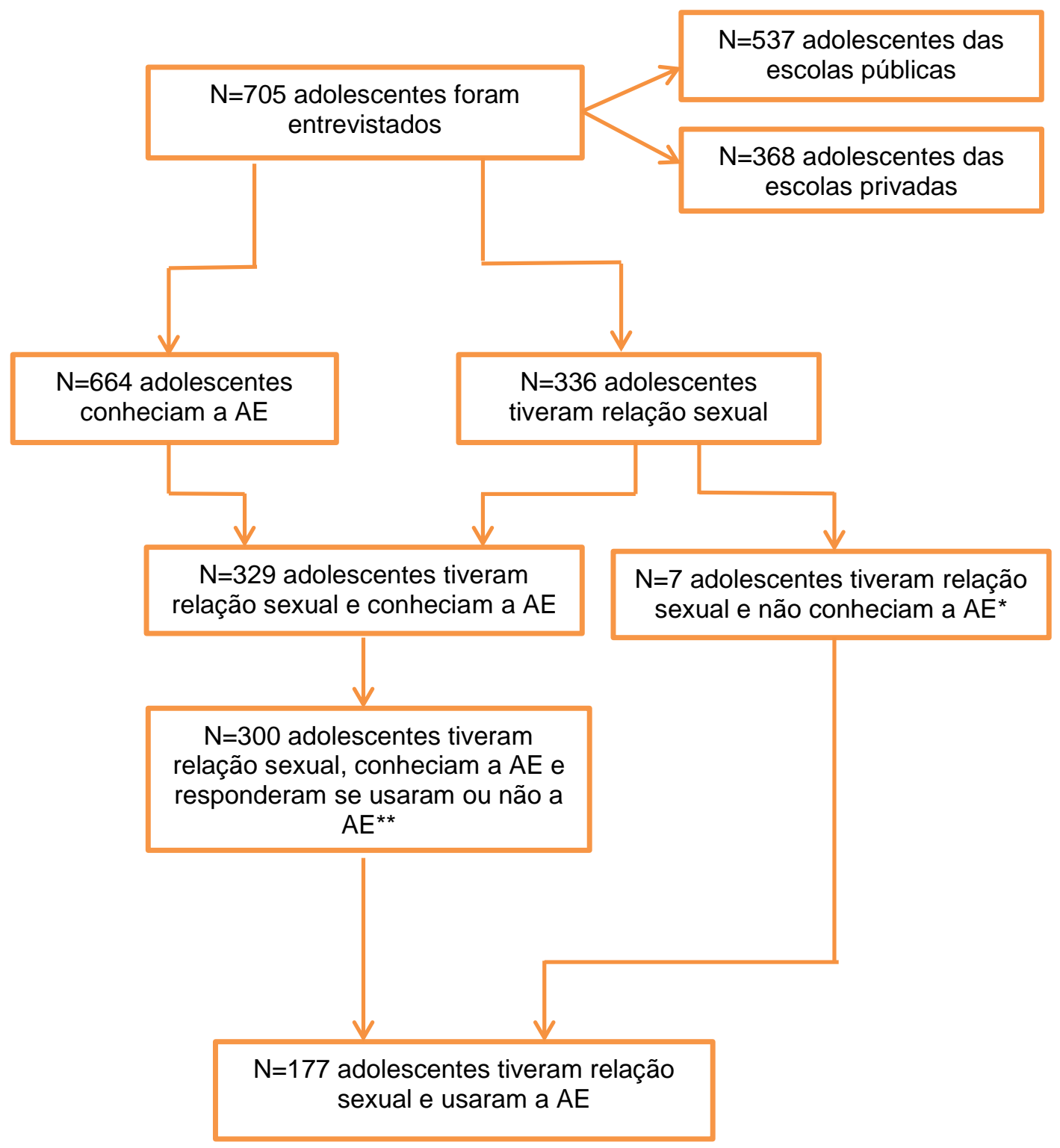

*Os 7 adolescentes que tiveram relação sexual e não conheciam a $A E$ foram mantidos na análise, mas foi considerado que eles não usaram a $A E$.

**29 adolescentes do sexo masculino não souberam responder se a parceira havia usado a $\mathrm{AE}$, portanto foram excluídos da análise. 


\subsection{CONSIDERAÇÕES ÉTICAS}

Este projeto foi aprovado pelo Comitê de Ética em Pesquisa da Escola de Enfermagem da Universidade de São Paulo e autorizado pela Diretoria de Ensino, conforme descrito no item 4.5.

No dia anterior à distribuição dos questionários, foi enfatizado que o instrumento era constituído de perguntas de cunho íntimo e pessoal, que a participação do(a) estudante era livre e espontânea e que não havia qualquer tipo de prejuízo caso o(a) mesmo(a) não quisesse participar. Também foi enfatizado que não haveria qualquer tipo de remuneração caso participasse. Os participantes tiveram assegurada a confidencialidade dos relatos fornecidos e foram respeitados os valores socioculturais. Além disso, os adolescentes foram orientados para não se identificarem no questionário.

Os sujeitos desta pesquisa tiveram total liberdade em participar ou não da pesquisa e ainda deixar a pesquisa em qualquer momento, se assim o desejassem.

Este estudo adotou procedimentos que garantiram a nãodiscriminação ou a não-estigmatização dos indivíduos envolvidos na pesquisa. 


\section{RESULTADOS}

\subsection{CARACTERÍSTICAS SOCIODEMOGRÁFICAS DOS ADOLESCENTES}

Dos 705 adolescentes solteiros que responderam o questionário, $76,2 \%$ eram estudantes de escolas públicas e $26,8 \%$ eram de escolas privadas.

$\mathrm{Na}$ Tabela 1, são apresentadas as características sociodemográficas dos adolescentes, por tipo de escola. Ano escolar, idade e sexo mostraramse estatisticamente diferentes entre os adolescentes das escolas públicas e privadas. Nas escolas públicas, a proporção maior de adolescentes que respondeu a pesquisa foi do $1^{\circ}$ ano do ensino médio, sendo que, nas escolas privadas, foi do $3^{\circ}$ ano do ensino médio, com $\mathrm{p}<0,001$.

Ainda de acordo com a Tabela 1, houve maior proporção de adolescentes do sexo masculino nas escolas públicas e do sexo feminino nas escolas privadas, com $p=0,002$. Não foi observada diferença estatisticamente significativa entre a religião e a coabitação, segundo o tipo de escola. 
Tabela 1 - Número e proporção de adolescentes entrevistados, segundo as características sociodemográficas, por tipo de escola, Arujá - 2011

\begin{tabular}{|c|c|c|c|c|c|c|c|}
\hline \multirow[t]{3}{*}{ Variáveis } & \multicolumn{4}{|c|}{ Tipo de Escola } & \multicolumn{2}{|c|}{ Total } & \multirow[t]{3}{*}{$\mathbf{p}^{\star}$} \\
\hline & \multicolumn{2}{|c|}{ Pública } & \multicolumn{2}{|c|}{ Privada } & & & \\
\hline & $\mathrm{N}$ & $\%$ & $\mathrm{~N}$ & $\%$ & $\mathrm{~N}$ & $\%$ & \\
\hline \multicolumn{8}{|l|}{ Ano escolar } \\
\hline $1^{\circ}$ ano & 231 & 43,0 & 40 & 23,8 & 271 & 38,4 & $<0,001$ \\
\hline $2^{\circ}$ ano & 165 & 30,7 & 46 & 27,4 & 211 & 29,9 & \\
\hline $3^{\circ}$ ano & 141 & 26,3 & 82 & 48,8 & 223 & 31,6 & \\
\hline \multicolumn{8}{|l|}{ Idade } \\
\hline $15-16$ anos & 348 & 64,8 & 85 & 50,6 & 433 & 61,4 & 0,001 \\
\hline $17-19$ anos & 189 & 35,2 & 83 & 49,4 & 272 & 38,6 & \\
\hline \multicolumn{8}{|l|}{ Sexo } \\
\hline Masculino & 272 & 50,7 & 62 & 36,9 & 334 & 47,4 & 0,002 \\
\hline Feminino & 265 & 49,3 & 106 & 63,1 & 371 & 52,6 & \\
\hline \multicolumn{8}{|l|}{ Religião } \\
\hline Nenhuma & 101 & 18,8 & 28 & 16,7 & 29 & 18,3 & 0,148 \\
\hline Evangélica & 221 & 41,2 & 56 & 33,3 & 277 & 39,3 & \\
\hline Católica & 177 & 33,0 & 70 & 41,7 & 247 & 35,0 & \\
\hline Outras** & 38 & 7,1 & 14 & 8,3 & 52 & 7,4 & \\
\hline \multicolumn{8}{|l|}{ Coabitação } \\
\hline Ambos pais & 401 & 74,7 & 128 & 76,2 & 529 & 75,0 & 0,920 \\
\hline Somente mãe & 103 & 19,2 & 30 & 17,9 & 133 & 18,9 & \\
\hline Outras $^{* * *}$ & 33 & 6,1 & 10 & 6,0 & 43 & 6,1 & \\
\hline Total & 537 & 100,0 & 168 & 100,0 & 705 & 100,0 & \\
\hline
\end{tabular}

*Nível descritivo do teste de associação pelo Qui-quadrado.

**Outras religiões incluem: Espiritismo, Judaísmo, Testemunha de Jeová, Budismo e Muçulmano.

${ }^{* *}$ Outras coabitações incluem: somente com o pai, amigos, avós e tios. 


\subsection{INÍCIO DA VIDA SEXUAL}

Dos 705 adolescentes entrevistados, pouco menos da metade $(47,7 \%)$ já havia iniciado a vida sexual, sendo este porcentual diferente em relação ao tipo de escola, conforme é mostrado na Figura $2(p=0,002)$. A idade média da primeira relação sexual dos adolescentes das escolas públicas foi 14,5 anos ( $d p=1,49$ ), já nas escolas privadas a idade média da primeira relação sexual foi 15,1 anos $(\mathrm{dp}=1,08)(\mathrm{p}<0,001)$. Ademais, a média do número de parceiros sexuais entre os adolescentes das escolas públicas foi 3,4 , enquanto nas escolas privadas foi 2,3 parceiros sexuais $(p=0,003)$.

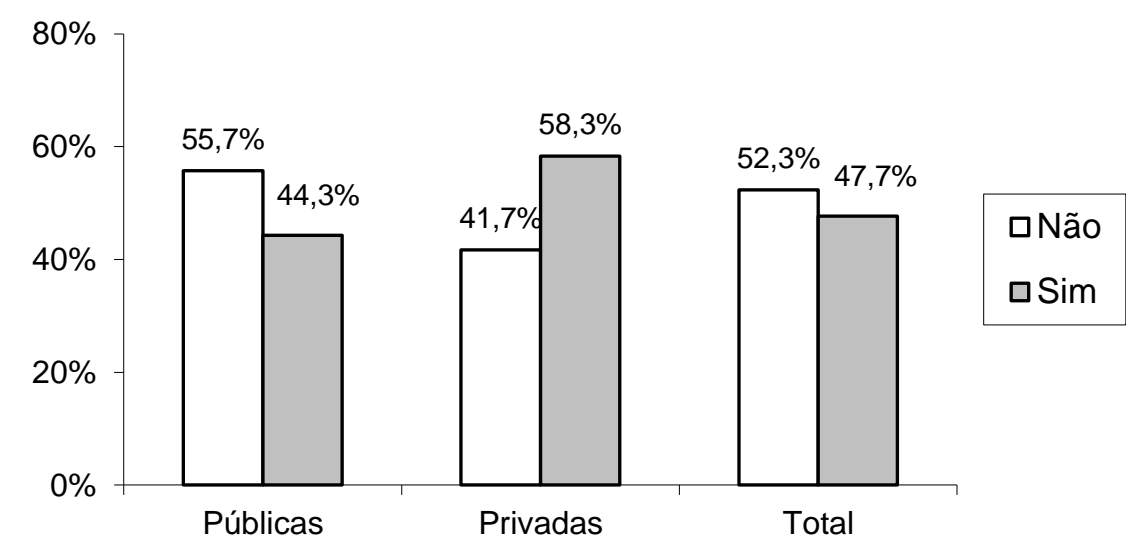

Figura 2 - Distribuição dos adolescentes entrevistados, segundo o início da vida sexual, por tipo de escola, Arujá - 2011

\subsection{CONHECIMENTO DA ANTICONCEPÇÃO DE EMERGÊNCIA}

Dos 705 adolescentes solteiros que responderam o questionário, 664 $(94,2 \%)$ relataram conhecer a AE. Na Tabela 2, são descritas as fontes de informação sobre a $A E$ entre os adolescentes que a conhecem, independente do início da vida sexual. Cabe salientar que admitiu-se múltipla resposta no questionamento sobre fontes de informação da $\mathrm{AE}$. 
Foi observado que os adolescentes receberam informações sobre a $\mathrm{AE}$ essencialmente dos amigos (48,5\%); em segundo lugar, na escola $(37,5 \%)$ e, em terceiro lugar, pela televisão (33,3\%). As fontes de informação menos referidas pelos adolescentes foram internet, revistas ou jornais, serviços de saúde, farmácia e outras fontes, como cursos e trabalhos. Não houve diferença estatisticamente significativa entres as fontes de informações e o tipo de escola.

Tabela 2 - Número e proporção de adolescentes entrevistados, segundo as fontes de informação sobre a anticoncepção de emergência, por tipo de escola, Arujá - 2011

\begin{tabular}{|c|c|c|c|c|c|c|c|}
\hline \multirow[t]{3}{*}{ Fontes de informação* } & \multicolumn{4}{|c|}{ Tipo de Escola } & \multirow{2}{*}{\multicolumn{2}{|c|}{ Total }} & \multirow[t]{3}{*}{$\mathbf{p}^{\star *}$} \\
\hline & \multicolumn{2}{|c|}{ Pública } & \multicolumn{2}{|c|}{ Privada } & & & \\
\hline & $\mathrm{N}$ & $\%$ & $\mathrm{~N}$ & $\%$ & $\mathrm{~N}$ & $\%$ & \\
\hline \multicolumn{8}{|l|}{ Com amigos/conhecidos } \\
\hline Não & 265 & 53,2 & 77 & 46,4 & 342 & 51,5 & 0,127 \\
\hline Sim & 233 & 46,8 & 89 & 53,6 & 322 & 48,5 & \\
\hline \multicolumn{8}{|l|}{ Na escola } \\
\hline Não & 306 & 61,4 & 109 & 65,7 & 415 & 62,5 & 0,331 \\
\hline Sim & 192 & 38,6 & 57 & 34,3 & 249 & 37,5 & \\
\hline \multicolumn{8}{|l|}{ Na televisão } \\
\hline Não & 328 & 65,9 & 115 & 69,3 & 443 & 66,7 & 0,419 \\
\hline Sim & 170 & 34,1 & 51 & 30,7 & 221 & 33,3 & \\
\hline \multicolumn{8}{|l|}{ Com pais/parentes } \\
\hline Não & 364 & 73,1 & 130 & 78,3 & 494 & 74,4 & 0,182 \\
\hline Sim & 134 & 26,9 & 36 & 21,7 & 170 & 25,6 & \\
\hline \multicolumn{8}{|l|}{$\mathrm{Na}$ internet } \\
\hline Não & 418 & 83,9 & 140 & 84,3 & 558 & 84,0 & 0,903 \\
\hline Sim & 80 & 16,1 & 26 & 15,7 & 106 & 16,0 & \\
\hline \multicolumn{8}{|l|}{ Em revistas ou jornais } \\
\hline Não & 425 & 85,3 & 137 & 82,5 & 562 & 84,6 & 0,384 \\
\hline Sim & 73 & 14,7 & 29 & 17,5 & 102 & 15,4 & \\
\hline \multicolumn{8}{|l|}{ Nos serviços de saúde } \\
\hline Não & 436 & 87,6 & 139 & 83,7 & 575 & 86,6 & 0,211 \\
\hline Sim & 62 & 12,4 & 27 & 16,3 & 89 & 13,4 & \\
\hline
\end{tabular}


Tabela 2 (Continuação) - Número e proporção de adolescentes entrevistados, segundo as fontes de informação sobre a anticoncepção de emergência, por tipo de escola, Arujá - 2011

\begin{tabular}{|c|c|c|c|c|c|}
\hline \multirow[t]{3}{*}{ Fontes de informação* } & \multicolumn{2}{|c|}{ Tipo de Escola } & \multirow{2}{*}{\multicolumn{2}{|c|}{ Total }} & \multirow[t]{3}{*}{$\mathbf{p}^{\star \star}$} \\
\hline & Pública & Privada & & & \\
\hline & $\%$ & $\%$ & $\mathrm{~N}$ & $\%$ & \\
\hline
\end{tabular}

Na farmácia

\begin{tabular}{lrrrrrrr} 
Não & 467 & 93,8 & 157 & 94,6 & 624 & 94,0 & 0,706 \\
Sim & 31 & 6,2 & 9 & 5,4 & 40 & 6,0 & \\
& & & & & & & \\
\hline Total & $\mathbf{4 9 8}$ & $\mathbf{1 0 0 , 0}$ & $\mathbf{1 6 6}$ & $\mathbf{1 0 0 , 0}$ & $\mathbf{6 6 4}$ & $\mathbf{1 0 0 , 0}$ & \\
\hline
\end{tabular}

* Questão que admitiu múltipla resposta.

** Nível descritivo do teste de associação pelo Qui-quadrado.

A maioria dos adolescentes revelou que nunca participou de palestras sobre a $A E$, independentemente do tipo de escola, com $p=0,763$ (Figura 3 ).

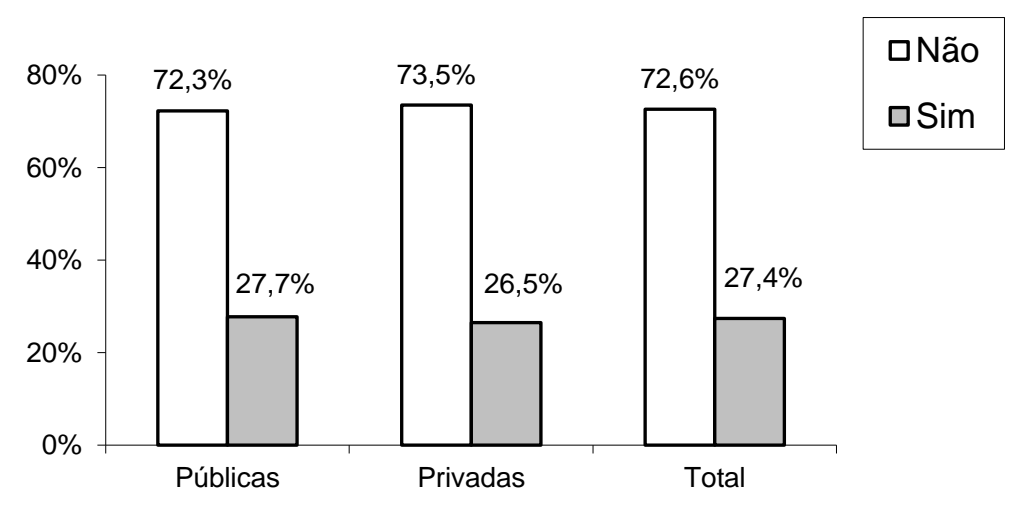

Figura 3 - Distribuição dos adolescentes entrevistados, segundo a participação de palestras sobre a anticoncepção de emergência, por tipo de escola, Arujá - 2011 


\subsection{NÍVEL DO CONHECIMENTO DA ANTICONCEPÇÃO DE EMERGÊNCIA}

Para avaliar o nível do conhecimento dos adolescentes sobre a $\mathrm{AE}$, foram realizadas duas análises. Na primeira análise, foram consideradas as respostas das questões sobre a AE como "falso", "verdadeiro" e "não sei". $\mathrm{Na}$ segunda análise, as respostas foram divididas em dois grupos: "Sabe" e "Não sabe". O grupo "Sabe" corresponde às respostas corretas, ou seja, à proporção de adolescentes que soube responder corretamente a questão. Já, o grupo "Não sabe" corresponde à somatória das respostas erradas com as respostas assinaladas como "não sei", ou seja, proporção de adolescentes que responderam erroneamente mais os que relataram não saber responder a questão.

\subsubsection{Questões sobre anticoncepção de emergência: respostas "Falso", "Verdadeiro" e "Não sei"}

Na Tabela 3, são apresentadas as questões com as respostas "falso", "verdadeiro" e "não sei" assinaladas pelos adolescentes sobre a AE, por tipo de escola. Na totalidade, foi observada maior porcentagem de respostas não sei nas questões: "Em caso de vômito até 2 horas após a ingestão da pílula do dia seguinte, deve-se repetir a dose" (55,1\%), "A pílula do dia seguinte pode substituir a pílula oral comum" (54,4\%), "A pílula do dia seguinte pode ser usada uma vez por mês” (50,9\%). Nas questões em que houve diferença estatisticamente significativa entre os adolescentes das escolas públicas e privadas, a proporção de respostas não sei foi consideravelmente maior nas escolas públicas. 
Tabela 3 - Número e proporção de adolescentes entrevistados, segundo as questões de conhecimento da anticoncepção de emergência, por tipo de escola, Arujá - 2011

\begin{tabular}{|c|c|c|c|c|c|c|c|}
\hline \multirow[t]{3}{*}{ Questões* } & \multicolumn{4}{|c|}{ Tipo de Escola } & \multicolumn{2}{|c|}{ Total } & \multirow[t]{3}{*}{$\mathbf{p}^{\star \star}$} \\
\hline & \multicolumn{2}{|c|}{ Pública } & \multicolumn{2}{|c|}{ Privada } & \multirow[b]{2}{*}{$\mathrm{N}$} & \multirow[b]{2}{*}{$\%$} & \\
\hline & $\mathrm{N}$ & $\%$ & $\mathrm{~N}$ & $\%$ & & & \\
\hline \multicolumn{8}{|c|}{$\begin{array}{l}\text { AE deve ser usada } \\
\text { antes da relação sexual }\end{array}$} \\
\hline Falso & 384 & 77,1 & 143 & 86,1 & 527 & 79,4 & 0,028 \\
\hline Verdadeiro & 45 & 9,0 & 12 & 7,2 & 57 & 8,6 & \\
\hline Não sei & 69 & 13,9 & 11 & 6,6 & 80 & 12,0 & \\
\hline \multicolumn{8}{|l|}{ AE previne $D S T^{\star \star \star}$} \\
\hline Falso & 362 & 72,7 & 144 & 86,7 & 506 & 76,2 & $<0,001$ \\
\hline Verdadeiro & 62 & 12,4 & 6 & 3,6 & 68 & 10,2 & \\
\hline Não sei & 74 & 14,9 & 16 & 9,6 & 90 & 13,6 & \\
\hline \multicolumn{8}{|c|}{$\begin{array}{l}\text { Em caso de vômito até } 2 \mathrm{~h} \text { da } \\
\text { ingestão da } A E \text {, deve-se repetir a dose }\end{array}$} \\
\hline Falso & 141 & 28,3 & 53 & 31,9 & 194 & 29,2 & 0,653 \\
\hline Verdadeiro & 78 & 15,7 & 26 & 15,7 & 104 & 15,7 & \\
\hline Não sei & 279 & 56,0 & 87 & 52,4 & 366 & 55,1 & \\
\hline \multicolumn{8}{|c|}{ AE é mais eficaz que outros MAC ${ }^{\star \star \star \star}$} \\
\hline Falso & 255 & 51,2 & 115 & 69,3 & 370 & 55,7 & $<0,001$ \\
\hline Verdadeiro & 69 & 13,9 & 15 & 9,0 & 84 & 12,7 & \\
\hline Não sei & 174 & 34,9 & 36 & 21,7 & 210 & 31,6 & \\
\hline \multicolumn{8}{|c|}{$\begin{array}{l}\text { Ao usar } \mathrm{AE} \text {, deve-se estar atento } \\
\text { para que isso ocorra em até } 5 \text { dias }\end{array}$} \\
\hline Falso & 158 & 31,7 & 50 & 30,1 & 208 & 31,3 & 0,011 \\
\hline Verdadeiro & 112 & 22,5 & 56 & 33,7 & 168 & 25,3 & \\
\hline Não sei & 288 & 45,8 & 60 & 36,1 & 288 & 43,4 & \\
\hline \multicolumn{8}{|c|}{ AE pode ser usada 1 vez por mês } \\
\hline Falso & 154 & 30,9 & 73 & 44,0 & 227 & 34,2 & 0,001 \\
\hline Verdadeiro & 70 & 14,1 & 29 & 17,5 & 99 & 14,9 & \\
\hline Não sei & 274 & 55,0 & 64 & 38,6 & 338 & 50,9 & \\
\hline \multicolumn{8}{|l|}{ AE é abortiva } \\
\hline Falso & 149 & 29,9 & 56 & 33,7 & 205 & 30,9 & 0,202 \\
\hline Verdadeiro & 142 & 28,5 & 54 & 32,5 & 196 & 29,5 & \\
\hline Não sei & 207 & 41,6 & 56 & 33,7 & 263 & 39,6 & \\
\hline \multicolumn{8}{|c|}{ AE precisa ser usada no período fértil } \\
\hline Falso & 171 & 34,3 & 81 & 48,8 & 252 & 38,0 & $<0,001$ \\
\hline Verdadeiro & 67 & 13,5 & 27 & 16,3 & 94 & 14,2 & \\
\hline Não sei & 260 & 52,5 & 58 & 34,9 & 318 & 47,9 & \\
\hline \multicolumn{8}{|c|}{ AE substitui a pílula oral comum } \\
\hline Falso & 150 & 30,1 & 88 & 53,0 & 238 & 35,8 & $<0,001$ \\
\hline Verdadeiro & 47 & 9,4 & 18 & 10,8 & 65 & 9,8 & \\
\hline Não sei & 301 & 60,4 & 60 & 36,1 & 361 & 54,4 & \\
\hline
\end{tabular}

(Continua) 
Tabela 3 (Continuação) - Número e proporção de adolescentes entrevistados, segundo as questões de conhecimento da anticoncepção de emergência, por tipo de escola, Arujá - 2011

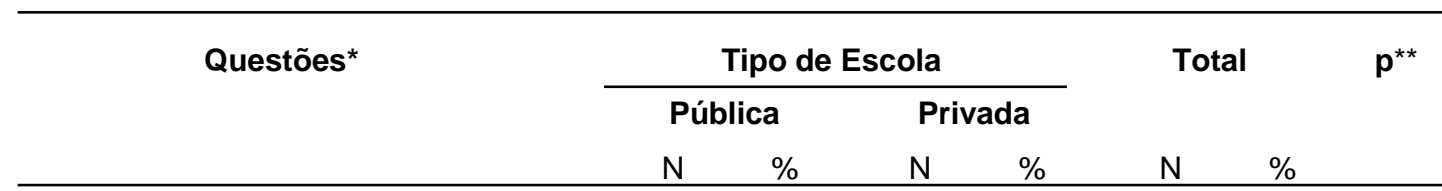

Ao usar AE, a mulher está protegida de uma gravidez até a chegada da menstruação

Falso

Verdadeiro

Não sei

\begin{tabular}{rrrrrrr}
111 & 22,3 & 71 & 42,8 & 182 & 27,4 & $<0,001$ \\
153 & 30,7 & 51 & 30,7 & 204 & 30,7 & \\
234 & 47,0 & 44 & 26,5 & 278 & 41,9 & \\
\hline 4 & $\mathbf{4 9 8}$ & $\mathbf{1 0 0 , 0}$ & $\mathbf{1 6 6}$ & $\mathbf{1 0 0 , 0}$ & $\mathbf{6 6 4}$ & $\mathbf{1 0 0 , 0}$
\end{tabular}

Total

tões estão em itálico.

* Questões: as respostas corretas das questões estão em itálico.
${ }^{* *}$ Nível descritivo do teste de associação pelo Qui-quadrado.

*** DST $=$ doenças sexualmente transmissíveis.

${ }^{\star * * *} \mathrm{MAC}=$ métodos contraceptivos.

\subsubsection{Questões sobre anticoncepção de emergência: "Sabe" e "Não sabe"}

$\mathrm{Na}$ Tabela 4, são apresentadas as questões sobre a $\mathrm{AE}$ com as respostas divididas em "Sabe" e "Não sabe", por tipo de escola. Observou-se que foi baixa a porcentagem de adolescentes que soube responder corretamente a maioria das questões. As questões nas quais o acerto foi mais alto foram: "AE deve ser usada antes da relação sexual" (79,4\%), "AE previne DST" (76,2\%) e "AE é mais eficaz que outros MAC" (55,7\%). Em contrapartida, as questões nas quais o acerto foi mais baixo foram: "Em caso de vômito até $2 \mathrm{~h}$ da ingestão da $A E$, deve-se repetir a dose" (15,7\%), "Ao usar $A E$, deve-se estar atento para que isso ocorra em até cinco dias $(25,3 \%)$ e "Ao usar a AE a mulher está protegida de uma gravidez até a chegada da menstruação" (27,4\%). Vale ressaltar que a proporção de adolescentes que acertou cada questão foi maior entre os adolescentes das escolas privadas, com exceção das questões "Em caso de vômito até 2 horas da ingestão da $\mathrm{AE}$, deve-se repetir a dose" e "AE é abortiva". 
Tabela 4 - Número e proporção de adolescentes, segundo as questões de conhecimento da anticoncepção de emergência separadas por "Sabe" e "Não sabe", por tipo de escola, Arujá - 2011

\begin{tabular}{llllllll}
\hline Questões & \multicolumn{3}{c}{ Tipo de Escola } & & Total & & $\mathbf{p}^{*}$ \\
\cline { 2 - 5 } & Pública & \multicolumn{2}{c}{ Privada } & & & \\
& $\mathrm{N}$ & $\%$ & $\mathrm{~N}$ & $\%$ & $\mathrm{~N}$ & $\%$ & \\
\hline
\end{tabular}

AE deve ser usada antes da relação sexual

Sabe

Não sabe

$\begin{array}{rrrrrrr}384 & 77,1 & 143 & 86,1 & 527 & 79,4 & 0,013 \\ 114 & 22,9 & 23 & 13,8 & 137 & 20,6 & \\ & & & & & & \\ 362 & 72,7 & 144 & 86,7 & 506 & 76,2 & <0,001 \\ 136 & 27,3 & 22 & 13,2 & 158 & 23,8 & \end{array}$

AE previne DST ${ }^{\star *}$

Sabe

Não sabe

Em caso de vômito até $2 \mathrm{~h}$ da

ingestão da $\mathrm{AE}$, deve-se

repetir a dose

Sabe

Não sabe

$\begin{array}{rrrrrrr}78 & 15,7 & 26 & 15,7 & 104 & 15,7 & 1,000 \\ 420 & 84,3 & 140 & 84,3 & 560 & 84,3 & \end{array}$

$A E$ é mais eficaz que outros MAC ${ }^{* * *}$

Sabe

Não sabe

$\begin{array}{rrrrrrr}255 & 51,2 & 115 & 69,3 & 370 & 55,7 & <0,001 \\ 243 & 48,8 & 51 & 30,7 & 294 & 44,3 & \end{array}$

Ao usar AE, deve-se estar atento para que isso ocorra em até 5 dias

Sabe

Não sabe

$\begin{array}{rrrrrrr}112 & 22,5 & 56 & 33,7 & 168 & 25,3 & 0,004 \\ 386 & 77,5 & 110 & 66,2 & 496 & 74,7 & \\ & & & & & & \\ 154 & 30,9 & 73 & 44,0 & 227 & 34,2 & 0,002 \\ 344 & 69,1 & 93 & 56,1 & 437 & 65,8 & \\ & & & & & & \\ 149 & 29,9 & 56 & 33,7 & 205 & 30,9 & 0,357 \\ 349 & 70,1 & 11 & 66,2 & 432 & 69,1 & \end{array}$

AE pode ser usada 1 vez por mês

Sabe

Não sabe

294

AE é abortiva

Sabe

Não sabe

AE precisa ser usada no período fértil

Sabe

Não sabe

17

AE substitui a pílula oral comum

Sabe

Não Sabe 327

171

327

150

348

$\begin{array}{llllll}34,3 & 81 & 48,8 & 252 & 38,0 & 0,001 \\ 65,7 & 85 & 51,2 & 412 & 62,1 & \\ & & & & & \\ 30,1 & 88 & 53,0 & 238 & 35,8 & <0,001 \\ 69,8 & 78 & 46,9 & 426 & 64,2 & \end{array}$

Ao usar AE, a mulher está protegida de uma gravidez até a chegada da menstruação

Sabe

Não sabe

$111 \quad 22,3$

$387 \quad 77,7$

$\begin{array}{lll}71 & 42,8 & 182\end{array}$

$95 \quad 57,2 \quad 482$

$27,4<0,001$

72,6

Total

$\begin{array}{llllll}498 & 100,0 & 166 & 100,0 & 664 & 100,0\end{array}$

* Nível descritivo do teste de associação pelo Qui-quadrado.

** DST = doenças sexualmente transmissíveis.

${ }^{* * *} \mathrm{MAC}=$ métodos contraceptivos. 


\subsection{DETERMINANTES DO NÍVEL DO CONHECIMENTO DA ANTICONCEPÇÃO DE EMERGÊNCIA}

$\mathrm{Na}$ Tabela 5, são apresentadas as médias dos escores de conhecimento da $A E$ das características sociodemográficas, de comportamento amoroso e sexual e fontes de informação da AE.

Foram fatores independentes para a análise de regressão linear múltipla $(p<0,20)$ as variáveis: tipo de escola, ano escolar, idade, sexo, coabitação, namoro atual, relação sexual, conhecer alguém que já usou a $A E$ e as fontes de informação: pais/parentes, amigos/conhecidos, serviços de saúde, revistas/jornais, farmácia e internet. Embora a variável namoro atual tenha apresentado diferença entre as médias, não permaneceu na análise múltipla, pois apresentou alta colinearidade* em relação à variável relação sexual (Coeficiente de Correlação de Pearson: $r=0,782$ ). Isto significa que a maioria dos adolescentes que estava namorando teve relação sexual.

Do mesmo modo, a variável idade não permaneceu no modelo múltiplo, visto a existência de uma associação linear positiva forte entre o ano escolar e a idade $(\mathrm{r}=0,803)$. Assim, optou-se pelas variáveis relação sexual e ano escolar no modelo final da análise de regressão linear múltipla, por conta do forte poder de ajuste das outras variáveis.

Ainda, houve uma diferença estatisticamente significativa entre 0 escore de conhecimento e o uso da $A E(\mathrm{p}<0,001)$. Os adolescentes que usaram a $A E$ tiveram uma média de acertos quase um ponto maior que aqueles que não a usaram. Entretanto, a diferença entre as médias pôde ser observada apenas na análise simples, uma vez que esta variável perdeu a força quando analisada em conjunto com outras variáveis. O mesmo pôde ser observado com as variáveis coabitação e fontes de informação.

${ }^{*}$ Colinearidade é a medida da relação entre duas variáveis, indicando a força e a direção do relacionamento linear entre elas; desse modo, as alterações sofridas por uma das variáveis são acompanhadas por alterações na outra (Santos, Santos, 2009). 
Foi observado que, no modelo final da análise de regressão linear múltipla, os adolescentes das escolas privadas apresentaram escore de conhecimento maior do que os adolescentes das escolas públicas $(\beta=-0,89$; IC95\%: -1,26--0,53). O ano escolar também esteve diretamente associado ao nível do conhecimento sobre a $\mathrm{AE}$; adolescentes do $1^{\circ}$ e do $2^{\circ}$ anos do ensino médio tiveram escore de conhecimento menor do que os adolescentes do $3^{\circ}$ ano do ensino médio. O sexo masculino esteve associado à diminuição no escore de conhecimento sobre a $A E$ e, ainda, o escore de conhecimento foi menor entre os adolescentes que nunca tiveram relação sexual e que não conheciam alguém que já utilizou a AE (Tabela 5).

Desse modo, os determinantes do maior escore de conhecimento ( $\beta=6,14$; IC95\%: 5,75-6,53) foram estudar em escola privada, estar no $3^{\circ}$ ano do ensino médio, ser do sexo feminino, ter iniciado a vida sexual e conhecer alguém que já usou a AE. Os demais adolescentes tiveram médias inferiores a esta, o que pode ser verificado no modelo final da análise múltipla disponível na Tabela 5.

Tabela 5 - Análise de regressão linear simples e múltipla do nível do conhecimento da anticoncepção de emergência, segundo as características sociodemográficas, de comportamento amoroso e sexual e fontes de informação, Arujá - 2011

\begin{tabular}{|c|c|c|c|c|c|c|}
\hline \multirow{2}{*}{ Variáveis } & \multicolumn{3}{|c|}{ Análise simples } & \multicolumn{3}{|c|}{ Análise múltipla } \\
\hline & $\begin{array}{c}\text { Média } \\
\text { bruta }\end{array}$ & $\mathrm{DP}^{*}$ & $p^{\star \star}$ & $\begin{array}{c}\beta \\
\text { ajust***}\end{array}$ & $\mathrm{IC}_{95 \%}$ & $p$ \\
\hline Intercepto & & & & 6,14 & $5,75-6,53$ & $<0,001$ \\
\hline \multicolumn{7}{|l|}{ Tipo de escola } \\
\hline Pública & 3,87 & 2,12 & $<0,001$ & $-0,89$ & $-1,26--0,53$ & $<0,001$ \\
\hline Privada & 5,14 & 2,00 & & 0,00 & - & \\
\hline \multicolumn{7}{|l|}{ Ano escolar } \\
\hline $1^{\circ}$ ano & 3,80 & 2,21 & $<0,001$ & $-0,80$ & $-1,18--0,43$ & $<0,001$ \\
\hline $2^{\circ}$ ano & 3,86 & 2,03 & & $-0,86$ & $-1,25--0,47$ & \\
\hline $3^{\circ}$ ano & 4,93 & 2,04 & & 0,00 & - & \\
\hline \multicolumn{7}{|l|}{ Idade } \\
\hline $15-16$ anos & 3,90 & 2,13 & $<0,001$ & & - & \\
\hline $17-19$ anos & 4,63 & 2,15 & & & - & \\
\hline
\end{tabular}


Tabela 5 (Continuação) - Análise de regressão linear simples e múltipla do nível do conhecimento da anticoncepção de emergência, segundo as características sociodemográficas, de comportamento amoroso e sexual e fontes de informação, Arujá - 2011

\begin{tabular}{lllllllll}
\hline Variáveis & \multicolumn{3}{c}{ Análise simples } & & \multicolumn{3}{c}{ Análise múltipla } \\
\cline { 2 - 3 } \cline { 5 - 7 } & $\begin{array}{c}\text { Média } \\
\text { bruta }\end{array}$ & $\mathrm{DP}^{*}$ & $\mathrm{p}^{* *}$ & & $\begin{array}{c}\beta \\
\text { ajust }\end{array}$ & $\mathrm{IC}_{95 \%}$ & $\mathrm{p}$ \\
\hline
\end{tabular}

\section{Sexo}

Masculino

Feminino

Religião

Nenhuma

Católica

Evangélica

Outras****

\section{Coabitação}

Ambos pais

Somente mãe

Outras ${ }^{\star \star \star \star *}$

Namoro atual

Não

Sim

\section{Relação sexual}

Não

Sim

\section{Palestra AE}

Não

Sim

\section{Conhece alguém que}

já usou a $A E$

Não

Sim

$$
\begin{array}{lll}
3,55 & 0,14 & <0,001 \\
4,54 & 0,10 &
\end{array}
$$$$
\begin{array}{lll}
4,18 & 2,33 & 0,338
\end{array}
$$$$
4,35 \quad 2,17
$$$$
4,01 \quad 2,09
$$$$
4,35 \quad 2,02
$$

$\begin{array}{lll}4,11 & 2,18 & 0,128 \\ 4,54 & 2,11 & \\ 4,02 & 2,08\end{array}$

$\begin{array}{lll}4,05 & 2,09 & 0,021\end{array}$

$4,45 \quad 2,27$

$3,77 \quad 2,09<0,001$

$4,61 \quad 2,16$

$-0,58$

0,00

$-0,90--0,26<0,001$

$\begin{array}{lll}4,22 & 2,17 & 0,554 \\ 4,10 & 2,15\end{array}$

Fontes de informação da $A E$

Pais/parentes

Não

Sim

$\begin{array}{lll}4,11 & 2,20 & 0,156 \\ 4,39 & 2,05\end{array}$


Tabela 5 (Conclusão) - Análise de regressão linear simples e múltipla do nível do conhecimento da anticoncepção de emergência, segundo as características sociodemográficas, de comportamento amoroso e sexual e fontes de informação, Arujá - 2011

\begin{tabular}{|c|c|c|c|c|c|c|}
\hline \multirow[t]{2}{*}{ Variáveis } & \multicolumn{3}{|c|}{ Análise simples } & \multicolumn{3}{|c|}{ Análise múltipla } \\
\hline & $\begin{array}{c}\text { Média } \\
\text { bruta }\end{array}$ & $\mathrm{DP}^{\star}$ & $\mathrm{p}^{\star \star}$ & $\begin{array}{c}\beta \\
\text { ajust }^{* \star *}\end{array}$ & $\mathrm{IC}_{95 \%}$ & $p$ \\
\hline \multicolumn{7}{|l|}{ Amigos/conhecidos } \\
\hline Não & 4,02 & 2,23 & 0,039 & - & - & \\
\hline Sim & 4,36 & 2,08 & & - & - & \\
\hline
\end{tabular}

\section{Serviços de saúde}

Não

$4,08 \quad 2,17 \quad 0,031$

Sim

$4,89 \quad 1,95$

\section{Revistas ou jornais}

Não

$4,12 \quad 2,14 \quad 0,058$

Sim

$4,56 \quad 2,24$

Televisão

Não

$4,26 \quad 2,21 \quad 0,224$

Sim

$4,04 \quad 2,07$

\section{Farmácia}

Não

$\begin{array}{ccc}4,14 & 0,09 & 0,001 \\ 4,9 & 0,34 & \end{array}$

Sim

$4,9 \quad 0,34$

\section{Escola}

Não

Sim

$\begin{array}{lll}4,24 & 2,17 & 0,371 \\ 4,09 & 2,14 & \end{array}$

Internet

Não

$4,13 \quad 2,19 \quad 0,102$

Sim

$4,50 \quad 1,99$

Uso da AE

Não

$3,98 \quad 0,10<0,001$

Sim

$4,86 \quad 0,16$

${ }^{*} \mathrm{DP}=$ desvio-padrão.

${ }^{* *} \mathrm{H}_{0}: \beta=0$.

***Ajustado por: tipo de escola, ano escolar, sexo, relação sexual e conhecer alguém que já usou a AE. Coeficiente de determinação ajustado: $R^{2}=0,153$.

**** Outras religiões incluem: Espiritismo, Judaísmo, Testemunha de Jeová, Budismo e Muçulmano.

***** Outras coabitações incluem: somente com pai, avós e tios. 


\subsection{USO DA ANTICONCEPÇÃO DE EMERGÊNCIA}

$\mathrm{Na}$ Tabela 6, são apresentadas as características do uso da AE por tipo de escola. Foi verificado que, no total, $57,7 \%$ dos adolescentes usaram a $A E$ alguma vez na vida, sendo que o uso da $A E$ foi $57,9 \%$ nas escolas públicas e $57,0 \%$ nas escolas privadas, sem diferença estatisticamente significativa $(p=0,876)$.

Houve diferença estatisticamente significativa entre o tipo de relacionamento ao usar a $A E$ na última vez e a forma de aquisição da $A E$. Observou-se que os adolescentes que usaram a $\mathrm{AE}$ tinham um relacionamento fixo/regular $(67,8 \%)$ e adquiriram a $A E$ sem receita médica (84,7\%).

Além disso, são apresentadas na Tabela 6 a quantidade (dias) de utilização da $A E$ após a relação sexual desprotegida e a frequência de uso da $A E$ no último ano. As respostas do tempo de uso descritas em horas foram convertidas em dias, sendo assim, para aqueles que responderam que usaram a $A E$ até 24 horas após a relação sexual desprotegida foi considerada que a adolescente a usou 1 dia após a relação sexual; consequentemente, após 24 horas, foram considerados 2 dias. Não houve respostas superiores a 2 dias e os adolescentes que não responderam às questões sobre a quantidade e a frequência de uso da $A E$ foram desconsiderados. Foi verificado que $89,2 \%$ dos adolescentes usaram a $\mathrm{AE}$ até 1 dia após a relação sexual desprotegida $(p=0,372)$ e que $55,3 \%$ dos adolescentes usaram 1 vez a $A E$ no último ano $(p=0,105)$. Contudo, foi observado, no total, que $18,5 \%$ dos adolescentes usaram a $A E 3$ vezes ou mais no último ano, sendo que $23,7 \%$ eram adolescentes de escolas públicas e 9,6\% eram de escolas privadas. A média de uso da $A E$ no último ano foi 1,96 nas escolas públicas e 1,45 nas escolas privadas $(p=0,141)$. 
Tabela 6 - Número e proporção de adolescentes entrevistados, segundo as características de uso da anticoncepção de emergência, por tipo de escola, Arujá - 2011

\begin{tabular}{lllllllll}
\hline \multirow{3}{*}{ Variáveis } & \multicolumn{4}{c}{ Tipo de Escola } & & \multirow{2}{*}{ Total } & & \multirow{2}{*}{$\mathbf{p}^{*}$} \\
\cline { 2 - 5 } & Pública & Privada & & & \\
& $\mathrm{N}$ & $\%$ & $\mathrm{~N}$ & $\%$ & $\mathrm{~N}$ & $\%$ & \\
\hline
\end{tabular}

Motivos de uso da AE

Por pura insegurança

Esqueceu de usar algum MAC**

O MAC que usava falhou

Não quis usar nenhum MAC

Foi vítima de violência sexual

Tipo de relacionamento

Fixo/regular

Eventual

\section{Uso de MAC ao usar a $A E$}

\section{Nenhum}

Não

Sim

\section{Camisinha masculina}

Não

Sim

\section{Pílula oral comum}

Não

Sim

\section{Anticoncepcional injetável}

Não

Sim

\section{Outros ${ }^{\star \star *}$}

Não

Sim

Aquisição da $\mathrm{AE}$ com receita médica

Não

Sim

$\begin{array}{rrrrrrr}42 & 33,9 & 14 & 26,4 & 56 & 31,6 & 0,860 \\ 33 & 26,6 & 15 & 28,3 & 48 & 27,1 & \\ 24 & 19,4 & 12 & 22,6 & 36 & 20,3 & \\ 24 & 19,4 & 11 & 20,8 & 35 & 19,8 & \\ 1 & 0,8 & 1 & 1,9 & 2 & 1,1 & \\ & & & & & & \\ & & & & & & \\ 78 & 62,9 & 42 & 79,2 & 120 & 67,8 & 0,033 \\ 46 & 37,1 & 11 & 20,8 & 57 & 32,2 & \end{array}$

$\begin{array}{rrrrrrr}69 & 55,6 & 36 & 67,9 & 105 & 59,3 & 0,128 \\ 55 & 44,4 & 17 & 32,1 & 72 & 40,7 & \end{array}$

$\begin{array}{rrrrrrr}72 & 58,1 & 29 & 54,7 & 101 & 57,1 & 0,680 \\ 52 & 41,9 & 24 & 45,3 & 76 & 42,9 & \end{array}$

$\begin{array}{rrrrrrr}103 & 83,1 & 48 & 90,6 & 151 & 85,3 & 0,197 \\ 21 & 16,9 & 5 & 9,4 & 26 & 14,7 & \end{array}$

$\begin{array}{rrrrrrr}123 & 99,2 & 48 & 90,6 & 171 & 96,6 & 0,004\end{array}$

$\begin{array}{llllll}1 & 0,8 & 5 & 9,4 & 6 & 3,4\end{array}$

$\begin{array}{rrrrrrr}122 & 98,4 & 51 & 96,2 & 173 & 97,7 & 0,897 \\ 2 & 1,6 & 2 & 3,8 & 4 & 2,3 & \\ & & & & & & \\ 99 & 79,8 & 51 & 96,2 & 150 & 84,7 & 0,005 \\ 25 & 20,2 & 2 & 3,8 & 27 & 15,3 & \end{array}$

(Continua) 
Tabela 6 (Continuação) - Número e proporção de adolescentes entrevistados, segundo as características de uso da anticoncepção de emergência, por tipo de escola, Arujá - 2011

\begin{tabular}{llllllllll}
\hline \multirow{3}{*}{ Variáveis } & \multicolumn{4}{c}{ Tipo de Escola } & & Total & & \multirow{2}{*}{$\mathbf{p}^{\star *}$} \\
\cline { 2 - 4 } & Pública & Privada & & & \\
& $\mathrm{N}$ & $\%$ & $\mathrm{~N}$ & $\%$ & $\mathrm{~N}$ & $\%$ & \\
\hline
\end{tabular}

\section{Fontes de obtenção da $\mathrm{AE}$}

$\begin{array}{lrrrrrrr}\text { Farmácia } & 86 & 69,4 & 46 & 86,8 & 132 & 74,6 & 0,099 \\ \text { Posto de saúde } & 11 & 8,9 & 1 & 1,9 & 12 & 6,8 & \\ \text { Médico particular ou do convênio }_{\text {Outras }^{* * *}} & 3 & 2,4 & 2 & 3,8 & 5 & 2,8 & \\ & 23 & 19,4 & 4 & 7,6 & 28 & 15,7 & \end{array}$

Total

$124 \quad 100,0 \quad 53 \quad 100,0 \quad 177 \quad 100,0$

* Nível descritivo do teste de associação pelo Qui-quadrado.

** $\mathrm{MAC}=$ métodos contraceptivos.

*** Outros métodos contraceptivos incluem: tabelinha e coito interrompido.

**** Outras fontes de obtenção da AE incluem: amigos/conhecidos, namorado e parente.

\subsection{DETERMINANTES DO USO DA ANTICONCEPÇÃO DE EMERGÊNCIA}

Nesta etapa, é analisada a associação entre o uso da AE (não/sim) e as variáveis sociodemográficas dos adolescentes, as variáveis de comportamento amoroso e sexual e as fontes de informação da $\mathrm{AE}$ (Tabela 7).

Foi observada maior proporção do uso da $\mathrm{AE}$ entre adolescentes que estavam namorando no momento da pesquisa (57,6\%), que não tiveram palestra sobre a $A E$ na escola (65,5\%), que conheciam alguém que já usou a $A E(89,8 \%)$ e entre aqueles que tiveram informações sobre a $A E$ com amigos ou conhecidos (63,3\%). 
Tabela 7 - Número e proporção de adolescentes entrevistados, sexualmente experientes, segundo as características sociodemográficas, as experiências amorosas/sexuais e as fontes de informação, por uso da anticoncepção de emergência, Arujá - 2011

\begin{tabular}{|c|c|c|c|c|c|c|c|}
\hline \multirow[t]{3}{*}{ Variáveis } & \multicolumn{4}{|c|}{ Uso da $\mathrm{AE}$} & \multicolumn{2}{|c|}{ Total } & \multirow[t]{3}{*}{$\mathbf{p}^{*}$} \\
\hline & \multicolumn{2}{|c|}{ Não } & \multicolumn{2}{|c|}{ Sim } & \multirow[b]{2}{*}{$\mathrm{N}$} & \multirow[b]{2}{*}{$\%$} & \\
\hline & $\mathrm{N}$ & $\%$ & $\mathrm{~N}$ & $\%$ & & & \\
\hline \multicolumn{8}{|l|}{ Ano escolar } \\
\hline $1^{\circ}$ ano & 48 & 36,9 & 55 & 31,1 & 103 & 33,6 & 0,555 \\
\hline $2^{\circ}$ ano & 34 & 26,2 & 52 & 29,4 & 86 & 28,0 & \\
\hline $3^{\circ}$ ano & 48 & 36,9 & 70 & 39,5 & 118 & 38,4 & \\
\hline \multicolumn{8}{|l|}{ Idade } \\
\hline $15-16$ anos & 70 & 53,8 & 98 & 55,4 & 168 & 54,7 & 0,791 \\
\hline $17-19$ anos & 60 & 46,2 & 79 & 44,6 & 139 & 45,3 & \\
\hline \multicolumn{8}{|l|}{ Sexo } \\
\hline Masculino & 71 & 54,6 & 63 & 35,6 & 134 & 43,6 & 0,001 \\
\hline Feminino & 59 & 45,4 & 114 & 64,4 & 173 & 56,4 & \\
\hline \multicolumn{8}{|l|}{ Religião } \\
\hline Nenhuma & 23 & 17,7 & 53 & 29,9 & 76 & 24,8 & 0,105 \\
\hline Católica & 48 & 36,9 & 58 & 32,8 & 106 & 34,5 & \\
\hline Evangélica & 47 & 36,2 & 52 & 29,4 & 99 & 32,2 & \\
\hline Outras** & 12 & 9,2 & 14 & 7,9 & 26 & 8,5 & \\
\hline \multicolumn{8}{|l|}{ Coabitação } \\
\hline Ambos pais & 88 & 67,7 & 124 & 70,1 & 212 & 69,1 & 0,462 \\
\hline Somente mãe & 33 & 25,4 & 36 & 20,3 & 69 & 22,5 & \\
\hline Outras $s^{* * *}$ & 9 & 6,9 & 17 & 9,6 & 26 & 8,5 & \\
\hline \multicolumn{8}{|l|}{ Namoro atual } \\
\hline Não & 82 & 63,1 & 75 & 42,4 & 157 & 51,1 & $<0,001$ \\
\hline Sim & 48 & 36,9 & 102 & 57,6 & 150 & 48,9 & \\
\hline \multicolumn{8}{|c|}{ Idade na 1a relação sexual } \\
\hline$\leq 14$ anos & 52 & 40,0 & 70 & 39,5 & 122 & 39,7 & 0,936 \\
\hline$\geq 15$ anos & 78 & 60,0 & 107 & 60,5 & 185 & 60,3 & \\
\hline
\end{tabular}

(Continua) 
Tabela 7 (Continuação) - Número e proporção de adolescentes entrevistados, sexualmente experientes, segundo as características sociodemográficas, as experiências amorosas/sexuais e as fontes de informação, por uso da anticoncepção de emergência, Arujá - 2011

\begin{tabular}{|c|c|c|c|c|c|c|c|}
\hline \multirow[t]{3}{*}{ Variáveis } & \multicolumn{4}{|c|}{ Uso da AE } & \multirow{2}{*}{\multicolumn{2}{|c|}{ Total }} & \multirow[t]{3}{*}{$\mathbf{p}^{*}$} \\
\hline & & & & & & & \\
\hline & $\mathrm{N}$ & $\%$ & $\mathrm{~N}$ & $\%$ & $\mathrm{~N}$ & $\%$ & \\
\hline
\end{tabular}

Número de parceiros sexuais

1 - 2 pessoas
3 - 4 pessoas
5 ou + pessoas

Palestra sobre MAC

Não

Sim

Palestra AE

Não

Sim

Conhece alguém que já usou $A E$

Não

Sim

Fontes de informação da $\mathrm{AE}$

Com amigos/conhecidos

Não

Sim

67

63

$51,5 \quad 65$

36,7

41,8

58,

70,1

212

69,1

0,462

33

25,4

20,3

$69 \quad 22,5$

$\begin{array}{llllll}9 & 6,9 & 17 & 9,6 & 26 & 8,5\end{array}$

58

72

55,

99

76,2

116

65

31

23,8

61

34

$52 \quad 40$

78

60

$48,5 \quad 112$

$63,3 \quad 175 \quad 57,0$

Na televisão

Não

Sim

86

44

$66,2 \quad 133$

75

24

$33,8 \quad 44$

Na escola

Não

Sim

89

41

68,5

31,5

106

59,9

40

195

63,5

0,123

Com pais/parentes

Não

96

Sim

$\begin{array}{ccccccc}96 & 73,8 & 134 & 75,7 & 230 & 74,9 & 0,710 \\ 34 & 26,2 & 43 & 24,3 & 77 & 25,1 & \end{array}$

(Continua) 
Tabela 7 (Conclusão) - Número e proporção de adolescentes entrevistados, sexualmente experientes, segundo as características sociodemográficas, as experiências amorosas/sexuais e as fontes de informação, por uso da anticoncepção de emergência, Arujá - 2011

\begin{tabular}{|c|c|c|c|c|c|c|}
\hline \multirow[t]{3}{*}{ Variáveis } & \multicolumn{3}{|c|}{ Uso da $\mathrm{AE}$} & \multirow{2}{*}{\multicolumn{2}{|c|}{ Total }} & \multirow[t]{3}{*}{$\mathbf{p}^{*}$} \\
\hline & & & & & & \\
\hline & $\mathrm{N}$ & $\%$ & $\mathrm{~N}$ & $\mathrm{~N}$ & $\%$ & \\
\hline
\end{tabular}

Na internet

$\begin{array}{llllllll}\text { Não } & 103 & 79,2 & 149 & 84,2 & 252 & 82,1 & 0,264\end{array}$

Sim

$\begin{array}{llllll}27 & 20,8 & 28 & 15,8 & 55 & 17,9\end{array}$

Nos serviços de saúde

Não

$\begin{array}{ccccccc}110 & 84,6 & 149 & 84,2 & 259 & 84,4 & 0,917 \\ 20 & 15,4 & 28 & 15,8 & 48 & 15,6 & \end{array}$

Sim

Em revistas ou jornais

Não

$\begin{array}{lllllll}113 & 86,9 & 154 & 87,0 & 267 & 87,0 & 0,983\end{array}$

Sim

$\begin{array}{llllll}17 & 13,1 & 23 & 13,0 & 40 & 13,0\end{array}$

Na farmácia

$\begin{array}{llllllll}\text { Não } & 123 & 94,6 & 161 & 91,0 & 284 & 92,5 & 0,229\end{array}$

Sim

$\begin{array}{llllll}7 & 5,4 & 16 & 9,0 & 23 & 7,5\end{array}$

Total

$\begin{array}{llllll}130 & 100,0 & 177 & 100,0 & 307 & 100,0\end{array}$

* Nível descritivo do teste de associação pelo Qui-quadrado.

** Outras religiões incluem: Espiritismo, Judaísmo, Testemunha de Jeová, Budismo e Muçulmano.

*** Outras coabitações incluem: somente com o pai, amigos, avós e tios.

\subsubsection{Modelo final de regressão logística múltipla para o uso da anticoncepção de emergência}

Na Tabela 8, são apresentados os modelos univariado e múltiplo de regressão logística, segundo os fatores associados ao uso da $A E$. A variável do escore de conhecimento da $A E$ foi analisada baseando-se na comparação entre os escores ( 0 a 10), ou seja, se o acréscimo de 1 escore aumenta as chances de uso da AE (comparação entre o escore 0 com o escore 1, escore 1 com o escore 2 e assim, sucessivamente). Desse modo, 
é verificado, na análise univariada, que o acréscimo de 1 escore no conhecimento da $A E$ aumenta 1,12 vezes a chance de usar a $A E$.

O tipo de escola foi mantido na análise múltipla como ajuste, mesmo não tendo apresentado $p<0,20$ (Tabela 6).

Os resultados revelaram que ter uma religião mostrou-se um fator de proteção ao uso da $A E$, sendo que os adolescentes católicos tiveram $53 \%$ menos chance de usar a $A E$ em relação aos que não tinham religião. Os adolescentes que estavam namorando tiveram 2,24 vezes a chance de usar a $A E$ do que aqueles que não estavam namorando. Além disso, os adolescentes que conheciam alguém que já usou a $A E$ tiveram 6,04 vezes a chance de usar a $A E$ do que aqueles que não conheciam ninguém que a tivesse usado. Em síntese, os adolescentes que mais usaram a $A E$ são aqueles que não eram católicos, que namoravam e que conheciam alguém que já usou a $A E$.

Tabela 8 - Análise de regressão logística univariada e múltipla, segundo os fatores associados ao uso da anticoncepção de emergência, Arujá - 2011

\begin{tabular}{|c|c|c|c|c|c|}
\hline \multirow[t]{2}{*}{ Variáveis } & \multirow[t]{2}{*}{ Categorias } & \multicolumn{2}{|c|}{ Univariada } & \multicolumn{2}{|c|}{$\begin{array}{c}\text { Modelo final do } \\
\text { bloco }\end{array}$} \\
\hline & & $\begin{array}{c}\text { OR } \\
\text { bruta }\end{array}$ & $\mathrm{IC}_{95 \%}$ & $\begin{array}{c}\text { OR } \\
\text { ajust }^{\star}\end{array}$ & $\mathbf{I C}_{95 \%}$ \\
\hline \multirow[t]{2}{*}{ Tipo de escola } & Pública & 1,00 & - & 1,00 & - \\
\hline & Privada & 0,96 & $0,59-1,57$ & 0,74 & $0,43-1,27$ \\
\hline \multirow[t]{4}{*}{ Religião } & Nenhuma & 1,00 & - & 1,00 & - \\
\hline & Católica & 0,52 & $0,28-0,98$ & 0,47 & $0,24-0,92$ \\
\hline & Evangélica & 0,48 & $0,26-0,90$ & 0,50 & $0,25-1,01$ \\
\hline & Outras** & 0,51 & $0,20-1,26$ & 0,53 & $0,20-1,43$ \\
\hline \multirow[t]{2}{*}{ Namoro atual } & Não & 1,00 & - & 1,00 & - \\
\hline & Sim & 2,32 & $1,46-3,70$ & 2,24 & $1,35-3,71$ \\
\hline \multirow[t]{2}{*}{ Palestra AE } & Não & 1,00 & - & - & - \\
\hline & Sim & 1,68 & $1,01-2,79$ & - & - \\
\hline
\end{tabular}


Tabela 8 (Continuação) - Análise de regressão logística univariada e múltipla, segundo os fatores associados ao uso da anticoncepção de emergência, Arujá - 2011

\begin{tabular}{|c|c|c|c|c|c|}
\hline \multirow[t]{2}{*}{ Variáveis } & \multirow[t]{2}{*}{ Categorias } & \multicolumn{2}{|c|}{ Univariada } & \multicolumn{2}{|c|}{$\begin{array}{c}\text { Modelo final do } \\
\text { bloco }\end{array}$} \\
\hline & & $\begin{array}{c}\text { OR } \\
\text { bruta }\end{array}$ & $I C_{95 \%}$ & $\begin{array}{c}\text { OR } \\
\text { ajust }^{*}\end{array}$ & $\mathrm{IC}_{95 \%}$ \\
\hline
\end{tabular}

$\begin{array}{llllll}\begin{array}{l}\text { Conhece alguém que } \\ \text { já usou AE }\end{array} & \text { Não } & 1,00 & - & 1,00 & - \\ & \text { Sim } & 5,89 & 3,23-10,74 & 6,04 & 3,21-11,39 \\ \text { Escore de conhecimento AE } & \text { 0 a 10 } & 1,12 & 1,01-1,25 & - & -\end{array}$

Fontes de informação da AE

\begin{tabular}{lllcll} 
Amigos ou conhecidos & Não & 1,00 & - & - & - \\
& Sim & 1,83 & $1,16-2,90$ & - & - \\
\multirow{2}{*}{ Televisão } & & & & - & - \\
& Não & 1,00 & - & - & - \\
& Sim & 0,65 & $0,39-1,06$ & - & - \\
Escola & & & & & - \\
& Não & 1,00 & - & - & -
\end{tabular}

*Ajustado por: tipo de escola, religião, namoro atual e conhece alguém que já usou a $A E$. Teste Hosmer-Lemeshow: $\mathrm{p}=0,998$.

** Outras religiões incluem: Espiritismo, Judaísmo, Testemunha de Jeová, Budismo e Muçulmano. 


\section{DISCUSSÃO}

\subsection{DIFICULDADES E LIMITAÇÕES DO ESTUDO}

Várias foram as dificuldades para a realização desta pesquisa. Dentre elas, destacam-se 0 acesso às escolas privadas e a captação dos adolescentes.

Dentre as escolas privadas selecionadas para participar na pesquisa, três recusaram o convite. Isto ratifica a dificuldade em conduzir pesquisas em instituições privadas de ensino e, consequentemente, a predominância de estudos sobre o comportamento sexual e contraceptivo de adolescentes estudantes de escolas públicas. Dessa forma, poucos são os estudos que possibilitam comparações entre os estudantes das escolas públicas com os das escolas privadas.

Dentre as escolas privadas que aceitaram participar do estudo, apenas uma autorizou entrevistas com estudantes mais novos, ou seja, do $1^{\circ}$ ano do ensino médio. Deste modo, houve maior número de entrevistados do $3^{\circ}$ ano do ensino médio nas escolas privadas. A maioria das escolas privadas que não autorizou a pesquisa alegou que a temática era imprópria aos alunos. No entanto, este pretexto não pode ser considerado válido, uma vez que, na maioria das vezes, é justamente na adolescência que ocorre o início da vida sexual (Borges, Schor, 2005).

Por outro lado, nas escolas públicas, um problema enfrentado foi as faltas dos estudantes às sextas-feiras. Em uma das escolas, por exemplo, a pedido da direção, o instrumento só pôde ser aplicado em uma sexta-feira, quando havia poucos alunos na escola, o que acarretou a coleta de menos questionários do que estava previsto.

Outra dificuldade foi a não disponibilidade do TCLE assinado, pois muitos adolescentes esqueceram-se de entregar aos pais ou aos responsáveis. Em uma das escolas públicas, houve, aproximadamente, 70 alunos que não puderam participar da pesquisa porque não levaram o TCLE 
assinado. Admitindo as dificuldades para obtenção do TCLE assinado pelos pais ou responsáveis, já relatadas em outro estudo (Pirotta, 2005), foi proposto, inicialmente, a utilização do TCLE negativo, baseado no estudo de Araújo e Costa (2009). No TCLE negativo, os pais ou responsáveis dos adolescentes menores de 18 anos de idade somente assinam quando não concordam que o adolescente participe da pesquisa. No entanto, o Comitê de Ética em Pesquisa não autorizou seu uso.

Segundo Pirotta (2005), "existem situações em que o objetivo da pesquisa é justamente dar voz a um grupo social vulnerável para que se possa compreender suas práticas e necessidades" (p.10). O Ministério da Saúde, em seu Manual de Anticoncepção de Emergência - perguntas e respostas para profissionais de saúde (Brasil 2011), define que a $A E$ deve ser ofertada aos adolescentes que buscam atenção em contracepção, de forma que sejam garantidas sua autonomia, privacidade, sigilo e confidencialidade das informações prestadas.

Isto significa que o adolescente tem plena autonomia para solicitar e usar a $A E$ sem que seja necessária a presença ou autorização de seus pais ou responsáveis. Para Zoboli e Araújo (2009), o respeito à autonomia do adolescente significa "reconhecer seu direito de tomar decisões e, no mínimo, acatar seu direito de ter opiniões próprias, de fazer escolhas, de agir de acordo com seus valores e crenças pessoais" (p. 256). Nesta perspectiva, considera-se que o adolescente também tenha autonomia para responder a um questionário sobre o seu comportamento contraceptivo.

Estas adversidades não prejudicaram o desenvolvimento da pesquisa e a amostra estudada pode ser considerada representativa da população escolar adolescente, permitindo a comparação entre os dois grupos: escolas públicas e privadas.

Algumas limitações devem ser destacadas, como o fato do estudo não ter incluído adolescentes que não estudavam, e que constituem um grupo extremamente vulnerável, uma vez que a escolaridade pode estar associada ao maior conhecimento da AE. Além disso, pode ter ocorrido algum viés de informação em relação ao comportamento sexual e contraceptivo, visto que o questionamento sobre esta temática pode causar 
constrangimento quanto ao sigilo das informações coletadas. Neste sentido, alguns cuidados foram tomados: os questionários foram anônimos, a participação foi voluntária e urnas foram colocadas na frente da sala de aula para depósito dos questionários preenchidos.

\subsection{CARACTERIZAÇÃO SOCIODEMOGRÁFICA DOS ADOLESCENTES}

A maioria dos adolescentes das escolas públicas cursava $01^{\circ}$ ano do ensino médio. Por sua vez, nas escolas privadas, a maioria cursava $03^{\circ}$ ano, pelas razões mencionadas no item 7.1. Isto pode explicar que a idade média dos adolescentes das escolas públicas foi um pouco menor em relação à idade nas escolas privadas.

Houve predomínio de estudantes do sexo masculino nas escolas públicas e feminino nas escolas privadas. Este resultado não era esperado, visto que tem havido maior participação das mulheres nos estudos sobre adolescentes (Borges, 2004; Araújo, 2009) e, em geral, os estudantes do período diurno tendem a ser, em maior proporção, não trabalhadores, mais jovens e do sexo feminino (Catharino, Giffin, 2002).

A maior parte dos adolescentes relatou ter alguma religião. A religião mais citada foi a evangélica, o que difere dos dados censitários de 2010 (IBGE, 2010a), que mostraram que a religião predominante no Brasil ainda é a católica. Os evangélicos apresentam especificidades quando se trata do comportamento sexual e contraceptivo: são mais eficazes do que a igreja católica em desencorajar as relações sexuais pré-matrimoniais entre os adolescentes (McKinnon, Potter, Garrard-Burnett, 2008). Verona e Dias Júnior (2008) verificaram que os adolescentes evangélicos apresentaram uma chance menor de ter a primeira relação sexual antes do casamento do que adolescentes católicos.

De acordo com Silva et al. (2008), a maioria dos adolescentes evangélicos herda e pratica assiduamente a mesma religião dos pais, ao 
passo que os católicos nem sempre aderem à mesma religião dos seus familiares. Entre os que aderem, muitos não participam dos rituais religiosos, e são mais flexíveis no que concerne, por exemplo, ao uso do preservativo masculino e ao sexo antes do casamento. Assim, os católicos sentem maior abertura para o início sexual antes do casamento do que os evangélicos, uma vez que estes consideram o sexo fora da união estável um "pecado". Muitos, inclusive, casam-se rapidamente para antecipar o direito ao sexo.

A maioria dos adolescentes coabitava com ambos os pais, sugerindo que a convivência familiar está presente no seu dia a dia. Este resultado era esperado, pois os adolescentes nesta faixa etária ainda mantêm dependência econômica dos pais. No entanto, apesar do convívio familiar propiciar o compartilhamento de experiências e informações, foi constatado que os pais foram pouco referidos como fontes de informações sobre a AE. Para Brandão e Souza (2009), alguns pais impõem obstáculos às conversas sobre utilização de contraceptivo porque não querem que seus filhos se tornem sexualmente ativos. Do mesmo modo, Borges, Nichiata e Schor (2006) constataram que os pais, principalmente a figura paterna, foram pouco mencionados pelos adolescentes como fonte de esclarecimentos de dúvidas sobre sexo e prevenção de gestação e DTS/AIDS.

Aparentemente, a família atua pouco ativamente como fonte de informação acerca de sexualidade e contracepção. Isto significa que os adolescentes não procuram os pais como um recurso de aprendizagem sobre métodos contraceptivos e, ainda, que as conversas sobre assuntos relativos a sexo são escassas, seja pela falta de informações adequadas dos pais ou pelo fato deste assunto ser considerado ainda um "tabu" no ambiente familiar (Pirotta, 2002). 


\subsection{COMPORTAMENTO SEXUAL: DIFERENÇAS ENTRE ESTUDANTES DE ESCOLAS PÚBLICAS E PRIVADAS}

Os adolescentes das escolas privadas vivenciam o início da vida sexual de forma diferenciada em comparação aos adolescentes das escolas públicas.

Menos da metade dos adolescentes iniciou a vida sexual, diferentemente dos achados de Figueiredo e Andalaft Neto (2005), Ahern et al. (2010), Fine e Mollen (2010) e Perpétuo (2010), que encontraram de $55,1 \%$ a $95,0 \%$ dos adolescentes de 15 a 19 anos de idade já sexualmente ativos. Este resultado provavelmente está associado ao fato de que a maioria dos adolescentes era evangélica, conforme já discutido no item 7.2.

Nas escolas públicas, houve menor percentual de adolescentes que iniciou a vida sexual do que nas escolas privadas. Embora seja o oposto do que foi observado por Custódio et al. (2009), isto é explicado pelo fato que os adolescentes das escolas públicas eram mais novos que os das escolas privadas - e já se sabe que a chance de iniciação sexual na adolescência aumenta com a idade (Santelli et al., 2000; Borges, 2004).

Constatou-se também que os adolescentes das escolas privadas iniciaram a vida sexual um pouco mais velhos que os das escolas públicas similar ao relatado por Martins et al. (2006) - e referiram menor número de parceiros sexuais. Pode-se dizer que eram menos experientes sexualmente.

\subsection{CONHECIMENTO DA ANTICONCEPÇÃO DE EMERGÊNCIA}

A AE é majoritariamente conhecida pelos adolescentes, o que já foi observado em diversos outros estudos nacionais e internacionais (Nunes, 2005; Figueiredo, Andalaft Neto, 2005; Araújo, 2009; Adhikari, 2009; Ahern et al., 2010; Leyva-López et al., 2010). Este conhecimento foi testado de 
forma estimulada, não permitindo observar se o escore seria tão alto se os adolescentes respondessem de forma espontânea.

Segundo a PNDS 2006 (Brasil, 2008), a maior parte das adolescentes entre 15 e 19 anos de idade respondeu afirmativamente quando questionadas se já tinham ouvido falar da $A E$, mas apenas $6,0 \%$ referiram a $\mathrm{AE}$ espontaneamente. Isto pode indicar que, após uma relação sexual desprotegida, adolescentes não necessariamente se lembrariam da $A E$ como uma opção de método pós-coital.

Os amigos/conhecidos e a escola foram as fontes de informação sobre $\mathrm{AE}$ mais referidos pelos adolescentes, igualmente aos resultados de Costa et al. (2006), Figueiredo et al. (2008), Araújo (2009) e Ahern et al. (2010) nos EUA. Embora os amigos tenham sido referidos como fontes de informação, trabalho conduzido com estudantes de escolas públicas de Pernambuco verificou associação estatisticamente significativa entre os amigos como agentes de informação sobre a $A E$ e o intervalo incorreto de tempo entre a relação desprotegida e o uso do método (Araújo, 2009).

A internet, apesar da sua relevância na divulgação de informações e de ser um meio de comunicação interativo e atrativo, com ampla disseminação na sociedade brasileira (IBGE, 2010b), foi pouco mencionada pelos adolescentes, sendo apenas a quinta fonte de informação mais referida, o oposto do observado por Nunes (2005). Isto indica que, na busca por informações sobre sexualidade e contracepção, os adolescentes dão preferência aos amigos ao invés da internet. Isto possivelmente ocorre, pois, por se tratar de um assunto mais íntimo e pessoal, os adolescentes se sentem mais seguros e menos expostos para tirarem suas dúvidas por meio das conversas entre amigos, os quais compartilham pessoalmente suas vivências, o que não pode ser verificado no caso da internet.

Um fato preocupante que os resultados desta pesquisa apontam é a baixa participação dos profissionais da saúde como agentes de informação, tal e qual constataram Araújo (2009) e Nunes (2005). Nunes (2005) tem duas explicações para esta participação restrita dos profissionais de saúde: uma delas é o pudor do adolescente em buscar nos adultos informações 
sobre sexualidade e a outra é o despreparo dos próprios profissionais em abordar a $\mathrm{AE}$ com adolescentes.

Ademais, os serviços de saúde não estão organizados para receber os adolescentes e, assim, suas demandas não são adequadamente contempladas (Figueiredo, Bastos, 2008). Inversamente, estudo conduzido na Espanha indicou os profissionais de saúde como a principal fonte de informação sobre a AE (Brasa Andrés et al., 2007), o que reflete que as dificuldades de acesso dos adolescentes aos serviços públicos de saúde no Brasil configuram-se como uma lacuna nas políticas de saúde dirigidas para este grupo, fazendo-se necessário a melhoria na promoção da saúde e do bem-estar dos adolescentes.

Outro achado interessante foi a menção à televisão, que desempenhou papel de destaque como fonte de informação referida pelos adolescentes. Numa sociedade em que a relação interpessoal vem sendo desgastada, assim como a falta de diálogo sobre sexualidade entre pais e filhos, a mídia adquire papel importante na divulgação de informações a respeito de contracepção nos diferentes grupos sociais. Desse modo, a mídia pode propiciar a democratização das informações sobre a AE (Díaz et al., 2003; Leite, Rodrigues, Fonseca, 2004), embora, muitas vezes, as informações veiculadas sejam equivocadas (Souza, Brandão 2012).

Araújo (2009) observou que as adolescentes que tiveram as propagandas como agentes de informação usaram a $A E$ corretamente. De toda forma, Perpétuo (2010) enfatizou que a disseminação da informação sobre $A E$ é ainda insuficiente, principalmente nos grupos populacionais socialmente menos privilegiados, uma vez que neles a iniciação sexual é mais precoce e a ocorrência de gravidez é maior.

Ademais, grande parte dos adolescentes revelou que nunca participou de oficinas sobre a AE nas escolas. Pode ser que a escola seja justamente 0 local onde ocorrem trocas de experiências entre os amigos, mas não atua como promotora de informações sobre a AE. Estudo conduzido com estudantes, professores e diretores de escolas públicas de São Paulo observou que a abordagem de temas sobre sexualidade e contracepção nas escolas ainda acontece de forma incipiente (Pirotta, 2010). Da mesma 
forma, estudo realizado em três grandes centros urbanos brasileiros reafirmou a necessidade de ações educativas sobre sexualidade nas escolas, devido às lacunas entre o binômio saúde e educação (Heilborn, 2006).

Foi observado que, nas oficinas sobre métodos contraceptivos realizadas nas escolas participantes, os adolescentes mostraram-se bastante interessados e abertos a respeito do tema. Estudos conduzidos na Espanha e no Nepal (Adhkari, 2009; López-Amoro's et al., 2010) observaram que a maioria dos adolescentes que referiram conhecer a $\mathrm{AE}$ tinha conhecido este método por meio de educação sexual nas escolas e que estes adolescentes foram mais propícios a usá-la, ou seja, ações de educação sexual nas escolas são fundamentais. As escolas necessitam superar os preconceitos e os receios que cercam a vivência da sexualidade na adolescência e ser um espaço de ação, a fim de contribuir efetivamente na promoção da saúde do adolescente.

\subsubsection{Nível do conhecimento da anticoncepção de emergência}

A análise das dez questões específicas sobre o conhecimento da $A E$ mostrou que a maior parte dos adolescentes das escolas públicas respondeu "não sei" em sete questões. Nas escolas privadas, a maior parte dos adolescentes respondeu "não sei" em apenas três questões.

Apenas duas questões não apresentaram diferença estatisticamente significativa entre as escolas: em caso de vômito até $2 h$ após a ingestão da $A E$, deve-se repetir a dose - questão com maior quantidade de respostas "não sei" - e a $A E$ é abortiva. Isto significa que, no primeiro caso, os adolescentes realmente não obtêm informações sobre a $A E$ em serviços de saúde, tal como abordado anteriormente, visto que se trata de uma questão mais específica e clínica. No segundo caso, há divulgação equivocada na mídia, que associa o mecanismo de ação da AE com efeitos na nidação e/ou no embrião, segundo Souza e Brandão (2012). Especialistas da área da 
saúde são pouco acionados pela mídia para explicar o mecanismo de ação da $A E$ e raramente reportam discursos baseados na perspectiva dos direitos sexuais e reprodutivos. A própria Organização Mundial da Saúde (WHO, 2012) enfatiza que a $A E$ de levonorgestrel não interrompe uma gravidez estabelecida e nem prejudica um embrião em desenvolvimento.

A questão Ao usar AE, deve-se estar atento para que isso ocorra até cinco dias foi a única em que houve maior prevalência de respostas "não sei" em ambas escolas. Fisberg et al. (2010) observaram que nenhum estudante universitário sabia que 120 horas é o tempo máximo de utilização da $A E$ e Nunes (2005) observou que, no total, apenas $15,8 \%$ das adolescentes responderam adequadamente sobre o período de utilização da $\mathrm{AE}$. Isto pode ter ocorrido porque o nome popular "pílula do dia seguinte" sugere que este método só poderia ser usado no dia seguinte ao da relação sexual desprotegida. Outro aspecto a ser lembrado é que, até recentemente, a indicação era que a $A E$ fosse ingerida até 72 horas após a relação sexual desprotegida (Brasil, 2011).

Outras duas questões com alta proporção de respostas "não sei" entre os adolescentes das escolas públicas merecem atenção: $A E$ pode substituir a pílula oral comum e $A E$ pode ser usada uma vez por mês. Parece que os adolescentes ainda não sabem identificar a diferença entre a pílula oral comum e a $A E$ e, por conseguinte, não sabem que a eficácia da AE diminui com o uso repetido.

Foram também analisadas as respostas agrupadas em dois grupos de adolescentes: aquele que "Sabe" e aquele que "Não sabe". As questões com maior acerto em ambas as escolas foram: $A E$ deve ser usada antes da relação sexual, $A E$ previne $D S T$ e $A E$ é mais eficaz que os outros MAC. Igualmente, estudo conduzido nos EUA (Ahern et al., 2010) observou que $69,6 \%$ das adolescentes listaram corretamente a $\mathrm{AE}$ como método contraceptivo pós-coital. Estas questões tiveram maior acerto, provavelmente, porque estão em maior destaque nos debates entre amigos ou na mídia.

É importante destacar que os adolescentes não consideraram que a $A E$ previna DST/AIDS, indicando que estão esclarecidos quanto a isto. Com 
o surgimento AIDS, houve ampla divulgação da importância do uso coletivo do preservativo masculino (Paiva et al., 2011). Além disso, as discussões sobre DST/AIDS estão comumente em pauta nas escolas, nos serviços de saúde e nas revistas em geral.

As questões que apresentaram baixa proporção de acerto foram: $E m$ caso de vômito até $2 h$ após a ingestão da $A E$, deve-se repetir a dose; Ao usar a $\mathrm{AE}$, deve-se estar atento para que isso ocorra em torno de cinco dias após a relação sexual desprotegida e Ao utilizar a $A E$, a mulher está protegida de uma gravidez até a chegada da menstruação. A primeira e a segunda questões já foram discutidas anteriormente. Já a terceira questão revela que os adolescentes acreditam, equivocadamente, que a $A E$ protege a mulher durante todo o ciclo menstrual. Esta confusão também foi observada em relação às questões $A E$ substitui a pílula oral comum e $A E$ pode ser usada uma vez por mês. Poder-se-ia pensar que os adolescentes tendem a substituir a contracepção regular, especialmente pílulas orais, pela $A E$, fato que não foi comprovado em estudos recentes (Figueiredo, Andalaft Neto, 2005; Sidebottom et al., 2008; Araújo, 2009; Fine et al., 2008; Mollen et al., 2008; Borges et al., 2010). De qualquer forma, estas são questões imprescindíveis que precisam ser esclarecidas para os adolescentes, uma vez que essas dúvidas podem acarretar no uso incorreto da $A E$.

Em oito questões, a proporção de acertos foi maior entre adolescentes das escolas privadas do que os das escolas públicas. Embora os adolescentes das escolas privadas tenham alcançado porcentagem maior de acerto que os das escolas públicas, os resultados mostram que os adolescentes dos dois grupos sabem pouco sobre a $A E$, o que está em consonância com a literatura pesquisada (Mollen et al., 2008; Castro, Rodrigues, 2009; Araújo, 2009; Adhikari, 2009; Ahern et al., 2010).

Estudo conduzido com adolescentes estudantes de cinco escolas nos EUA observou que quase metade não foi capaz de responder corretamente às perguntas sobre a $\mathrm{AE}$ (Sidebottom et al., 2008). Na Califórnia, apenas $15 \%$ dos adolescentes responderam corretamente todas as cinco perguntas de conhecimento (Raine et al., 2000). Em Portugal, Castro e Rodrigues (2009) verificaram que $89,5 \%$ dos adolescentes não tinham conhecimento 
adequado e Nunes (2005) identificou que apenas 15,8\% foram capazes de identificar a forma correta de uso. Diaz et al. (2003), ao estudarem adolescentes residentes no Brasil, no Chile e no México, consideraram incompleto seu conhecimento sobre AE. No Brasil, Costa et al. (2006), ao investigarem 135 adolescentes do ensino médio de escolas públicas do Rio de Janeiro, relataram que 53,3\% consideravam insuficientes as informações que dispunham para a utilização deste método. A análise do nível do conhecimento da $\mathrm{AE}$ por meio de questões específicas permitiu verificar que os adolescentes têm muitas dúvidas sobre este método. Esta lacuna no conhecimento da $\mathrm{AE}$ merece destaque e o acesso à informação correta necessita ser ampliado.

\subsubsection{Determinantes do nível do conhecimento da anticoncepção de emergência}

A análise de regressão linear múltipla realizada permitiu identificar como variáveis associadas ao conhecimento da $\mathrm{AE}$ o tipo de escola, o nível de escolaridade, o sexo, a experiência sexual e o fato de conhecer alguém que já usou a $A E$.

O tipo de escola foi um elemento preponderante no nível do conhecimento da $\mathrm{AE}$, pois os adolescentes das escolas privadas tiveram uma média de acertos quase dois pontos maior que os das escolas públicas. O conhecimento da AE cresce com o nível socioeconômico, sendo uma das variáveis mais importantes em sua definição (Perpétuo, 2010). Os adolescentes pertencentes aos grupos sociais mais elevados, em geral, utilizam bons serviços de saúde privado e podem ter maior acesso a informações sobre métodos contraceptivos (Ahmed et al., 2012).

O nível de escolaridade esteve associado ao maior nível de conhecimento sobre a $\mathrm{AE}$, pois alunos do $3^{\circ}$ ano do ensino médio apresentaram uma média de escore superior aos demais. Foi também observada associação estatisticamente significativa entre a experiência 
sexual e o nível do conhecimento da $A E$, tal e qual os achados de Araújo (2009), Ahern et al. (2010) e Leyva-López (2010).

Quanto mais velho o adolescente, maior a experiência sexual. Adolescentes que tiveram relação sexual preocupam-se em obter informações sobre métodos contraceptivos, sobretudo em relação à $A E$, pois pode haver preocupação com a saúde reprodutiva, uma vez que passam a se sentir vulneráveis a uma gravidez e se deparam com situações de descontinuidades e falhas no uso de métodos, justamente as indicações de uso da $A E$.

Em relação ao sexo, as meninas apresentaram média maior de escore de conhecimento em relação aos meninos, igualmente ao que foi encontrado nos estudos de Araújo (2009), Adhikari et al. (2009) e LeyvaLópez et al. (2010). Isto pode ser reflexo da tradicional ideia de que a anticoncepção é ainda uma atribuição exclusiva das mulheres, em detrimento da participação masculina (Hoga, 2003). Para muitas mulheres, a participação masculina na contracepção restringe-se apenas ao apoio no processo da regulação da fecundidade, não se manifestando em práticas efetivas (Carvalho, Pirotta, Schor, 2001). Desta forma, as responsabilidades frente à contracepção e à opção pelo método contraceptivo revelam a importância que os diferenciais de gênero assumem diante da sexualidade e da vida reprodutiva (Pirotta, 2002).

Foi observado maior nível do conhecimento entre adolescentes que conheciam alguém que já usou a $A E$. Isso ocorre porque o uso da $A E$ é comentado entre as amigas, contribuindo para o compartilhamento do conhecimento deste método por meio do diálogo entre os pares (Borges et al., 2010).

Faz-se necessário destacar que o uso da anticoncepção de emergência esteve associado ao maior escore de conhecimento, todavia esta influência pôde ser observada apenas na análise de regressão linear simples. Isso parece indicar que outros aspectos já mencionados são mais determinantes para o conhecimento da anticoncepção de emergência e a experiência no uso não favorece a busca de informações sobre este método entre adolescentes. 
Em síntese, foi observado que adolescentes mulheres do $3^{\circ}$ ano do ensino médio das escolas privadas, que já haviam iniciado a vida sexual e que conheciam alguém que já usou a $A E$, alcançaram maior escore de conhecimento da AE (a média foi 6,14). Em contrapartida, os adolescentes do sexo masculino, mais novos, estudantes das escolas públicas, sexualmente inexperientes e cercados de amigos que não haviam usado a $A E$, foram os que tiveram menor escore de conhecimento (a média foi 1,94).

Apesar de haver variações nas médias dos escores, estimar uma média de escore e classificá-la como conhecimento adequado seria inadequado, pois muitas das perguntas formuladas expressavam certo grau de complexidade.

\subsection{USO DA ANTICONCEPÇÃO DE EMERGÊNCIA}

\subsubsection{Perfil do uso da anticoncepção de emergência}

Um pouco mais da metade dos adolescentes usou a $A E$ alguma vez na vida. Esta proporção foi superior à encontrada em outros estudos internacionais e nacionais. Nos EUA, o uso da AE entre as adolescentes variou entre 12,5\% e 38,5\% (Sidebottom et al., 2008; Krishnamurti, Eggers, Fischhoff, 2008; Fine et al., 2009; Ahern et al., 2010). Na China, 44,0\% das adolescentes usaram a $\mathrm{AE}$ (Xu, Cheng, 2008). Na Espanha, a taxa de uso da $\mathrm{AE}$ entre as adolescentes variou de 8,4\% a 24,5\% (Brasa Andrés et al., 2007; López-Amoro's et al., 2010). Já no Brasil, Custódio et al. (2009) observaram que 33,0\% das adolescentes de Santa Catarina usaram a $\mathrm{AE}$; Figueiredo, Puppo e Segri (2008) verificaram que 46,0\% das adolescentes de escolas públicas de São Paulo usaram a AE; e Costa et al. (2006) indicaram que $32,6 \%$ das adolescentes de escolas públicas do Rio de Janeiro usaram a AE. 
A alta porcentagem no uso da $A E$ verificada neste estudo pode ser considerada em duas perspectivas: uma positiva, pois sinaliza que os adolescentes utilizam um método pós-coital a fim de evitar uma gestação não planejada; outra negativa, pois pode estar havendo falhas e descontinuidades no uso de métodos contraceptivos de uso regular.

Do mesmo modo, alguns estudos (Figueiredo, Puppo, Segri, 2008; Meyer, Gold, Haggerty, 2011) indicam que a maior utilização da AE não tem efeitos negativos significativos sobre uso de anticoncepcionais que estão em curso. Neste estudo, foi verificado que $82,1 \%$ dos adolescentes (dado não apresentado) usaram algum método contraceptivo na última relação sexual, revelando que a $A E$ parece não afetar a adoção dos métodos contraceptivos de rotina, sendo utilizada em situações de risco.

Logo, o que se observa é que o uso da $A E$ está muito mais relacionado às descontinuidades da utilização de métodos contraceptivos do que ao não uso de métodos (Borges et al., 2010). Isto é ratificado pela razão mais referida para o uso da $A E$, que foi por pura insegurança, evidenciando que os adolescentes utilizam métodos contraceptivos, porém ficam inseguros, provavelmente, devido às falhas no seu uso.

De qualquer forma, cabe ressaltar que parcela razoável dos adolescentes respondeu que utilizou a $\mathrm{AE}$ porque não quis usar nenhum método contraceptivo. Este achado é similar ao encontrado por Figueiredo et al. (2008), que verificaram que $18,9 \%$ das adolescentes que usaram a $A E$ o fizeram porque optaram por não usar o preservativo masculino. Talvez este seja o grupo mais vulnerável e mais difícil de ser alcançado por ações de promoção da saúde sexual e reprodutiva que enfocam o uso de métodos contraceptivos.

Ainda neste contexto, metade dos adolescentes usou a $A E$ apenas uma vez no último ano, o que sugere que não identificam a $A E$ como anticoncepcional de rotina, mas, sim, efetivamente, como um meio contraceptivo de emergência. Esses resultados foram também observados na pesquisa quanti-qualitativa realizada por Lefreve e Lefreve (2010), em que a maioria dos adolescentes usou a $\mathrm{AE}$ apenas nas situações de risco. Da mesma forma, Araújo (2009) observou que a maioria dos adolescentes 
estudantes do ensino médio de Pernambuco não usou, ou usou apenas uma única vez, a $A E$ no último ano. $O$ baixo índice de repetição do uso da $A E$ também foi encontrado em estudos internacionais (Alford et al. 2010; Ahern et al., 2010), indicando que não há uma tendência de banalização do seu uso entre adolescentes, conforme argumentam alguns opositores deste método (Perpétuo, 2010).

Em relação ao intervalo de tempo de uso da $A E$, a grande maioria dos adolescentes usou a $A E$ até um dia após a relação sexual desprotegida, dado semelhante ao encontrado nos estudos de Costa et al. (2006), Sidebottom et al. (2008) e Ahern et al. (2010). Em contraste, Araújo (2009) observou que $74,7 \%$ das adolescentes usaram a $\mathrm{AE}$ após 72 horas da relação sexual desprotegida e, portanto, o uso foi incorreto. Vale ressaltar que alguns estudos, principalmente os mais remotos, referem que a $A E$ deveria ser usada até 72 horas após a relação sexual desprotegida. No entanto, recentemente, a indicação de intervalo de tempo ampliou-se para até 120 horas (Brasil, 2011).

Mesmo assim, apesar dos adolescentes não terem respondido corretamente a questão Ao usar a $A E$, deve-se estar atento para que isso ocorra em torno de cinco dias após uma relação sexual desprotegida, o uso foi dentro do intervalo considerado adequado. Essa confusão em relação ao intervalo de tempo que a $A E$ deve ser ingerida após a relação sexual desprotegida - 72 horas versus 120 horas - pode acarretar o não uso em situações que ainda seria recomendado.

Adolescentes de ambas escolas estavam em um relacionamento estável quando usaram a $A E$. Pode ser que a duração do relacionamento afetivo-amoroso, por acarretar maiores descontinuidades no uso de métodos regulares, predisponha ao uso da $A E$. De fato, o comportamento contraceptivo na adolescência pode ser definido pelo tipo de relacionamento, ocorrendo negociações a cada troca de parceiros e acarretando alternâncias de métodos durante o mesmo relacionamento (Borges, 2004). Figueiredo et al. (2008) também verificaram que o uso da $A E$ ocorre predominantemente com parceiros fixos, ressaltando que, em um relacionamento mais estável, o 
adolescente não sente a necessidade de negociar o uso do preservativo, devido a uma suposta confiança mútua.

Em relacionamentos esporádicos, nos quais não se estabelece um compromisso entre o casal, há maior tendência de se usar o preservativo masculino, devido à preocupação com a proteção contra DST/AIDS (Pirotta, 2002, Aquino et al., 2003). Logo, o que se observa é que a contracepção na adolescência parece mostrar uma dinâmica própria, na qual as condutas frente ao uso da $A E$ estão mais focadas nas situações que envolvem os relacionamentos de parceira fixa, por conta das descontinuidades no uso dos métodos contraceptivos de uso regular.

$A$ aquisição da $A E$ ocorreu majoritariamente sem receita médica. Uma proporção maior de adolescentes das escolas privadas adquiriu a $A E$ sem receita médica em comparação com aqueles das escolas públicas. Este dado pode estar relacionado ao fato de que houve proporção maior de adolescentes das escolas públicas que adquiriu a $A E$ em serviços de saúde público, que exigem receita médica. De toda forma, a grande maioria dos adolescentes adquiriu a $A E$ em farmácias privadas, ressaltando que o uso da $A E$ acontece sem o apoio dos serviços de saúde.

Por meio de contato telefônico, a Secretaria de Saúde do Município de Arujá relatou que a distribuição da $A E$ na Atenção Básica de Saúde é efetiva. No entanto, ao contatar algumas Unidades Básicas de Saúde, verificou-se que a oferta da $A E$ é inadequada, pois algumas sequer tinham disponível o método e outras relataram que o fornecimento da $A E$ aos adolescentes deveria ser realizado apenas por médicos, necessitando agendar uma consulta.

Estas barreiras à difusão da $A E$ também foram observadas por Figueiredo e Bastos (2008) que, ao estudarem o perfil da distribuição da AE para adolescentes em municípios do Estado de São Paulo, verificaram que mais da metade dos municípios não ofertam este método para este grupo nos serviços públicos de saúde. O Ministério da Saúde (Brasil, 2004), para facilitar a distribuição da $\mathrm{AE}$, autorizou a prescrição, a orientação e 0 acompanhamento da $\mathrm{AE}$ pelos enfermeiros, visto a diminuição da eficácia do método na espera por uma consulta agendada, facilitando, portanto, o 
acesso à $\mathrm{AE}$. Contudo, esta norma é somente efetivada no município de São Paulo, sendo que, nos demais municípios, os enfermeiros não realizam o fornecimento da $\mathrm{AE}$, conforme autorizam os protocolos e a legislação sobre sua prescrição (Figueiredo, 2007).

Neste contexto, as restrições à oferta da $A E$ aos adolescentes indica negação na efetivação dos direitos sexuais e reprodutivos neste grupo. Segundo o Ministério da Saúde (Brasil, 2011), todas as adolescentes com risco de gravidez não planejada devem ter garantia de acesso à informação e ao uso da $A E$. No entanto, esta medida muitas vezes não é concretizada e a $A E$ deixa de ser uma alternativa estratégica para a promoção dos direitos reprodutivos (Figueiredo, 2010). Assim sendo, os setores públicos deveriam estabelecer e adotar ações que incorporassem a $A E$ dentro dos direitos sexuais e reprodutivos.

Ademais, a seletividade na dispensa da $A E$ e a baixa oferta na Atenção Básica de Saúde resultam no alto índice de consumo deste método por meio de aquisição direta em farmácias. Cabe ressaltar que o Ministério da Saúde (Formenti, 2012) notificou que pretende dispensar a exigência de receita médica para o fornecimento da $A E$ nos postos de saúde do SUS, tal como é verificado nas farmácias. Esta iniciativa, se efetivada, representará grande avanço na oferta da $A E$ na atenção contraceptiva na rede pública de saúde, beneficiando toda a população, em especial os adolescentes.

Nos EUA, a FDA (Agência de Drogas e Medicamentos) aprovou a comercialização da $A E$ nas farmácias sem a necessidade da prescrição médica somente para adolescentes com 17 anos de idade ou mais (Krishnamurti, Eggers, Fischhoff, 2008). Posterirormente, a FDA analisou um estudo desenvolvido por um laboratório fabricante da $\mathrm{AE}$ com adolescentes entre 11 e 17 anos de idade e verificou que cerca de 90,0\% das adolescentes que procuraram o método souberam utilizá-lo corretamente. Diante do resultado, a FDA liberou a venda da AE sem receita médica a todas as mulheres em idade reprodutiva; contudo, a Secretaria de Saúde dos Estados Unidos vetou a decisão da FDA (CCR, 2011). Este episódio ratifica que ainda há inúmeras restrições quanto ao exercício do direito sexual e reprodutivo, indicando um retrocesso que pode dificultar o acesso à 
$A E$ em países com leis mais restritivas na área de saúde do que nos Estados Unidos.

\subsubsection{Determinantes do uso da anticoncepção de emergência}

Curiosamente, ao contrário do conhecimento, o uso da $A E$ não foi diferente entre os adolescentes das escolas públicas e privadas. A análise de regressão logística múltipla realizada permitiu identificar como variáveis associadas ao uso da AE entre os adolescentes, a religião, o namoro atual e conhecer alguém que já usou a $A E$. As variáveis palestras sobre $A E$ na escola, escore de conhecimento da $A E$ e ter obtido informações da $A E$ com amigos/conhecidos, na televisão e na escola foram associadas ao seu uso, porém essa influência pôde ser observada apenas na análise univariada. Isto significa que estas variáveis perderam significância na presença dos outros fatores.

A variável religião chamou a atenção pelo fato de que apenas a católica mostrou uma associação com o uso da $A E$, sendo que os adolescentes católicos tiveram menos chance de usar a $A E$ em relação aos que não tinham nenhuma religião. $O$ uso da $A E$ envolve questionamentos relacionados à ética e à religião. Setores da Igreja Católica e de instituições a ela ligadas argumentam que a $\mathrm{AE}$ é um método abortivo e que provoca o exercício desenfreado da sexualidade, tanto de mulheres adultas quanto de adolescentes (Souza, Brandão, 2012). Segundo Arilha e Citeli (2010), as tentativas de criação de leis contrárias ao uso da $A E$, no caso do Estado de São Paulo, ocorrem em áreas geográficas de amplo poder da Igreja Católica e de grande concentração de renda per capita, sugerindo uma possível associação entre os grupos de elite econômica e setores religiosos de alta influência no Estado de São Paulo. Este cenário de valores, questões culturais e informações distorcidas sobre a $A E$, muitas vezes veiculadas pelas religiões e ratificadas pela mídia, pode se transformar em barreiras relativas à aceitação e ao acesso entre potenciais usuárias. Certamente, tais 
barreiras no acesso à $A E$ podem provocar atraso no uso deste método, ocasionando baixa eficácia.

É importante destacar que, apesar das barreiras culturais e religiosas, há grupos opositores às forças católicas e defensores da $A E$, como, por exemplo, o CLAE. Devido às atuações de oposição do CLAE, a AE tem sido difundida e utilizada gradativamente, especialmente nos países como Peru, Brasil e Chile (Faúndes et al, 2007).

Em relação ao namoro atual, verificou-se que os adolescentes que estavam namorando tinham o dobro de chance de usar a $A E$ do que aqueles que não namoravam. Isto significa que, na relação de namoro, os adolescentes podem ter mais relações sexuais; concomitantemente, 0 namoro, como discutido anteriormente, predispõe ao uso da $A E$ devido às alternâncias de métodos contraceptivos de uso regular.

A variável conhece alguém que já usou a $A E$ apresentou forte associação em relação ao uso da $\mathrm{AE}$, sendo que os adolescentes que conheciam alguém que já tinha usado a $A E$ tiveram mais chance de usar a $A E$ do que aqueles que não conheciam ninguém que a tivesse usado. $O$ mesmo resultado foi encontrado por Borges et al. (2010). Como citado anteriormente, o uso da $\mathrm{AE}$ é dialogado entre as adolescentes; assim, a troca de experiências e informações quanto ao modo de usar e as indicações consistem em incentivo para o uso deste método.

Surpreendentemente, o nível do conhecimento da $A E$ não afetou o seu uso. Ou seja, do mesmo modo que o uso não afetou o conhecimento da $A E$, este não foi determinante para o uso. Isto significa que o uso da $A E$ está relacionado muito mais a outros aspectos, como a religião, o namoro atual e conhecer alguém que já usou a $A E$ do que ao nível do conhecimento propriamente dito. Logo, a inadequação do conhecimento sobre a $A E$ não atua como uma barreira ao seu uso. Aparentemente, quando há situações de exposição ao risco de uma gravidez, os adolescentes usam a $A E$ independentemente do seu nível do conhecimento.

Diante da escassez de estudos nacionais sobre a $A E$, os resultados dessa pesquisa destacam a necessidade de futuros estudos para se compreender melhor a relação entre o nível do conhecimento e o uso da AE. 


\section{CONCLUSÃO}

Em relação ao nível do conhecimento da $\mathrm{AE}$, evidenciou-se que os adolescentes conhecem este método; todavia, poucos estão corretamente informados sobre as indicações e os mecanismos de ação, apresentando dúvidas e ideias equivocadas sobre a mesma.

Por meio da análise de regressão linear múltipla, verificou-se que os adolescentes das escolas privadas tiveram nível do conhecimento maior do que os das escolas públicas. Outro fator associado ao nível do conhecimento da $A E$ foi o ano escolar, ou seja, quanto mais velho o adolescente, maior o seu nível do conhecimento. Os adolescentes do sexo feminino, sexualmente experientes e que conheciam alguém que já tinha usado a $A E$, também tiveram maior nível de conhecimento sobre este método. Logo, os resultados indicaram que o tipo de escola é determinante no nível do conhecimento da AE e, ainda, o ano escolar/idade, o sexo e os aspectos socioafetivos, tais como a experiência sexual, o namoro atual e conhecer alguém que já usou a $A E$, foram associados ao nível do conhecimento da $A E$, confirmando parte da hipótese desta pesquisa.

Em relação ao uso da $\mathrm{AE}$, conclui-se que, apesar das lacunas no conhecimento, os adolescentes utilizam este método em situações nas quais pensam estar em risco de engravidar, seja pelo não uso de métodos contraceptivos regulares ou pelas falhas na sua utilização. Embora a prevalência de uso tenha sido superior à encontrada na literatura, este trabalho não contemplou situações nas quais as adolescentes poderiam ter utilizado $A E$ e não o fizeram, ou seja, não se sabe se o método foi subutilizado por esta população.

$\mathrm{Na}$ análise de regressão de logística múltipla, verificou-se que a maior chance de uso da $\mathrm{AE}$ esteve presente entre os adolescentes que não tinham nenhuma religião e os que estavam namorando, ratificando que o estabelecimento de relações fixas causa mudança no padrão contraceptivo dos adolescentes. Ademais, o fato de conhecer alguém que já usou a AE, ou seja, a troca de experiências entre os pares, esteve relacionado à maior 
chance de uso. Portanto, foram fatores determinantes para o uso da $A E$, a religião, o namoro atual e conhecer alguém que já usou a $A E$; sendo que a experiência sexual, a idade e o tipo de escola não foram associados ao seu uso, conforme foi pressuposto na hipótese deste estudo.

$O$ uso da $A E$ foi pontual, não ocorrendo de forma abusiva entre os adolescentes. A maioria dos adolescentes que usou a $A E$ não teve informações sobre este método nas escolas. Isto leva a crer que a escola, enquanto espaço social, teve pouca participação na orientação sexual e reprodutiva para os adolescentes. Neste contexto, a experiência extraída do projeto mostra a necessidade de elaboração e execução de novas propostas para a educação em saúde nas escolas. 


\section{REFERÊNCIAS}

Adhikari R. Factors affecting awareness of emergency contraception among college students in Kathmandu, Nepal. BMC Womens Health.2009;9(27):1-5.

Ahern R, Frattarelli LA, Delto J, Kaneshiro B. Knowledge and awareness of emergency contraception in adolescentes. J Pediatr Adolesc Gynecol. 2010;23(5):273-78.

Ahmed FA, Moussa KM, Petterson KO, Asamoah BO. Assessing knowledge, attitude, and practice of emergency contraception: a cross- sectional study among Ethiopian undergraduate female students. BMC Public Health. 2012;(12):1-9.

Alford SM, Lappin RE, Wells K, Barone AR, Dalton VK. Adolescent and young adult women's use of emergency contraception. J Pediatr Adolesc Gynecol. 2010;23(5):279-84.

Almeida MCC, Aquino EML, Gaffikin L, Magnani RJ. Uso de contracepção por adolescentes de escolas públicas na Bahia. Rev Saude Publica. 2003;37(5):566-75.

Aquino EML, Heilbor ML, Knauth D, Bozon M, Almeida MC, Araújo J, Menezes G. Adolescência e reprodução no Brasil: a heterogeneidade dos perfis sociais. Cad Saude Publica. 2003;19(Sup.2):377-88.

Araújo MSP, Costa LOBF. Comportamento sexual e contracepção de emergência entre adolescentes de escolas públicas de Pernambuco, Brasil. Cad Saude Publica. 2009;25(3):551-62.

Araújo MSP. Contracepção de emergência entre adolescentes de escolas públicas de Pernambuco. [Tese de Mestrado]. Camaragibe: Faculdade de Odontologia da Universidade de Pernambuco; 2007.

Arilha M, Berquó E. Cairo+15: trajetórias globais e caminhos brasileiros em saúde reprodtiva e direitos reprodutivos. In: ABEP, UNFPA. Brasil, 15 anos após a conferência de Cairo. Campinas, São Paulo; 2009. p. 96. 
Arilha M, Citeli MT. Intervenções restritivas ao acesso da Contracepção de Emergência no Brasil (1999-2009): um mapa geopolítico das barreiras aos direitos reprodutivos no país. In: Arilha M, Lapa TS, Pisaneschi TC. Contracepção de emergência no Brasil e América Latina: dinâmicas políticas e direitos sexuais e reprodutivos. São Paulo; 2010. p. 135-162.

Belzer M, Yoshida E, Tejirian T, Tucker D, Chung K. Advanced supply of emergency contraception for adolescent mothers increased utilization without reducing condom or primary contraception use. J Adolesc Health. 2003;32(2):122-3.

Bergallo $\mathrm{P}$. Bergallo $\mathrm{P}$, Borràs $\mathrm{CP}$, editoras. Argumentos para la defense legal de la anticoncepción de emergência en América Latina y el Caribe. $2^{a}$ ed. América Latina e Caribe: 2011.

Berquó ES, Souza JMP, Gotlieb SLD. Bioestatística. São Paulo: E.P.U (editora pedagógica e universitária Ltda); 1981. p. 73, 137-141.

Borges ALV. Adolescência e vida sexual: análise do início da vida sexual de adolescentes residentes na zona leste do município de São Paulo. [Tese de Doutorado]. São Paulo: Faculdade de Saúde Pública da USP; 2004.

Borges ALV, Schor N. Início da vida sexual na adolescência e relações de gênero: um estudo transversal em São Paulo, Brasil, 2002. Cad Saude Publica. 2005;21(2):499-507.

Borges ALV, Nichiata LY, Schor N. Conversando sobre sexo: a rede sóciofamiliar como base de promoção da saúde sexual e reprodutiva de adolescentes. Rev Latino-Am Enfermagem. 2006;14(3):422-7.

Borges ALV. Relações de gênero e iniciação sexual de mulheres adolescentes. Rev Saude Publica. 2007;41(4):597-604.

Borges ALV. Início da vida sexual. In: Borges ALV, Fujimori E, organizadoras. Enfermagem e a saúde do adolescente. São Paulo: Manole; 2009. p. 283-84.

Borges ALV, Fujimori E. Condições de vida e saúde da população adolescente no Brasil. In: Borges ALV, Fujimori E, organizadoras. Enfermagem e a saúde do adolescente. São Paulo: Manole; 2009. p. 23-4. 
Borges ALV, Fujimori E, Hoga LAK, Contim M. Práticas contraceptivas entre jovens universitários: uso da anticoncepção de emergência. Cad Saude Publica. 2010;26 (4):816-26.

Brandão ER. Iniciação sexual e afetiva: exercício da autonomia juvenil. In: Heilborn ML. Família e sexualidade. São Paulo: FGV; 2004. p. 77-8.

Brasa Andrés J, Celada Pérez MS, Estepa Jorge AI, Menéndez Ortiz de Zárate MM. Contracepción de emergencia: Una perspectiva desde la adolescencia. Index Enferm [periódico na internet]. 2007 dez. [citado 2012 Ago 29]; 16(56):22-5. Disponível em: http://scielo.iscii.es/scielo.php?script= ciarttext\&pid=S1132-12962007000100005\&Ing=es.

Brasil. Ministério da Saúde. Portaria SMS n. 295, de19 de maio de 2004. Contracepção de emergência pode ser prescrita, orientada e acompanhada por Enfermeiro, inclusive para as adolescentes. Disponível em: http://www.prefeitura.sp.gov.br/cidade/secretarias/upload/saude/arquivos/ass istenciafarmaceutica/contraceptivos_reversiveis.pdf.

Brasil. Ministério da Saúde. Direitos sexuais e direitos reprodutivos: uma prioridade do governo.Brasília; 2005a. [atualizado 2012 set. 10]. Disponível em: http://bvms.saude.gov.br/bvs/publicacoes/cartilha_direitos_sexuais_ reprodutivos.pdf.

Brasil. Ministério da Saúde. Política Nacional de Atenção Integrada à Saúde da Mulher - plano de ação 2004-2007 / Série C. Projetos, Programas e Relatórios. Brasília; 2005b. p. 39-42.

Brasil. Ministério da Saúde. Secretaria de Atenção à Saúde. Departamento de Ações Programáticas e Estratégicas. Marco teorico e referencial: saúde sexual e saúde reprodutiva de adolescentes e jovens. Brasília; 2006. [atualizado 2011 abr. 18]. Disponível em: http://files.bvs.br/upload/MS/20 06/Brasil_Marco_teorico.pdf.

Brasil. Ministério da Saúde. Secretaria da Ciência, Tecnologia e Insumos Estratégicos. Departamento de Ciência e Tecnologia. PNDS 2006: Pesquisa Nacional de Demografia e Saúde da Criança e da Mulher: relatório. Brasília; 2008.[atualizado 2010 nov. 19]. Disponível em: http://bvms.saude.gov.br/ bvs/publicacoes/relatorio_pnds_2006.pdf. 
Brasil. Ministério da Saúde. Saúde Sexual e Saúde Reprodutiva. Brasília; 2010. [atualizado 2010 nov. 29]. Disponível em: http://189.28.128.100/dab //docs/publicacoes/cadernos_ab/abcad26.pdf.

Brasil. Ministério da Saúde. Anticoncepção de Emergência - perguntas e respostas para profissionais de saúde. Brasília; 2011. [atualizado 2010 nov. 19].Disponível em: http://bvms.saude.gov.br/bvs/publicacoes/anticoncep cao_emergencia_perguntas_respostas_2ed.pdf.

Carvalho MLO, Pirotta KCM, Schor N. A participação masculina na contracepção pela ótica masculina. Rev Saude Publica [periódico na internet]. 2001 fev. [atualizado 2012 ago. 29];35(1):23-31. Disponível em: http://www.scielo.br/pdf/rsp/v35n1/4132.pdf.

Castro JF, Rodrigues VMCP. Conhecimentos e atitudes dos jovens face à contracepção de emergência. Rev Esc Enferm USP. 2009;43(4):889-94.

Catharino TR, Giffin K. Gravidez e adolescência - investigação de um problema moderno. In: XIII Encontro da Associação Brasileira de Estudos Populacionais. Ouro Preto: Associação Brasileira de Estudos Populacionais; 2002. p. 1-20.

Cheng L, Gülmezoglu AM, Piaggio G, Ezcurra E, Van Look PFA. Cochrane Database Syst Rev. 2008;16 (2):1-154.

Chinaglia MLM, Petta CA, Aldrighi JM. Anticoncepção de Emergência. In: Anticoncepção: aspectos contemporâneos. São Paulo: Atheneu; 2005. p. 121-24.

Comissão de Cidadania e Reprodução (CCR). A (nova) política da contracepção nos Estados Unidos. São Paulo; 2011. [atualizado 2012 jul. 18]. Disponível em: http://www.ccr.org.br/editorial-detalhe.asp?cod=26.

Conselho Federal de Medicina (CFM). Normas técnicas para a utilização da contracepção de emergência. Resolução n 1811 - Diário Oficial da União. 2007; 12.ed. [atualizado 2012 ago. 30]. Disponível em: http://www.portalmedi co.org.br/resolucoes/cfm/2006/1811_2006.htm. 
Costa KBS, Carvalho ACG, Santos KB, Mendes SHFM, Soares A. Contracepção de adolescentes do Rio de Janeiro. Rev SOGIA-BR. 2006;7(2):3-6.

Custódio G, Massuti AM, Schuelter-Trevisol F, Trevisol DJ. Comportamento sexual e de risco para DST e gravidez em adolescentes. J Bras Doenças sex Transm. 2009;21(2):60-4.

Díaz S, Hardy E, Alvarado G, Ezcurra E. Acceptability of emergency contraception in Brazil, Chile and Mexico. 1 - Perceptions of emergency oral contraceptive. Cad Saude Publica. 2003;19(5):1507-17.

Faúndes, A. Távara L, Brache V, Alvarez F. Emergency contraception under attack in Latin America: response of the medical establishment and civil society. Reprod Health Matters. 2007;15(29):130-8.

Figueiredo, R. Contracepção de emergência no Brasil: necessidade, acesso e política nacional. São Paulo; 2004 set. [atualizado 2010 nov. 19].Disponível em: http://nepaids.vitis.uspnet.usp.br/wp-content/uploads/2010/04/ipas.pdf.

Figueiredo R, Andalaft Neto J. Uso de contracepção de emergência e camisinha entre adolescentes e jovens. Rev SOGIA-BR. 2005;6(2):1-11.

Figueiredo R, Bastos S, Soares MA, Telles JL, Miranda M. Distribuição da contracepção de emergência na atenção básica de São Paulo: caracterização de oferta em PSF e UBS dos municípios do estado. BIS, Bol. Inst. Saúde [periódico na internet]. 2007 ago. [atualizado 2012 set. 17]; (42):27-30. Disponível em: http://www.isaude.sp.gov.br/smartsitephp/media/ isaude/file/bis/bis42-tecnologia_completo.pdf

Figueiredo $R$, Bastos $S$. Relatório final da pesquisa de avaliação e monitoramento da distribuição da contracepção de emergência entre adolescentes nos municípios do estado de São Paulo. São Paulo: Instituto de Saúde, 2008.

Figueiredo R, Puppo LR, Porto Alves MC, Escuder MM. Comportamento sexual, uso de preservativos e contracepção de emergência entre adolescentes do município de São Paulo. São Paulo: Insituto de Saúde/SES, 2008. 
Figueiredo R, Puppo LR, Segri NJ. Comportamento sexual e preventivo de adolescentes de São Paulo: um estudo com estudantes do ensino médio. BIS, Bol. Inst. Saúde [periódico na internet]. 2008 dez. [atualizado 2012 ago. 29]; (46):31-3. Disponível em: http://periodicos.ses.sp.bvs.br/pdf/bis/n46a09. pdf.

Figueiredo R. Contracepção de emergência: estratégia fundamental para o exercício dos direitos sexuais e reprodutivos de jovens adolescentes. In: Arilha M, Lapa TS, Pisaneschi TC. Contracepção de emergência no Brasil e América Latina: dinâmicas políticas e direitos sexuais e reprodutivos. São Paulo; 2010. p. 130.

Fine LC, Mollen CJ. A pilot study to assess candidacy for emergency contraception and interest in sexual health education in a pediatric emergency department population. Pediatr Emerg Care. 2010;26(6):413-6.

Fisberg M, Silva FC, Vitalle MSS, Maranhão HS, Canuto MHA, Pires MMS. Diferenças regionais do conhecimento, opinião e uso de contraceptivo de emergência entre universitários brasileiros de cursos da área de saúde. Cad Saude Publica. 2010;26 (9):1821-1831.

Formenti L. Pílula do dia seguinte não exigirá receita. São Paulo; 2012. [atualizado 2012 jul. 10]. Disponível em: http://www.noticias.uol.com.br/sau de/ultimas-noticias/estado/2012/06/28/pilula-do-dia-seguinte-nao-exigiramais-receita.htm.

Kaymak O, Simsek Y, Doganay M, Yildiz Y, Mollamahmutoglu L. Ectopic pregnancy following levonorgestrel emergency contraception: a case report. J Turkish German Gynecol Assoc. 2010;11:168-9.

Krishnamurti T, Eggers SL, Fischhoff B. The impact of over-the-counter availability of "Plan B" on teens contraceptive decision making. Soc Sci Med. 2008;(67):618-27.

Heilborn ML. Experiência da sexualidade, reprodução e trajetórias biográficas juvenis. In: Heilborn ML et al, organizadores. O aprendizado da sexualidade: reprodução e trajetórias sociais de jovens brasileiros. Rio de Janeiro: Garamond/Fiocruz; 2006. p.20-59. 
Hensley Alford SM, Lappin RE, Wells K, Barone AR, Dalton VK. Adolescent and young adult women's use of emergency contraception. J Pediatr Adolesc Gynecol. 2010 23(5):279-84.

Hoga LAK. As práticas anticoncepcionais no cotidiano de uma comunidade. In: Merighi MAB, Praça NS. Abordagens teórico-metodológicas qualitativas: a vivência da mulher no período reprodutivo. Rio de Janeiro: Guanabara Koogan; 2003. p. 47-57.

Instituto Brasileiro de Geografia e Estatística (IBGE). Censo demográfico 2000. Caracterísiticas gerais da população: resultados da amostra. Rio de Janeiro; 2003. [atualizado 2011 jan. 26]. Disponível em: http://www.ibge.gov. br/home/estatistica/populacao/censo2000/tabelabrasil111.shtm.

Instituto Brasileiro de Geografia e Estatística (IBGE). Censo demográfico. Caracterísiticas gerais da população: resultados da amostra. Rio de Janeiro; 2010a.[atualizado 2011 jan. 26]. Disponível em: http://censo2010.ibge.gov.br

Instituto Brasileiro de Geografia e Estatística (IBGE). Pesquisa nacional por amostra de domicílios - 2009: síntese de indicadores. Rio de Janeiro; 2010b. [atualizado 2012 set. 28]. Disponível em: http://www.ibge.gov.br/home/ estatistica/populacao/trabalhoerendimento/pnad2009/pnad_sintese_2009.pdf

Jardim, DP. Como e quando começar a orientação sexual na escola: a opinião dos professores do município de Embú - SP. São Paulo; 2008. [Tese de Mestrado]. São Paulo: Universidade Federal de São Paulo; 2008.

Lefreve $F$, Lefreve AMC. O que pensam e dizem nossos jovens: resultados da pesquisa. In: Lefreve F, Lefreve AMC (organizadores). Aconteceu e daí? A pílula do dia seguinte, atalhos e caminhos. São Paulo: IPDSC; 2010. p.4593.

Leite IC, Rodrigues RN, Fonseca MC. Fatores associados com o comportamento sexual e reprodutivo entre adolescentes das regiões Sudeste e Nordeste do Brasil. Cad Saude Publica. 2004;20(2):474-81.

Leyva-López A, Chávez-Ayala R, Atienzo EE, Allen-Leigh B, RamírezVillalobos D, Yunez-Díaz E, Riviera-Rviera L. Anticoncepción de emergencia en estudiantes mexicanos. Salud Publica Mex. 2010;52(2):156-164. 
López-Amoro`s M, Schiaffino A, Moncada A, Pérez G. Factores asociados al uso autodeclarado de la anticoncepción de emergência em la pobación escolarizada de 14 a 18 anos de edad. Gac Sanit. 2010;24(5):404-09.

Marions L, Hultenby K, Lindell I, Sun X, St3bi B, Gemzell Danielsson K. Emergency contraception with mifepristone and levonorgestrel: mechanism of action. Obstet Gynecol. 2002;100(1):65 - 71.

Martins LBM, Costa-Paiva L, Osis MJD, Sousa MH, Neto AMP, Tadini V. Conhecimento sobre métodos anticoncepcionais por estudantes adolescentes. Rev Saude Publica. 2006;40(1):57-64.

Mckinnon S, Potter JE, Garrard-Burnett V. Adolescent fertility and religion in Rio de Janeiro, Brazil in the year 2000: The role of Protestantism. Popul Stud (Camb). 2008;62(3):289-303.

Mendonça RCM, Araújo TME. Métodos contraceptivos: a prática dos adolescentes das escolas agrícolas da Universidade Federal do Piauí. Esc Anna Nery Rev Enferm. 2009; 13(4):863-71.

Meyer JL, Gold MA, Haggerty CL. Advance provision of emergency contraception among adolescent and young adult women: a systematic review of literature. J Pediatr Adolesc Gynecol. 2011;24(1):2-9.

Minas Gerais. Secretaria de Estado de Saúde. Atenção à saúde do adolescente. Belo Horizonte: SAS/MG; 2006. $1^{\underline{a}}$ ed. 152 p.

Moizés, JS. A sexualidade na compreensão de professores do ensino fundamental. Ribeirão Preto; 2007. [Tese de Mestrado]. Ribeirão Preto: Universidade de São Paulo; 2007.

Mollen CJ, Barg FK, Hayes KL, Gotcsik M, Blades NM, Schwarz DF. Assessing attitudes about emergency contraception among urban, minority adolescent girls: an in-depth interview study. Pediatrics. 2008;122(2):395401.

Nunes MT. Conhecimento e utilização da contracepção de emergência em alunas do ensino secundário em Guimarães. Rev Port Clin Geral. 2005;21:247-56. 
Oliveira MAC. A adolescência, o adolescer e o adolescente: re-significação a partir da determinação social do processo saúde-doença. [Tese de Doutorado]. São Paulo: Faculdade de Saúde Pública da USP; 1997.

Organização das Nações Unidas (ONU). Programme of action of the UNICPD. A. Reproductive rights and reproductive health: basis for action. 1994. [atualizado 2012 jan. 31]. Disponível em: http://www.iisd.ca/linkages/ Cairo/program/p07002.html.

Organização das Nações Unidas (ONU). The fourth world conference on women. Beijing declaration plataform for action. 1995. [atualizado 2012 jan. 31]. Disponível em: http://www.un.org.

Paiva V, Ayres JRCM, Segurado AC, Lacerda R, Silva NG, Silva MH, Galano E, Gutierrez PL, Marques HHS, Negra MD, França-Júnior I. A sexualidade de adolescentes vivendo com HIV: direitos e desafios para o cuidado. Cien Saude Colet. Rio de Janeiro. 2011;16(10):4199-210.

Pereira PP, Cabar FR, Raiza LCP, Roncaglia MT, Zugaib M. Emergency contraception and ectopic pregnancy: report of 2 cases. J Turkish German Gynecol Assoc. 2010;11:168-9.

Peres F. Adolescência: em busca dos sujeitos sociais. [Tese de Doutorado]. São Paulo: Faculdade de Saúde Pública da USP; 1993.

Peres F, Rosenburg CP. Desvelando a concepção de adolescência/adolescente presente no discurso da saúde pública. Saúde Soc. 1998;7(1):53-86.

Perpétuo IHO. Contracepção de emergência na adolescência e a PNDS 2006. In: Arilha M, Lapa TS, Pisaneschi TC. Contracepção de emergência no Brasil e América Latina: dinâmicas políticas e direitos sexuais e reprodutivos. São Paulo; 2010. p. 91-120.

Pirotta KCM. Não há guarda chuva contra o amor: estudo do comportamento reprodutivo e de seu universo simbólico entre jovens universitários da USP. [Tese de Doutorado]. São Paulo: Faculdade de Saúde Pública da USP; 2002. 
Pirotta KCM. Juventude e saúde sexual e reprodutiva: estudo com alunos da rede estadual de ensino público no município de Santos, 2005. In: XV Encontro Nacional de Estudos Populacionais, ABEP; 2006 set. 18-22. Caxambu, MG. Instituto de Saúde/Secretaria de Estado da Saúde; 2006. p. 10.

Pirotta KCM, Barboza R, Pupo LR, Cavasin S, Unbehaum S. A educação sexual na escola: elementos para uma avaliação dos esforços realizados. BIS, Bol. Inst. Saúde. [periódico na internet]. 2008 dez. [atualizado 2012 ago. 29];(46):34-37.Disponível em: http://periodicos.ses.sp.bvs.br/pdf/bis/n46/n4a 10.pdf.

PNUD. Programa das Nações Unidas para o Desenvolvimento. Ranking do IDH-M do município de Arujá, 2000. [atualizado 2012 set. 11]. Disponível em: http://www.pnud.org.br/atlas/ranking/IDH-M\%2091\%2000\%20Ranking\%20 decrescente\%20\%28pelos\%20dados\%20de\%202000\%29.htm.

Practice Committe. Hormonal contraception: recent advances and controversies. The Practice Committee of the American Society for Reproductive Medicine. Fertil Steril. 2004;82(2):520-26.

Raine TR, Harper CC, Leon K. Darney PD. Emergency contraception: advance provision in a young, high-risk clinic population. Obstet Gynecol. 2000;6(1):1-7.

Raine TR, Harper CC, Rocca CH, Fischer R, Padian N, Klausner JD, Darney PD. Direct access to emergengy contraception through pharmacies and effect on unintended pregnancy and stis. JAMA. 2005;293(1):54-62.

Reis AOA. O discurso da saúde pública sobre a adolescente grávida: avatares. [Tese de Doutorado]. São Paulo: Faculdade de Saúde Pública da USP; 1993.

Romo LF, Berenson AB, WU Zh. The role of misconceptions on latino womens' acceptance of emergency contraceptive pills. Contraception. 2004;69:227-35.

Rubin A, Gold M, Kim Y, Schwarz E. Teen use of emergency contraception: methods of acces and perceived barriers. J Adolesc Health. 2010; 46 (2 Suppl 1): S6-7. 
Santelli JS, Lowry R, Brener N, Robin L. The association of sexual behavior with socioeconomic status, family structure ande race/ethnicity among US adolescents. Am J Public Health. 2000;90(10):1582-88.

Santos AS, Santos ES. Correlação e regressão estatística. Instituo de matemática da Universidade Federal da Bahia. Salvador; 2009. [atualizado 2012 jun. 27]. Disponível em: http://www.ebah.com.br/engenharia-civil.

SEADE. Índice Paulista de Vulnerabilidade Social. Espaços e dimensões da pobreza nos municípios do Estado de São Paulo. São Paulo: SEADE; 2009. [atualizado 2010 ago. 14]. Disponível em: http://www.seade.gov.br/produtos/ ipvs/municipios_pdf.php.

SEADE. Índice Paulista de Vulnerabilidade Social. Espaços e dimensões da pobreza nos municípios do Estado de São Paulo. São Paulo: SEADE; 2010. [atualizado 2011 jan. 28]. Disponível em: http://www.seade.gov.br/produtos/ perfil/perfilMunEstado.php.

Sidebottom A, Harrison PA, Donna A, Finnegan K. The varied circumstances prompting requests for emergency contraception at school-based clinics. $J$ Sch Health. 2008;78(5):258-63.

Silva NN. Amostragem probabilística. São Paulo: EDUSP; 1998. 124 p.

Silva CG, Santos AO, Licciardi DC, Paiva V. Religiosidade, juventude e sexualidade: entre a autonomia e a rigidez. Psicol Estud [periódico na internet]. 2008 dez. [atualizado 2012 ago. 29];13(4):683-92. Disponível em: http://www.scielo.br/pdf/pe/v13n4/v13n4a06.pdf.

Sociedade Brasileira de Pediatria (SBP), Federação Brasileira das Sociedades de Ginecologia e Obstetrícia (FEBRASCO). Adolescência, anticoncepção e ética - Diretrizes. J Pediatr. 2004;80(1):35-40.

Souza RA, Brandão ER. Marcos normativos da anticoncepção de emergência e as dificuldades de sua institucionalização nos serviços públicos de saúde. Rev Saude Coletiva. 2009;14(19):1067-86.

Souza RA, Brandão ER. À sombra do aborto: o debate social sobre a anticoncepção de emergência na mídia impressa brasileira (2005-2009) [periódico na internet]. 2012 abr. [atualizado 2012 ago. 29];16(40):161-76. 
Disponível em: http://www.scielo.br/scielo.php?pid=S1414-32832012000100 013\&script=sci_arttext.

Toneli MJF. Direitos sexuais e reprodutivos: algumas considerações para auxiliar a pensar o lugar da psicologia e sua produção teórica sobre a adolescência. Psicologia \& Sociedade. 2004;16(1):151-160.

Ventura M, Corrêa S. Adolescência, sexualidade e reprodução: construções culturais, controvérsias normativas, alternativas interpretativas. Cad Saude Publica. 2006; 22(7):1505-09.

Verona APA, Dias Júnior CS. Religião e fecundidade entre adolescentes no Brasil. Rev Panam Salud Publica. 2012;31(1):25-31.

$\mathrm{Xu}$ J, Cheng L. Awareness and usage of emergency contraception among teenagers seeking abortion: A Shanghai Surrey. Eur J Obstet Gynecol Reprod Biol. 2008;(141):143-46.

Zoboli ELCP, Araújo D. Questões éticas na atenção à saúde do adolescente. In: Borges ALV e Fujimori E. (org.) Enfermagem e a saúde do adolescente na atenção básica. Manole: São Paulo; 2009. p.249-79.

Zucchi RM, Júnior JE, Zucchi F, Camano L. Gravidez Ectópica após Uso de Contracepção de Emergência: Relato de Caso. Rev Bras Ginecol Obstet. 2004;26(9):741-43.

World Health Organization (WHO). Meeting on pregnancy and abortation in adolescence. Report. Geneva; 1975. (WHO - Technical Report Series, 583). [atualizado 2011 jan. 31]. Disponível em: http://whqlibdoc.who.int/trs/WHO_ TRS_583.pdf.

World Health Organization (WHO). Emergency contraception. Report. Geneva; 2012. (WHO - Technical Report Series, 244). [atualizado 2012 ago. 28]. Disponível em: http://www.who.int/mediacentre/factsheets/fs244/en. 


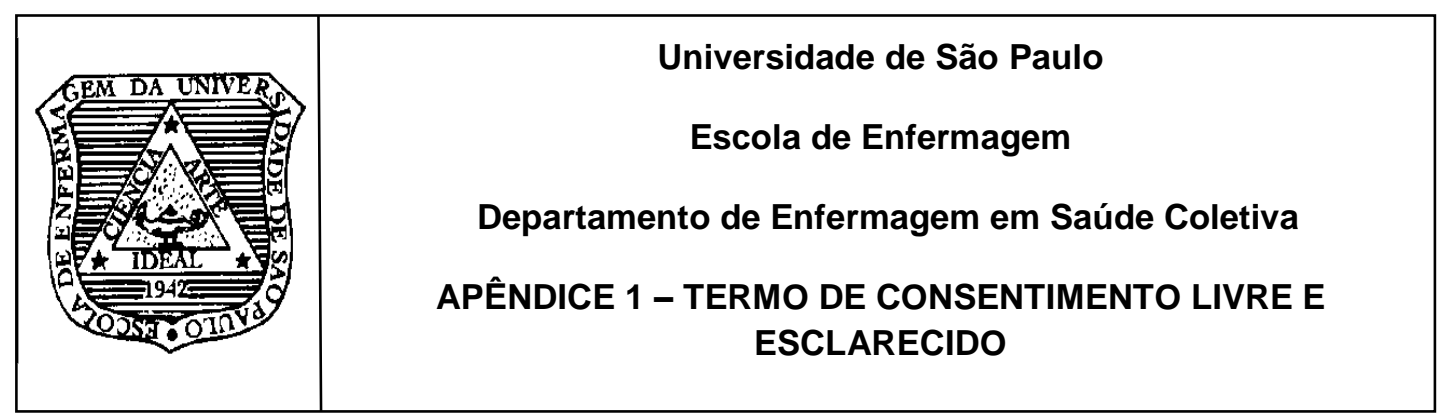

\section{TERMO DE CONSENTIMENTO LIVRE E ESCLARECIDO}

(Obrigatório para Pesquisas Científicas em Seres Humanos- Resolução no 196 de 10/10/96- CNS)

\section{Pesquisa - Conhecimento e Uso da Anticoncepção de Emergência entre Adolescentes Estudantes do Ensino Médio no Município de Arujá, São Paulo}

Sou obstetriz e mestranda da Escola de Enfermagem da USP. Estou conduzindo

um estudo sobre adolescentes. Gostaria de saber o quanto os adolescentes estudantes da Escola sabem sobre a pílula do dia seguinte e de que forma estão utilizando-a.

A pesquisa consiste em responder a um questionário que será distribuído em sala de aula. Neste questionário, há perguntas de cunho íntimo e pessoal, relativas a namoro e sexualidade, assim como ao conhecimento que se tem sobre a pílula do dia seguinte.

Garanto que você não será identificado(a) e todas as informações contidas no questionário permanecerão confidenciais. Logo após preencher o questionário, peço que o coloque dentro da urna que se encontra na sala de aula.

Esclareço que a participação na pesquisa é voluntária.

Este formulário serve para comprovar que você está de acordo em participar desta pesquisa.

Você precisa assinar as duas cópias, ficar com uma para você e devolver a outra para a pesquisadora.

Arujá, SP de de 2011. 


\begin{tabular}{|r|r|}
\hline $\begin{array}{r}\text { Escola de Enfermagem da Universidade de São Paulo } \\
\text { Conhecimento e Uso da Anticoncepção de Emergência entre } \\
\text { Adolescentes Estudantes do Ensino Médio de Arujá, São Paulo } \\
\text { APENDICE 2 - QUESTIONÁRIO }\end{array}$ \\
\hline
\end{tabular}

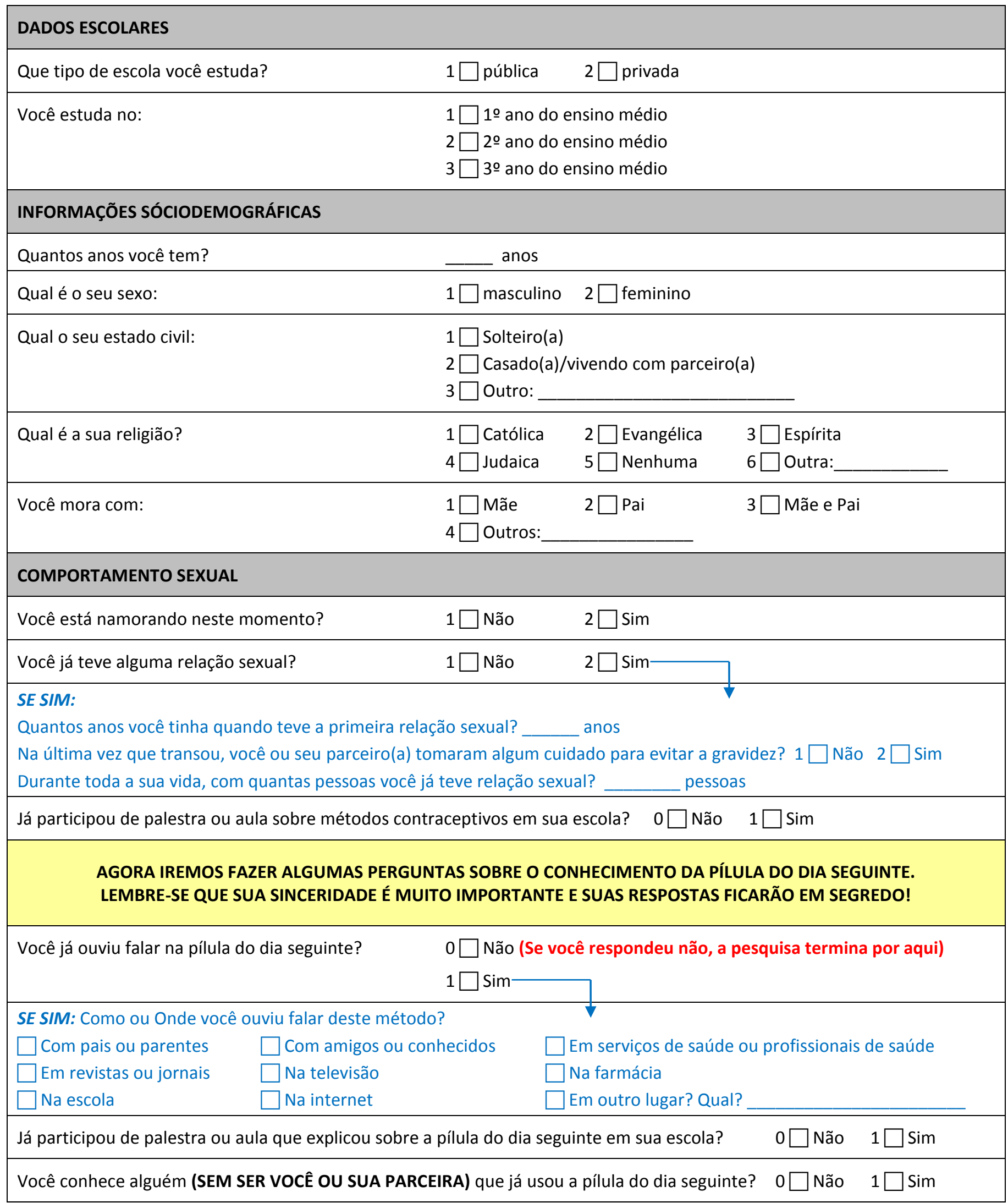




\begin{tabular}{|lrr}
\hline A SEGUIR, RESPONDA O QUE VOCÊ SABE SOBRE A PÍLULA DO DIA SEGUINTE. ANTES DE RESPONDER, ANALISE CADA QUESTÃO! \\
\hline QUESTÃO & FALSO & VERDADEIRO \\
\hline
\end{tabular}

a. A pílula do dia seguinte deve ser usada antes da relação sexual

b. A pílula do dia seguinte previne doenças sexualmente transmissíveis

c. Em caso de vômito até 2 horas após a ingestão da pílula do dia seguinte, deve-se repetir a dose

d. A pílula o dia seguinte é mais eficaz que os outros métodos contraceptivos (como camisinha, pílula, DIU)

e. Ao usar a pílula do dia seguinte, deve-se estar atento para que isso ocorra em torno de 5 dias após uma relação sexual desprotegida

f. A pílula do dia seguinte pode ser usada uma vez por mês

g. A pílula do dia seguinte é abortiva

h. A pílula do dia seguinte precisa ser utilizada somente quando a mulher está no período fértil

i. A pílula do dia seguinte pode substituir a pílula oral comum

j. Ao utilizar a pílula do dia seguinte, a mulher estará protegida de uma gravidez até a chegada da menstruação

\section{AGORA, PERGUNTAREMOS SOBRE O USO DA PÍLULA DO DIA SEGUINTE!}

Você ou alguma parceira já usou alguma vez a pílula do dia seguinte?
$0 \square$ Não (Se você marcou essa opção, a pesquisa termina por aqui)

$1 \square \operatorname{Sim}$

$2 \square$ Não Sei (Se você marcou essa opção, a pesquisa termina por aqui)

SE SIM: Da última vez em que usou a pílula do dia seguinte, qual foi a razão?
$1 \square$ o método que usava falhou
$2 \square$ Esqueci de usar algum método
$3 \square$ Não quis usar nenhum método
$4 \square$ Fui vítima de violência sexual
$5 \square$ Por pura insegurança
$6 \square$ Outros:

Nessa última vez que usou a pílula do $\quad 1 \square$ fixo(a)/regular, como com namorado(a) dia seguinte, o relacionamento era... $2 \square$ eventual, como com ficante

\begin{tabular}{|c|c|c|c|c|}
\hline \multirow{3}{*}{$\begin{array}{l}\text { Qual método contraceptivo estava } \\
\text { sendo usado quando usou a pílula do } \\
\text { dia seguinte? }\end{array}$} & 1 & $\square$ Nenhum & $2 \square$ Tabelinha & $3 \square$ Coito interrompido \\
\hline & 4 & $\square$ Pílula & $5 \square$ Camisinha & $6 \square$ Camisinha feminina \\
\hline & 7 & DIU & $8 \square$ Diafragma & $9 \square$ Anticoncepcional injetável \\
\hline
\end{tabular}

A pílula do dia seguinte foi adquirida com receita médica? $0 \square$ Não $1 \square$ Sim

Onde você ou sua parceira conseguiu a pílula do dia seguinte?
$1 \square$ Na farmácia
$2 \square$ No posto de saúde
$3 \square$ No médico particular ou do convênio
$4 \square$ Com amigos ou conhecidos
$5 \square$ Namorado(a) que trouxe
$6 \square$ Com parente
$7 \square$ Outros. Qual?

A pílula do dia seguinte foi tomada quanto tempo após a relação sexual desprotegida? horas ou dias Não sei

Quantas vezes você ou sua parceira utilizaram a pílula do dia seguinte no último ano? vezes $\square$ Não sei 


\begin{tabular}{|c|c|} 
Universidade de São Paulo \\
Escola de Enfermagem \\
APENADICE 3 - CONSTRUÇÃO DOS MODELOS DE REGRESSÃO \\
LINEAR
\end{tabular}

Construção dos modelos de regressão linear considerando as características sociodemográficas e das experiências amorosas e sexuais em relação ao escore de conhecimento da anticoncepção de emergência, Arujá 2011.

CONSTRUÇÃO DOS MODELOS DE REGRESSÃO LINEAR

\begin{tabular}{|c|c|c|c|c|}
\hline Modelos & Variáveis & Categorias & $\beta$ & $I C_{95 \%}$ \\
\hline \multirow[t]{6}{*}{1} & Intercepto & & 5,60 & $5,24-5,96$ \\
\hline & Tipo de escola & Pública & $-1,08$ & $-1,45--0,71$ \\
\hline & & Privada & 0,00 & - \\
\hline & Ano escolar & $1^{\circ}$ ano & $-0,90$ & $-1,28--0,52$ \\
\hline & & $2^{\circ}$ ano & $-0,91$ & $-1,31--0,51$ \\
\hline & & $3^{\circ}$ ano & 0,00 & - \\
\hline \multirow[t]{11}{*}{2} & Intercepto & & 5,52 & $3,50-7,54$ \\
\hline & Tipo de escola & Pública & $-1,08$ & $-1,46--0,71$ \\
\hline & & Privada & 0,00 & - \\
\hline & Ano escolar & $1^{\circ}$ ano & $-1,22$ & $-1,89--0,54$ \\
\hline & & $2^{\circ}$ ano & $-1,04$ & $-1,60--0,48$ \\
\hline & & $3^{\circ}$ ano & 0,00 & - \\
\hline & Idade & 15 anos & 0,49 & $-1,66-+2,63$ \\
\hline & & 16 anos & 0,22 & $-1,89-+2,32$ \\
\hline & & 17 anos & 0,11 & $-1,94-+2,16$ \\
\hline & & 18 anos & $-0,02$ & $-2,11-+2,07$ \\
\hline & & 19 anos & 0,00 & - \\
\hline
\end{tabular}


CONSTRUÇÃO DOS MODELOS DE REGRESSÃO LINEAR

\begin{tabular}{|c|c|c|c|c|}
\hline \multirow[t]{13}{*}{3} & Intercepto & & 5,96 & $3,95-7,98$ \\
\hline & Tipo de escola & Pública & $-1,01$ & $-1,38--0,64$ \\
\hline & & Privada & 0,00 & - \\
\hline & Ano escolar & $1^{\circ}$ ano & $-1,19$ & $-1,86--0,52$ \\
\hline & & $2^{\circ}$ ano & $-0,99$ & $-1,54--0,44$ \\
\hline & & $3^{\circ}$ ano & 0,00 & - \\
\hline & Idade & 15 anos & 0,24 & $-1,88-+2,37$ \\
\hline & & 16 anos & $-0,09$ & $-2,18-+2,00$ \\
\hline & & 17 anos & $-0,10$ & $-2,13-+1,93$ \\
\hline & & 18 anos & $-0,21$ & $-2,28-+1,86$ \\
\hline & & 19 anos & 0,00 & - \\
\hline & Sexo & Masculino & $-0,62$ & $-0,93--0,30$ \\
\hline & & Feminino & 0,00 & - \\
\hline \multirow[t]{16}{*}{4} & Intercepto & & 5,56 & $3,42-7,69$ \\
\hline & Tipo de escola & Pública & $-1,02$ & $-1,39--0,65$ \\
\hline & & Privada & 0,00 & - \\
\hline & Ano escolar & $1^{\circ}$ ano & $-1,15$ & $-1,82--0,48$ \\
\hline & & $2^{\circ}$ ano & $-0,96$ & $-1,51--0,41$ \\
\hline & & $3^{\circ}$ ano & 0,00 & - \\
\hline & Idade & 15 anos & 0,55 & $-1,59-+2,70$ \\
\hline & & 16 anos & 0,22 & $-1,89-+2,32$ \\
\hline & & 17 anos & 0,23 & $-1,82-+2,29$ \\
\hline & & 18 anos & 0,13 & $-1,97-+2,22$ \\
\hline & & 19 anos & 0,00 & - \\
\hline & Sexo & Masculino & $-0,62$ & $-0,94--0,31$ \\
\hline & & Feminino & 0,00 & - \\
\hline & Coabitação & Ambos pais & 0,01 & $-0,64-+0,65$ \\
\hline & & Somente mãe & 0,42 & $-0,30-+1,14$ \\
\hline & & Outras & 0,00 & - \\
\hline
\end{tabular}




\begin{tabular}{|c|c|c|c|c|c|}
\hline \multirow[t]{18}{*}{5} & Intercepto & & 5,60 & 3,47 & - 7,74 \\
\hline & Tipo de escola & Pública & $-1,01$ & $-1,38$ & $--0,64$ \\
\hline & & Privada & 0,00 & & - \\
\hline & Ano escolar & $1^{\circ}$ ano & $-1,17$ & $-1,84$ & $--0,50$ \\
\hline & & $2^{\circ}$ ano & $-0,97$ & $-1,53$ & $--0,42$ \\
\hline & & $3^{\circ}$ ano & 0,00 & & - \\
\hline & Idade & 15 anos & 0,61 & $-1,53$ & $-+2,76$ \\
\hline & & 16 anos & 0,26 & $-1,85$ & $-+2,37$ \\
\hline & & 17 anos & 0,27 & $-1,79$ & $-+2,33$ \\
\hline & & 18 anos & 0,14 & $-1,95$ & $-+2,24$ \\
\hline & & 19 anos & 0,00 & & - \\
\hline & Sexo & Masculino & $-0,58$ & $-0,91$ & $--0,26$ \\
\hline & & Feminino & 0,00 & & - \\
\hline & Coabitação & Ambos pais & 0,00 & $-0,64$ & $-+0,65$ \\
\hline & & mãe & 0,42 & $-0,30$ & - $+1,14$ \\
\hline & & Outras & 0,00 & & - \\
\hline & Namoro atual & Não & $-0,16$ & $-0,50$ & $-+0,18$ \\
\hline & & Sim & 0,00 & & - \\
\hline \multirow[t]{16}{*}{6} & Intercepto & & 6,06 & 3,94 & $-8,17$ \\
\hline & Tipo de escola & Pública & $-0,93$ & $-1,30$ & $--0,56$ \\
\hline & & Privada & 0,00 & & - \\
\hline & Ano escolar & $1^{\circ}$ ano & $-1,21$ & $-1,87$ & $--0,55$ \\
\hline & & $2^{\circ}$ ano & $-0,98$ & $-1,52$ & $-0,44$ \\
\hline & & $3^{\circ}$ ano & 0,00 & & - \\
\hline & Idade & 15 anos & 0,32 & $-1,80$ & - $+2,44$ \\
\hline & & 16 anos & $-10,00$ & $-2,19$ & $-+1,98$ \\
\hline & & 17 anos & $-0,15$ & $-2,18$ & $-+1,89$ \\
\hline & & 18 anos & $-0,33$ & $-2,40$ & $-+1,75$ \\
\hline & & 19 anos & 0,00 & & - \\
\hline & Sexo & Masculino & $-0,70$ & $-1,02$ & $-0,37$ \\
\hline & & Feminino & 0,00 & & - \\
\hline & Coabitação & $\begin{array}{c}\text { Ambos pais } \\
\text { Somente }\end{array}$ & 0,19 & $-0,45$ & $-+0,83$ \\
\hline & & mãe & 0,49 & $-0,22$ & $-+1,20$ \\
\hline & & Outras & 0,00 & & - \\
\hline
\end{tabular}




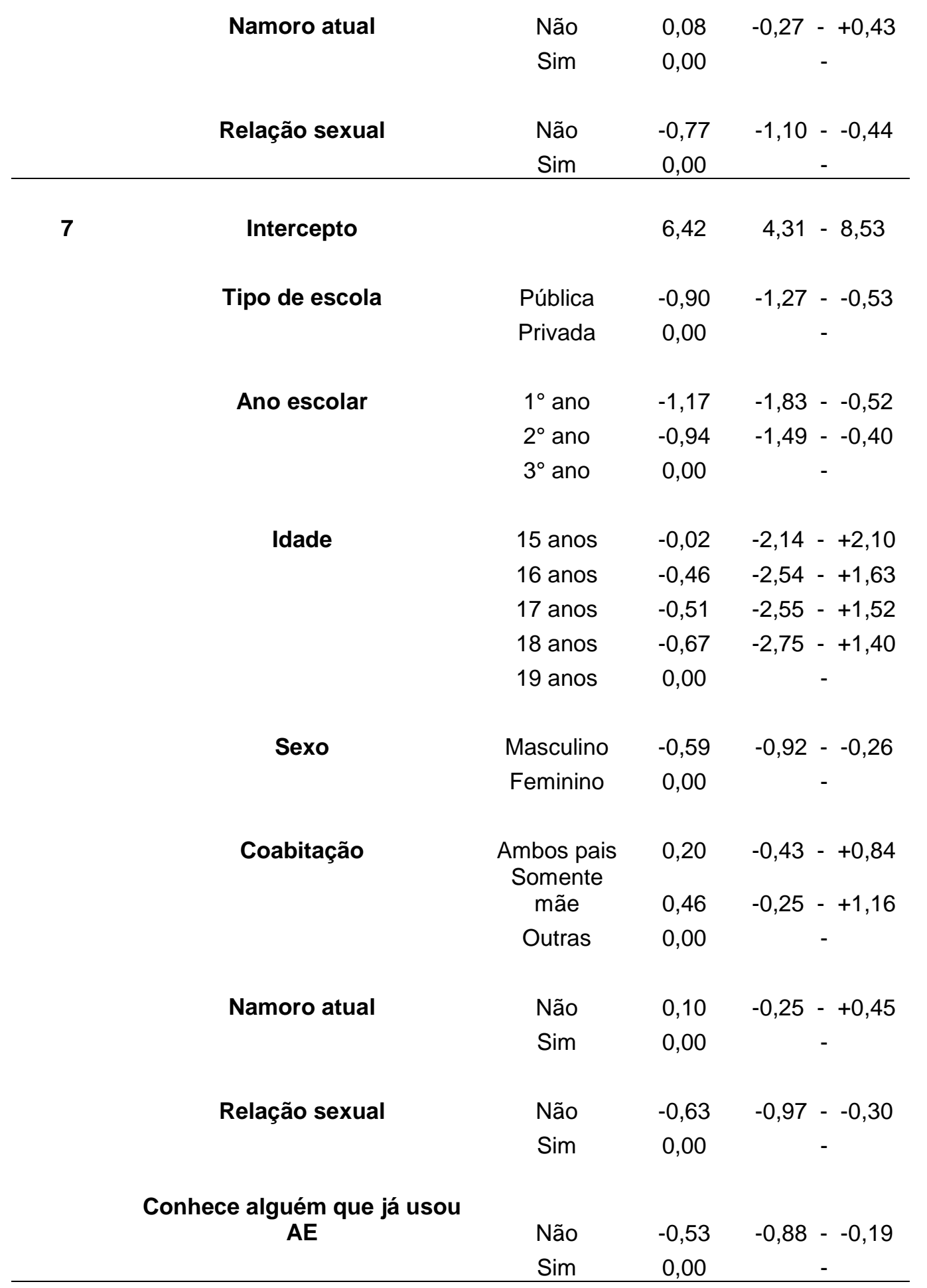


CONSTRUÇÃO DOS MODELOS DE REGRESSÃO LINEAR

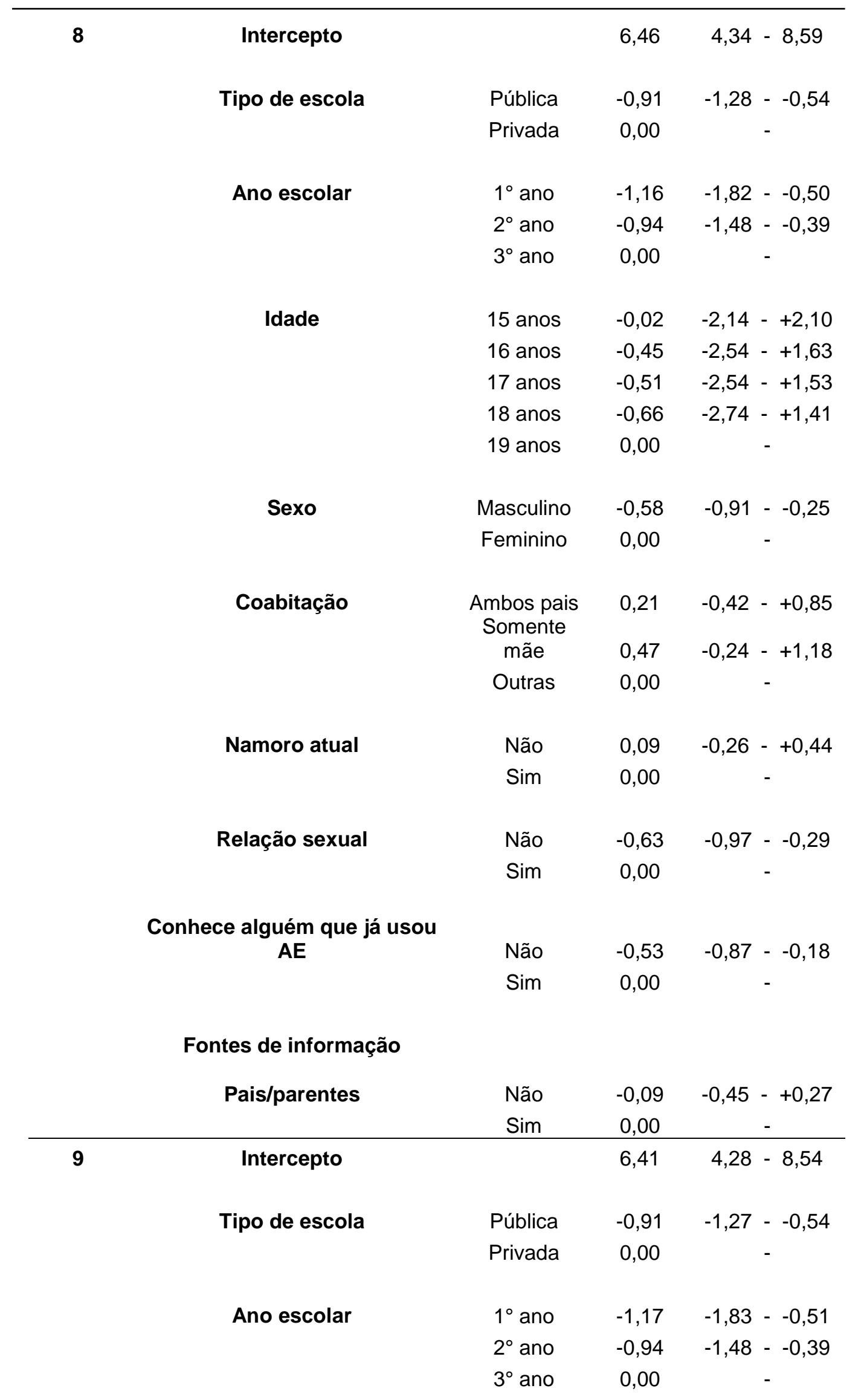




\begin{tabular}{|c|c|c|c|c|}
\hline \multirow[t]{5}{*}{ Idade } & 15 anos & $-0,02$ & $-2,14$ & $-+2,10$ \\
\hline & 16 anos & $-0,45$ & $-2,54$ & $-+1,63$ \\
\hline & 17 anos & $-0,51$ & $-2,54$ & $-+1,53$ \\
\hline & 18 anos & $-0,66$ & $-2,74$ & $-+1,41$ \\
\hline & 19 anos & 0,00 & & - \\
\hline \multirow[t]{2}{*}{ Sexo } & Masculino & $-0,60$ & $-0,93$ & $--0,26$ \\
\hline & Feminino & 0,00 & & - \\
\hline \multirow[t]{3}{*}{ Coabitação } & $\begin{array}{l}\text { Ambos pais } \\
\text { Somente }\end{array}$ & 0,23 & $-0,41$ & $-+0,87$ \\
\hline & mãe & 0,48 & $-0,23$ & $-+1,19$ \\
\hline & Outras & 0,00 & & - \\
\hline \multirow[t]{2}{*}{ Namoro atual } & Não & 0,09 & $-0,26$ & $-+0,44$ \\
\hline & Sim & 0,00 & & - \\
\hline \multirow[t]{2}{*}{ Relação sexual } & Não & $-0,64$ & $-0,99$ & $--0,30$ \\
\hline & Sim & 0,00 & & - \\
\hline \multicolumn{5}{|c|}{ ce alguém que já usou } \\
\hline \multirow[t]{2}{*}{$A E$} & Não & $-0,56$ & $-0,92$ & $--0,20$ \\
\hline & Sim & 0,00 & & - \\
\hline
\end{tabular}

Fontes de informação

Pais/parentes

Não $\quad-0,08 \quad-0,44-+0,28$

Sim

0,00

Amigos/conhecidos

Não $\quad 0,12 \quad-0,21-+0,41$

Sim

0,00

$10 \quad$ Intercepto

$6,72 \quad 4,56-8,87$

Tipo de escola

Pública

$-0,90 \quad-1,27--0,54$

Privada

0,00

Ano escolar

$1^{\circ}$ ano

$-1,16$

$-1,82--050$

$2^{\circ}$ ano

$-0,91 \quad-1,46--03,7$

$3^{\circ}$ ano

0,00

Idade

$\begin{array}{ccc}15 \text { anos } & -0,04 & -2,16-+2,07 \\ 16 \text { anos } & -0,48 & -2,56-+1,60 \\ 17 \text { anos } & -0,54 & -2,58-+1,49 \\ 18 \text { anos } & -0,75 & -2,82-+, 133 \\ 19 \text { anos } & 0,00 & -\end{array}$


CONSTRUÇÃO DOS MODELOS DE REGRESSÃO LINEAR

\begin{tabular}{|c|c|c|c|c|c|}
\hline & \multirow[t]{2}{*}{ Sexo } & Masculino & $-0,56$ & $-0,89$ & $--0,22$ \\
\hline & & Feminino & 0,00 & & - \\
\hline & \multirow[t]{3}{*}{ Coabitação } & Ambos pais & 0,27 & $-0,37$ & $-+0,91$ \\
\hline & & $\begin{array}{l}\text { Somente } \\
\text { mãe }\end{array}$ & 0,53 & $-0,18$ & $-+1,24$ \\
\hline & & Outras & 0,00 & & - \\
\hline & \multirow[t]{2}{*}{ Namoro atual } & Não & 0,10 & $-0,25$ & $-+0,45$ \\
\hline & & Sim & 0,00 & & - \\
\hline & \multirow[t]{2}{*}{ Relação sexual } & Não & $-0,64$ & $-0,98$ & $-0,30$ \\
\hline & & Sim & 0,00 & & - \\
\hline & \multirow{3}{*}{$\underset{A E}{\text { Conhece alguém que já usou }}$} & & & & \\
\hline & & Não & $-0,53$ & $-0,89$ & $--0,17$ \\
\hline & & Sim & 0,00 & & - \\
\hline & \multicolumn{5}{|l|}{ Fontes de informação } \\
\hline & \multirow[t]{2}{*}{ Pais/parentes } & Não & $-0,06$ & $-0,42$ & $-+0,30$ \\
\hline & & Sim & 0,00 & & - \\
\hline & \multirow[t]{2}{*}{ Amigos/conhecidos } & Não & 0,09 & $-0,24$ & $-+0,42$ \\
\hline & & Sim & 0,00 & & - \\
\hline & \multirow[t]{2}{*}{ Serviços de saúde } & Não & $-0,42$ & $-0,88$ & $-+0,04$ \\
\hline & & $\operatorname{Sim}$ & 0,00 & & - \\
\hline \multirow[t]{13}{*}{11} & Intercepto & & 6,86 & 4,69 & $-9,04$ \\
\hline & Tipo de escola & Pública & $-0,90$ & $-1,27$ & $--0,53$ \\
\hline & & Privada & 0,00 & & - \\
\hline & Ano escolar & $1^{\circ}$ ano & $-1,14$ & $-1,80$ & $--0,48$ \\
\hline & & $2^{\circ}$ ano & $-0,92$ & $-1,45$ & $--0,37$ \\
\hline & & $3^{\circ}$ ano & 0,00 & & - \\
\hline & Idade & 15 anos & $-0,08$ & $-2,20$ & $-+2,04$ \\
\hline & & 16 anos & $-0,50$ & $-2,58$ & $-+1,58$ \\
\hline & & 17 anos & $-0,58$ & $-2,62$ & $-+1,46$ \\
\hline & & 18 anos & $-0,78$ & $-2,85$ & $-+1,29$ \\
\hline & & 19 anos & 0,00 & & - \\
\hline & Sexo & Masculino & $-0,54$ & $-0,88$ & $--0,20$ \\
\hline & & Feminino & 0,00 & & - \\
\hline
\end{tabular}




\section{Coabitação}

Namoro atual

Relação sexual

Conhece alguém que já usou

$$
A E
$$

Não

Sim
$-0,36-+0,93$

Ambos pais

2,80

0,55

$-0,16-+1,27$

Outras

0,00

Não

Sim

$0,10 \quad-0,25-+0,45$

0,00

Não

$-0,64$

$-0,99--0,30$

Sim

0,00
$A E$

Fontes de informação

Pais/parentes

Amigos/conhecidos

Serviços de saúde

Revistas/jornais

12

Não

$-0,04$

$-0,40-+0,32$

Sim

0,00

Não

Sim

0,10

0,00

Não

$-0,39$

Sim

0,00

Não

$-0,21$

$-0,65-+0,23$

Sim

0,00

7,05

$4,85-9,25$

Tipo de escola

Ano escolar

Idade

Sexo

\begin{tabular}{|c|c|}
\hline Pública & $-0,91$ \\
\hline Privada & 0,00 \\
\hline
\end{tabular}

$1^{\circ}$ ano

$-1,14 \quad-1,80--0,48$

$2^{\circ}$ ano

$-0,93 \quad-1,47--0,39$

$3^{\circ}$ ano

0,00

15 anos

$-0,04 \quad-2,09-+2,17$

16 anos

$-0,38 \quad-2,47-+1,72$

17 anos

$-0,47 \quad-2,52-+1,57$

18 anos

$-0,67 \quad-2,75-+1,41$

19 anos

0,00

Masculino $\quad-0,53 \quad-0,87--0,19$

Feminino $\quad 0,00$ 
CONSTRUÇÃO DOS MODELOS DE REGRESSÃO LINEAR

\begin{tabular}{|c|c|c|c|c|c|}
\hline & \multirow[t]{3}{*}{ Coabitação } & Ambos pais & 0,28 & $-0,36$ & $-+0,92$ \\
\hline & & Somente mãe & 0,56 & $-0,15$ & $-+1,27$ \\
\hline & & Outras & 0,00 & & - \\
\hline & \multirow[t]{2}{*}{ Relação sexual } & Não & $-0,64$ & $-0,98$ & $--0,30$ \\
\hline & & Sim & 0,00 & & - \\
\hline & \multirow{3}{*}{$\underset{A E}{\text { Conhece alguém que já usou }}$} & & & & \\
\hline & & Não & $-0,53$ & $-0,89$ & $--0,17$ \\
\hline & & Sim & 0,00 & & - \\
\hline & \multicolumn{5}{|l|}{ Fontes de informação } \\
\hline & \multirow[t]{2}{*}{ Pais/parentes } & Não & $-0,04$ & $-0,40$ & $-+0,32$ \\
\hline & & Sim & 0,00 & & - \\
\hline & \multirow[t]{2}{*}{ Amigos/conhecidos } & Não & 0,10 & $-0,23$ & $-+0,43$ \\
\hline & & Sim & 0,00 & & - \\
\hline & \multirow[t]{2}{*}{ Serviços de saúde } & Não & $-0,34$ & $-0,82$ & $-+0,13$ \\
\hline & & Sim & 0,00 & & - \\
\hline & \multirow[t]{2}{*}{ Revistas/jornais } & Não & $-0,20$ & $-0,64$ & $-+0,25$ \\
\hline & & Sim & 0,00 & & - \\
\hline & \multirow[t]{2}{*}{ Farmácia } & Não & $-0,37$ & $-1,03$ & $-+0,29$ \\
\hline & & Sim & 0,00 & & - \\
\hline \multirow[t]{15}{*}{13} & Intercepto & & 7,17 & 4,97 & $-9,36$ \\
\hline & \multirow[t]{2}{*}{ Tipo de escola } & Pública & $-0,87$ & $-1,24$ & $--0,50$ \\
\hline & & Privada & 0,00 & & - \\
\hline & \multirow[t]{3}{*}{ Ano escolar } & $1^{\circ}$ ano & $-1,11$ & $-1,79$ & $--0,43$ \\
\hline & & $2^{\circ}$ ano & $-0,83$ & $-1,39$ & $--0,27$ \\
\hline & & $3^{\circ}$ ano & 0,00 & & - \\
\hline & \multirow[t]{5}{*}{ Idade } & 15 anos & $-0,04$ & $-2,15$ & $-+2,08$ \\
\hline & & 16 anos & $-0,51$ & $-2,59$ & - +1,57 \\
\hline & & 17 anos & $-0,51$ & $-2,54$ & $-+1,52$ \\
\hline & & 18 anos & $-0,81$ & $-2,88$ & $-+1,26$ \\
\hline & & 19 anos & 0,00 & & - \\
\hline & Sexo & $\begin{array}{l}\text { Masculino } \\
\text { Feminino }\end{array}$ & $-0,53$ & $-0,87$ & - $-0,19$ \\
\hline & \multirow[t]{3}{*}{ Coabitação } & Ambos pais & 0,38 & $-0,27$ & $-+1,04$ \\
\hline & & Somente mãe & 0,60 & $-0,13$ & $-+1,33$ \\
\hline & & Outras & 0,00 & & - \\
\hline
\end{tabular}




\begin{tabular}{|c|c|c|c|c|c|}
\hline & Relação sexual & Não & $-0,64$ & $-1,07$ & $--0,21$ \\
\hline & & Sim & 0,00 & & - \\
\hline & $\underset{A E}{\text { Conhece alguém que já usou }}$ & Não & $-0,53$ & $-0,90$ & $-0,16$ \\
\hline & & Sim & 0,00 & & - \\
\hline & Fontes de informação & & & & \\
\hline & Pais/parentes & Não & $-0,16$ & $-0,53$ & $-+0,20$ \\
\hline & & Sim & 0,00 & & - \\
\hline & Amigos/conhecidos & Não & 0,78 & $-0,26$ & $-+0,41$ \\
\hline & & Sim & 0,00 & & - \\
\hline & Serviços de saúde & Não & $-0,31$ & $-0,79$ & $-+0,17$ \\
\hline & & Sim & 0,00 & & - \\
\hline & Revistas/jornais & Não & $-0,32$ & $-0,79$ & $-+0,16$ \\
\hline & & Sim & 0,00 & & - \\
\hline & Farmácia & Não & $-0,32$ & $-0,98$ & $-+0,34$ \\
\hline & & Sim & 0,00 & & - \\
\hline & Internet & $\begin{array}{l}\text { Não } \\
\text { Sim }\end{array}$ & $\begin{array}{l}0,08 \\
0,00\end{array}$ & $-0,38$ & $-+0,55$ \\
\hline & Uso da AE & $\begin{array}{l}\text { Não } \\
\text { Sim }\end{array}$ & $-0,12$ & $-0,59$ & $-+0,35$ \\
\hline Modelo & Intercepto & & 6,14 & 5,75 & $-6,53$ \\
\hline & Tipo de escola & Pública & $-0,89$ & $-1,26$ & $--0,53$ \\
\hline & & Privada & 0,00 & & - \\
\hline & Ano escolar & $1^{\circ}$ ano & $-0,80$ & $-1,18$ & $--0,43$ \\
\hline & & $2^{\circ}$ ano & $-0,86$ & $-1,25$ & $--0,47$ \\
\hline & & $3^{\circ}$ ano & 0,00 & & - \\
\hline & Sexo & Masculino & $-0,55$ & $-0,86$ & $--0,23$ \\
\hline & & Feminino & 0,00 & & - \\
\hline & Relação sexual & Não & $-0,58$ & $-0,90$ & $--0,26$ \\
\hline & & Sim & 0,00 & & - \\
\hline & Conhece alguém que já usou & & & & \\
\hline & $\mathrm{AE}$ & Não & $-0,52$ & $-0,86$ & $--0,18$ \\
\hline & & Sim & 0,00 & & - \\
\hline
\end{tabular}




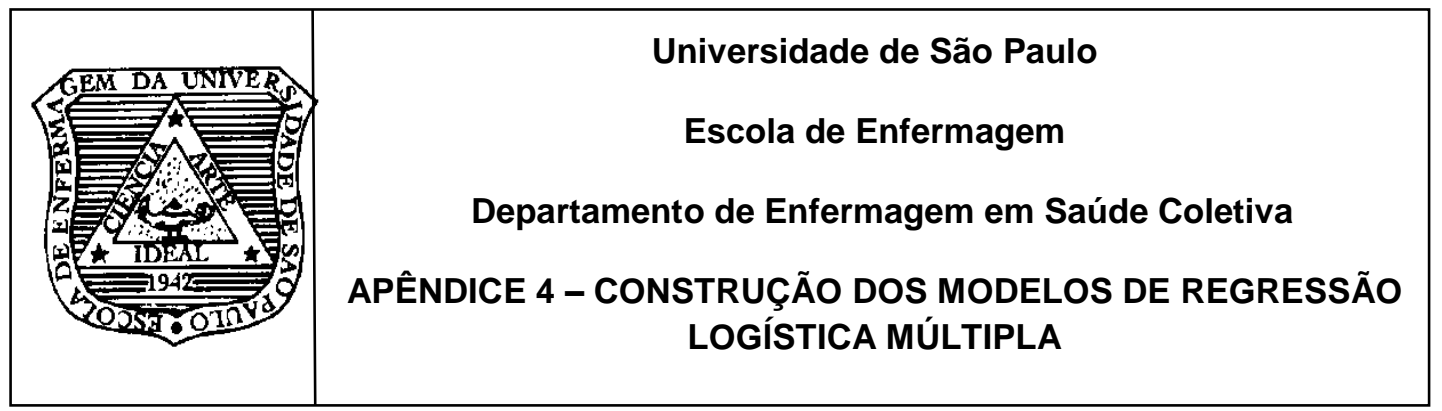

Construção dos modelos de regressão logística múltipla considerando as características sociodemográficas e das experiências amorosas e sexuais em relação ao uso da anticoncepção de emergência, Arujá - 2011.

\begin{tabular}{|c|c|c|c|c|}
\hline Modelo & Variáveis & Categorias & OR & $I_{95 \%}$ \\
\hline \multirow[t]{6}{*}{1} & Tipo de escola & Pública & 1,00 & - \\
\hline & & Privada & 0,99 & $0,61-1,64$ \\
\hline & Religião & Nenhuma & 1,00 & - \\
\hline & & Católica & 0,53 & $0,28-0,98$ \\
\hline & & Evangélica & 0,48 & $0,26-0,90$ \\
\hline & & Outras & 0,51 & $0,20-1,26$ \\
\hline \multirow[t]{8}{*}{2} & Tipo de escola & Pública & 1,00 & - \\
\hline & & Privada & 0,92 & $0,55-1,54$ \\
\hline & Religião & Nenhuma & 1,00 & - \\
\hline & & Católica & 0,54 & $0,29-1,02$ \\
\hline & & Evangélica & 0,44 & $0,23-0,84$ \\
\hline & & Outras & 0,49 & $0,19-1,25$ \\
\hline & Namoro atual & Não & 1,00 & - \\
\hline & & Sim & 2,42 & $1,51-3,90$ \\
\hline \multirow[t]{10}{*}{3} & Tipo de escola & Pública & 1,00 & - \\
\hline & & Privada & 0,94 & $0,57-1,58$ \\
\hline & Religião & Nenhuma & 1,00 & - \\
\hline & & Católica & 0,56 & $0,30-1,07$ \\
\hline & & Evangélica & 0,45 & $0,23-0,86$ \\
\hline & & Outras & 0,49 & $0,19-1,26$ \\
\hline & Namoro atual & Não & 1,00 & - \\
\hline & & Sim & 2,39 & $1,48-3,85$ \\
\hline & Palestra sobre AE & Não & 1,00 & - \\
\hline & & Sim & 1,58 & $0,93-2,68$ \\
\hline
\end{tabular}


CONSTRUÇÃO DOS MODELOS DE REGRESSÃO LOGÍSTICA

\begin{tabular}{|c|c|c|c|c|}
\hline \multirow[t]{12}{*}{4} & \multirow[t]{2}{*}{ Tipo de escola } & Pública & 1,00 & - \\
\hline & & Privada & 0,75 & $0,44-1,30$ \\
\hline & \multirow[t]{4}{*}{ Religião } & Nenhuma & 1,00 & - \\
\hline & & Católica & 0,49 & $0,25-0,96$ \\
\hline & & Evangélica & 0,51 & $0,25-1,02$ \\
\hline & & Outras & 0,54 & $0,20-1,45$ \\
\hline & \multirow[t]{2}{*}{ Namoro atual } & Não & 1,00 & - \\
\hline & & Sim & 2,22 & $1,34-3,68$ \\
\hline & \multirow[t]{2}{*}{ Palestra sobre AE } & Não & 1,00 & - \\
\hline & & Sim & 1,42 & $0,81-2,47$ \\
\hline & Conhece alguém que & Não & 1,00 & - \\
\hline & já usou AE & Sim & 5,89 & $\begin{array}{l}3,12- \\
11,12\end{array}$ \\
\hline \multirow[t]{13}{*}{5} & \multirow[t]{2}{*}{ Tipo de escola } & Pública & 1,00 & - \\
\hline & & Privada & 0,68 & $0,39-1,20$ \\
\hline & \multirow[t]{4}{*}{ Religião } & Nenhuma & 1,00 & - \\
\hline & & Católica & 0,48 & $0,24-0,95$ \\
\hline & & Evangélica & 0,52 & $0,26-1,04$ \\
\hline & & Outras & 0,54 & $0,20-1,44$ \\
\hline & \multirow[t]{2}{*}{ Namoro atual } & Não & 1,00 & - \\
\hline & & Sim & 2,17 & $1,31-3,60$ \\
\hline & \multirow[t]{2}{*}{ Palestra sobre AE } & Não & 1,00 & - \\
\hline & & Sim & 1,49 & $0,85-2,61$ \\
\hline & Conhece alguém que & Não & 1,00 & - \\
\hline & já usou $A E$ & Sim & 5,59 & $\begin{array}{l}2,94- \\
10,62\end{array}$ \\
\hline & $\begin{array}{l}\text { Escore de conhecimento } \\
A E\end{array}$ & 0 à 10 & 1,09 & $0,96-1,24$ \\
\hline
\end{tabular}




\begin{tabular}{|c|c|c|c|c|}
\hline \multirow[t]{15}{*}{6} & \multirow[t]{2}{*}{ Tipo de escola } & Pública & 1,00 & - \\
\hline & & Privada & 0,68 & $0,39-1,20$ \\
\hline & \multirow[t]{4}{*}{ Religião } & Nenhuma & 1,00 & - \\
\hline & & Católica & 0,48 & $0,24-0,94$ \\
\hline & & Evangélica & 0,52 & $0,26-1,04$ \\
\hline & & Outras & 0,53 & $0,20-1,42$ \\
\hline & \multirow[t]{2}{*}{ Namoro atual } & Não & 1,00 & - \\
\hline & & Sim & 2,15 & $1,29-3,58$ \\
\hline & \multirow[t]{2}{*}{ Palestra sobre AE } & Não & 1,00 & - \\
\hline & & Sim & 1,49 & $0,85-2,62$ \\
\hline & Conhece alguém que & Não & 1,00 & - \\
\hline & já usou $A E$ & Sim & 5,22 & $\begin{array}{l}2,70- \\
10,12\end{array}$ \\
\hline & Escore de conhecimento AE & 0 à 10 & 1,09 & $0,96-1,24$ \\
\hline & Amigos ou conhecidos & Não & 1,00 & - \\
\hline & & Sim & 1,24 & $0,73-2,09$ \\
\hline \multirow[t]{17}{*}{7} & \multirow[t]{2}{*}{ Tipo de escola } & Pública & 1,00 & - \\
\hline & & Privada & 0,68 & $0,39-1,20$ \\
\hline & \multirow[t]{4}{*}{ Religião } & Nenhuma & 1,00 & - \\
\hline & & Católica & 0,48 & $0,24-0,96$ \\
\hline & & Evangélica & 0,53 & $0,26-1,05$ \\
\hline & & Outras & 0,52 & $0,19-1,40$ \\
\hline & \multirow[t]{2}{*}{ Namoro atual } & Não & 1,00 & - \\
\hline & & Sim & 2,11 & $1,27-3,51$ \\
\hline & \multirow[t]{2}{*}{ Palestra sobre AE } & Não & 1,00 & - \\
\hline & & $\operatorname{Sim}$ & 1,52 & $0,86-2,67$ \\
\hline & Conhece alguém que & Não & 1,00 & - \\
\hline & já usou $A E$ & $\operatorname{Sim}$ & 5,20 & $\begin{array}{l}2,68- \\
10,10\end{array}$ \\
\hline & Escore de conhecimento AE & 0 à 10 & 1,10 & $0,97-1,24$ \\
\hline & \multirow[t]{2}{*}{ Amigos ou conhecidos } & Não & 1,00 & - \\
\hline & & Sim & 1,21 & $0,72-2,06$ \\
\hline & \multirow[t]{2}{*}{ Televisão } & Não & 1,00 & - \\
\hline & & Sim & 0,69 & $0,39-1,20$ \\
\hline
\end{tabular}




\begin{tabular}{|c|c|c|c|c|}
\hline \multicolumn{5}{|c|}{ CONSTRUÇÃO DOS MODELOS DE REGRESSÃO LOGÍSTICA } \\
\hline \multirow[t]{6}{*}{8} & \multirow[t]{2}{*}{ Tipo de escola } & Pública & 1,00 & - \\
\hline & & Privada & 0,69 & $0,39-1,21$ \\
\hline & \multirow[t]{4}{*}{ Religião } & Nenhuma & 1,00 & - \\
\hline & & Católica & 0,49 & $0,25-0,98$ \\
\hline & & Evangélica & 0,53 & $0,26-1,07$ \\
\hline & & Outras & 0,52 & $0,19-1,41$ \\
\hline & \multirow[t]{2}{*}{ Namoro atual } & Não & 1,00 & - \\
\hline & & Sim & 2,15 & $1,28-3,58$ \\
\hline & \multirow[t]{2}{*}{ Palestra sobre AE } & Não & 1,00 & - \\
\hline & & Sim & 1,31 & $0,70-2,45$ \\
\hline & Conhece alguém que & Não & 1,00 & - \\
\hline & já usou $A E$ & Sim & 5,17 & $\begin{array}{l}2,66- \\
10,06\end{array}$ \\
\hline & $\begin{array}{l}\text { Escore de conhecimento } \\
A E\end{array}$ & 0 à 10 & 1,10 & $0,97-1,25$ \\
\hline & \multirow[t]{2}{*}{ Amigos ou conhecidos } & Não & 1,00 & - \\
\hline & & Sim & 1,22 & $0,72-2,07$ \\
\hline & \multirow[t]{2}{*}{ Televisão } & Não & 1,00 & - \\
\hline & & Sim & 0,64 & $0,36-1,13$ \\
\hline & \multirow[t]{2}{*}{ Escola } & Não & 1,00 & - \\
\hline & & Sim & 1,39 & $0,76-2,55$ \\
\hline Final do & \multirow[t]{2}{*}{ Tipo de escola } & Pública & 1,00 & - \\
\hline \multirow[t]{9}{*}{ Bloco } & & Privada & 0,74 & $0,43-1,27$ \\
\hline & \multirow[t]{4}{*}{ Religião } & Nenhuma & 1,00 & - \\
\hline & & Católica & 0,47 & $0,24-0,92$ \\
\hline & & Evangélica & 0,50 & $0,25-1,01$ \\
\hline & & Outras & 0,53 & $0,20-1,43$ \\
\hline & \multirow[t]{2}{*}{ Namoro atual } & Não & 1,00 & - \\
\hline & & Sim & 2,24 & $1,35-3,71$ \\
\hline & Conhece alguém que & Não & 1,00 & - \\
\hline & já usou $\mathrm{AE}$ & Sim & 6,04 & $\begin{array}{l}3,21- \\
11,39 \\
\end{array}$ \\
\hline
\end{tabular}




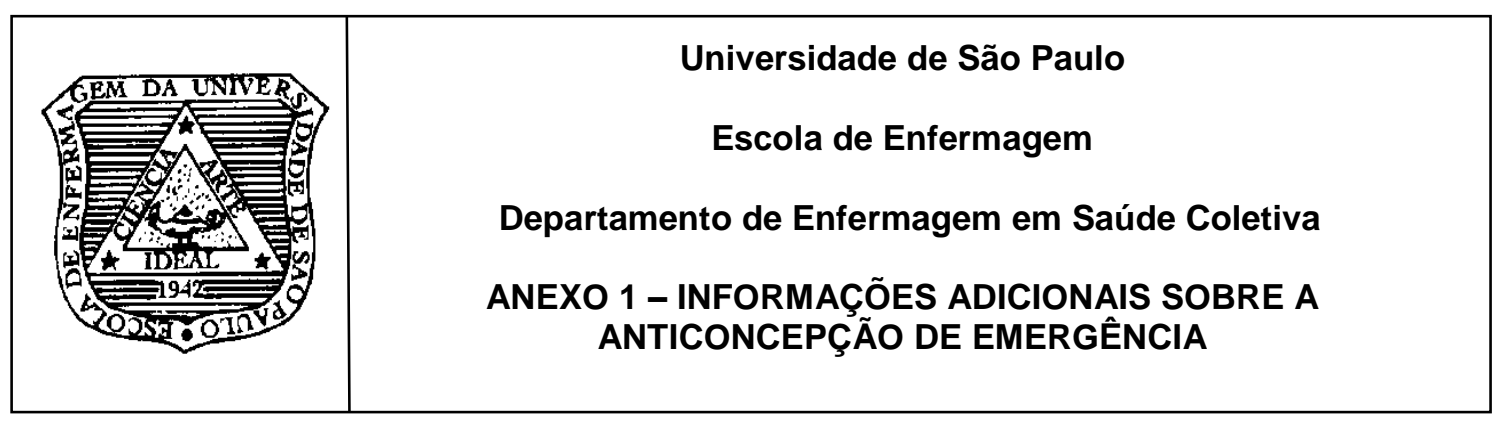

O método Yuzpe consiste na administração de pílulas anticoncepcionais combinadas, compostas de um estrogênio e um progestágeno sintéticos, administradas até cinco dias após a relação sexual desprotegida. A associação mais estudada, recomendada pela Organização Mundial de Saúde, é a que contém etinilestradiol e levonorgestrel. Para finalidade de anticoncepção de emergência, é necessária a dose total de $0,2 \mathrm{mg}$ de etinilestradiol e $1 \mathrm{mg}$ de levonorgestrel, divididas em duas doses iguais, com intervalo de 12 horas. A segunda forma de realizar a $A E$ é com o uso exclusivo de progestágeno, o levonorgestrel (LNG), na dose total de $1,5 \mathrm{mg}$. Nas apresentações comerciais com $0,75 \mathrm{mg}$ de levonorgestrel por comprimido, a $A E$ pode ser feita com a administração de 1 comprimido de $0,75 \mathrm{mg}$ a cada 12 horas ou, preferentemente, com 2 comprimidos de $0,75 \mathrm{mg}$ juntos, em dose única. Algumas preparações comerciais disponibilizam o levonorgestrel na dose de $1,5 \mathrm{mg}$ por comprimido. Nesse caso, utiliza-se 1 comprimido de $1,5 \mathrm{mg}$ em dose única. Este método, pode ser utilizado até cinco dias (120 horas) da relação sexual desprotegida.

Embora, as indicações do método de Yuzpe e do LNG sejam as mesmas, observam-se algumas vantagens do segundo sobre o primeiro. Como não contém estrogênios, o método do levonorgestrel está isento de efeitos colaterais e contraindicações. Outra vantagem do levonorgestrel é não apresentar interação farmacológica com medicamentos antirretrovirais. 


\begin{tabular}{|c|c|}
\hline (2) & $\begin{array}{c}\text { Universidade de São Paulo } \\
\text { Escola de Enfermagem } \\
\text { Departamento de Enfermagem em Saúde Coletiva } \\
\text { ANEXO } 1 \text { - INFORMAÇÕES ADICIONAIS SOBRE A } \\
\text { ANTICONCEPÇÃO DE EMERGÊNCIA }\end{array}$ \\
\hline
\end{tabular}

No método de Yuzpe, o etinil-estradiol pode interagir com alguns desses medicamentos e comprometer a eficácia da AE. Essa condição é importante para mulheres soropositivas que usam a $A E$, ou para mulheres em situação de violência sexual que utilizam, ao mesmo tempo, a AE para evitar a gravidez por estupro e os antirretrovirais para a profilaxia da infecção pelo HIV.

Além disso, embora ambos os métodos (LNG e método de Yuzpe) apresentam, em média, Índice de Efetividade entre 75 e 85\%, a eficácia da AE pode variar em função do tempo entre a relação sexual e sua administração (Brasil, 2010). A eficácia também está associada ao método utilizado, sendo significativamente maior para o levonorgestrel do que para o método Yuzpe. Segundo a Organização Mundial de Saúde, o método de Yuzpe apresenta taxas de falha de $2 \%$ entre 0 e 24 horas, de $4,1 \%$ entre 25 e 48 horas e de $4,7 \%$ entre 49 e 72 horas. Já para os mesmos períodos de tempo, as taxas de falha do levonorgestrel (LNG) são expressivamente menores, 0,4\%, 1,2\% e $2,7 \%$, respectivamente. Na média dos três primeiros dias, a taxa é de $3,2 \%$ para o método de Yuzpe e de 1,1\% para o levonorgestrel. Entre o $4^{\circ}$ e o $5^{\circ}$ dia, seguramente a taxa de falha da AE é mais elevada.

Fonte: Brasil. Ministério da Saúde. Saúde Sexual e Saúde Reprodutiva. Brasília; 2010. 


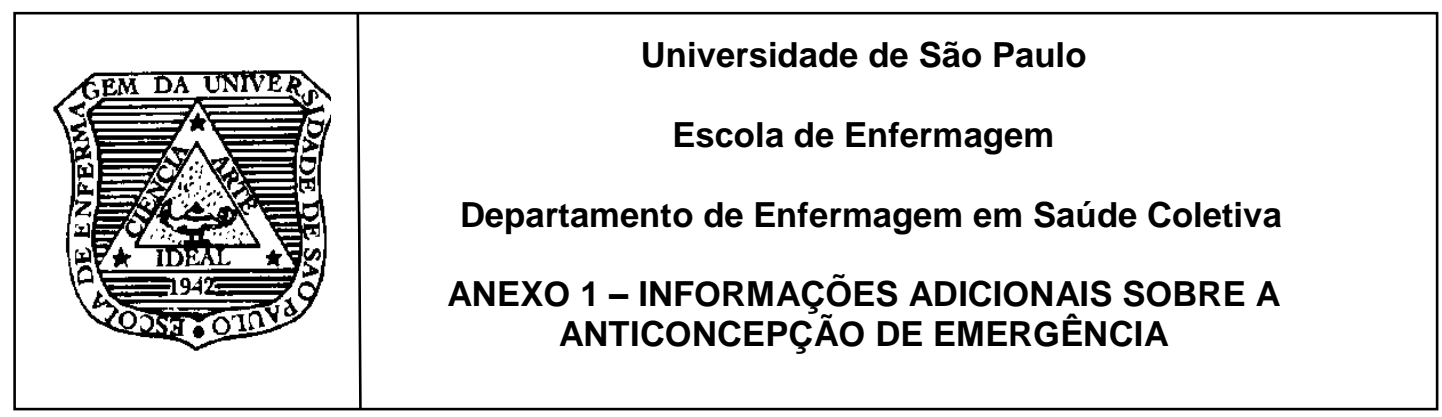

Outro fator relevante em relação à eficácia da $A E$ é que o uso repetitivo ou frequente compromete sua eficácia ao longo do tempo, que será sempre menor do que aquela obtida com o uso regular do método anticonceptivo de rotina no mesmo período.

Em relação ao funcionamento do método, este dependerá da época do ciclo menstrual na qual será utilizado. Dependendo do momento do ciclo menstrual em que é ministrada, seu mecanismo de ação variará bastante. Quando utilizada na primeira fase do ciclo, antes do pico do hormônio luteinizante $(\mathrm{LH})$, a $\mathrm{AE}$ altera o desenvolvimento dos folículos e, portanto, impede a ovulação ou a retarda por vários dias. No entanto, se a $A E$ for administrada muito próxima do momento da ruptura folicular ela terá pouca capacidade de impedir ou postergar a ovulação, o que pode explicar grande parte dos casos de falha do método. Quando administrada na segunda fase do ciclo menstrual, depois de ocorrida à ovulação, a $A E$ modifica a viscosidade do muco cervical, tornando-o espesso e hostil, impedindo ou dificultando a movimentação e deslocamento dos espermatozóides desde o colo do útero até as trompas, em direção ao óvulo. Vale ressaltar, que a $A E$ interfere nos eventos pré ou pós-ovulatórios imediatos, porém sempre antes da implantação. 


\begin{tabular}{|c|c|}
\hline & Universidade de São Paulo \\
& Escola de Enfermagem \\
\hline & Departamento de Enfermagem em Saúde Coletiva \\
\hline
\end{tabular}

\section{Estado de São Paulo - Município de Arujá}

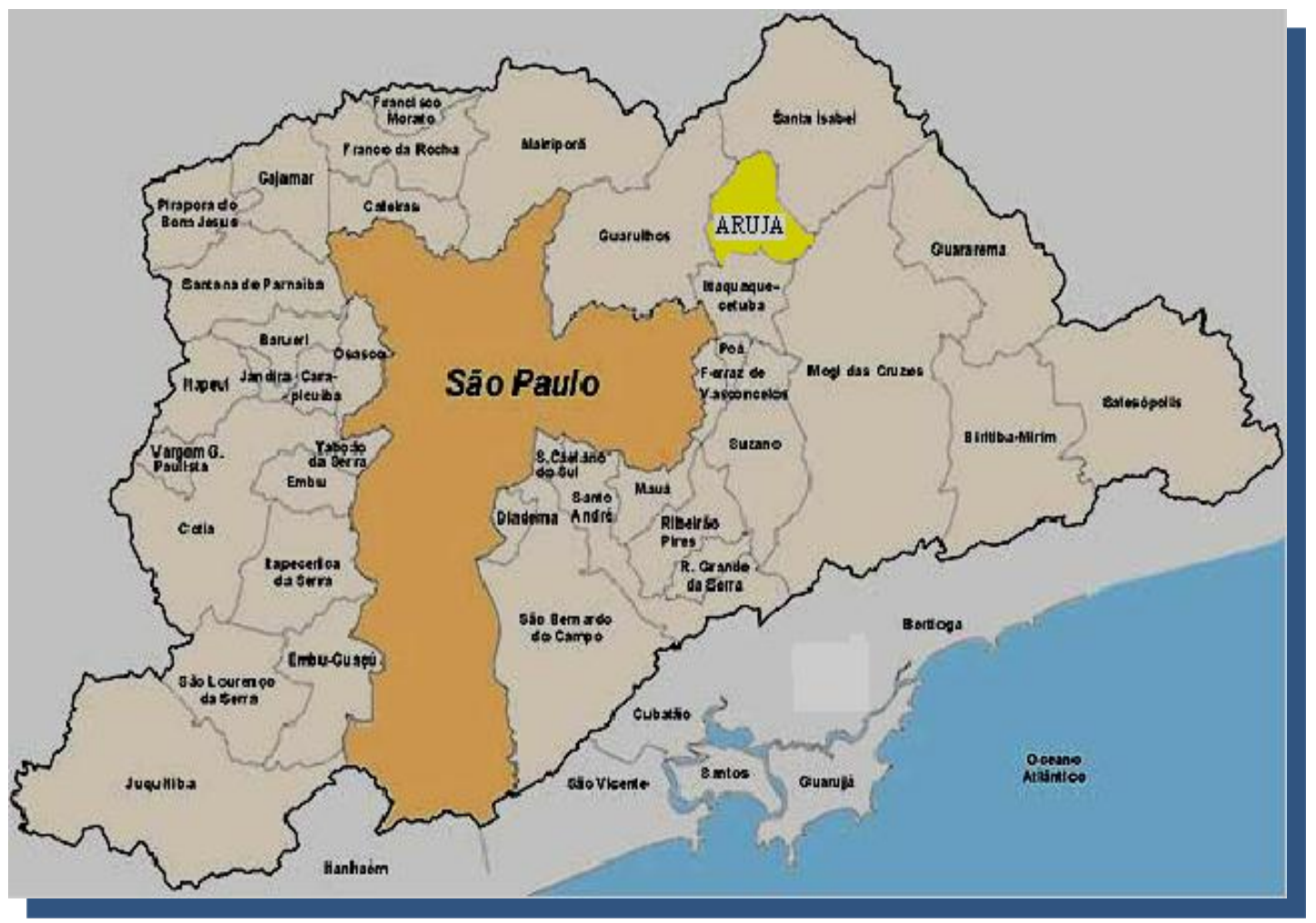

Fonte: Prefeitura de São Paulo: municípios da grande São Paulo. Disponível em: http://www.spturismo.com/grandesp.htm. 


\begin{tabular}{|c|c|} 
Universidade de São Paulo \\
Escola de Enfermagem \\
ANEXO 3 - APROVAÇÃO DO COMITÊ DE ÉTICA EM PESQUISA \\
ANTEmento de Enfermagem em Saúde Coletiva
\end{tabular}
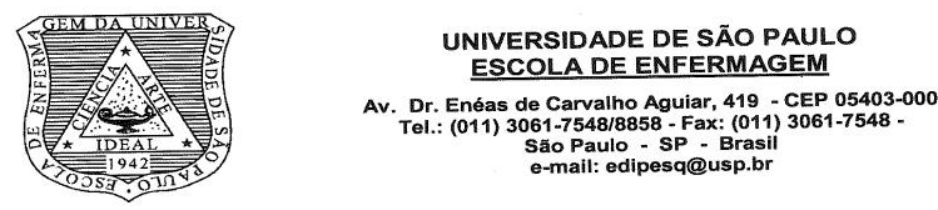

São Paulo, 06 de julho de 2011.

Ilm. ${ }^{a} \mathrm{Sr}^{\mathrm{a}}$

Prof. ${ }^{\text {a }}$ Dr. ${ }^{\text {a Ana Luiza Vilela Borges }}$

Ref.: Processo nº 1056/2011/CEP-EEUSP - SISNEP CAAE: 0063.0.196.196-11

Prezada Senhora,

Em atenção à solicitação referente à análise do projeto "Conhecimento e uso da anticoncepção de emergência entre adolescentes estudantes do ensino médio de Arujá, São Paulo", informamos que o mesmo foi considerado aprovado pelo Comitê de Ética em Pesquisa da Escola de Enfermagem da Universidade de São Paulo (CEP/EEUSP).

Analisado sob o aspecto ético-legal, atende às exigências da Resolução $\mathrm{n}^{\circ}$ 196/96 do Conselho Nacional de Saúde.

Esclarecemos que após o término da pesquisa, os resultados obtidos deverão ser encaminhados ao CEP/EEUSP, para serem anexados ao processo.

Atenciosamente,

Prof. Dr. Paolo Meneghin

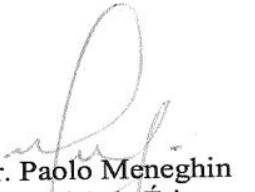

Vice-Coordenador do Comitê de Ética em Pesquisa da Escola de Enfermagem da Universidade de São Paulo 


\begin{tabular}{|c|c|}
\hline & Universidade de São Paulo \\
Escola de Enfermagem \\
ANEXO 4 - AUTORIZAÇÃO DA COORDENADORIA DE ENSINO \\
DO INTERIOR
\end{tabular}

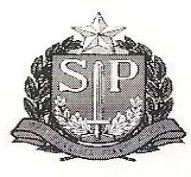

SECRETARIA DE ESTADO DA EDUCAÇÃO COORDENADORIA DE ENSINO DO INTERIOR DIRETORIA DE ENSINO-REGIÃO DE JACAREÍ

Rua Barão de Jacareí, 848 - centro - Jacareí/SP - fone: 3954-2640

Jacareí, 25 de agosto de 2011

Ofício n² 291/11

Assunto: Solicita autorização para pesquisa.

Prezada Senhora:

A Diretoria de Ensino - Região de Jacareí, pertencente a Secretaria de Estado da Educação, vem através do presente informar V.S $S^{a}$ que a Coordenadoria de Ensino do Interior CEI, autorizou a realização de pesquisa junto aos alunos do Ensino Médio das escolas estaduais no Município de Arujá, concernente ao Projeto "Conhecimento e Uso da Anticoncepção de Emergência entre Adolescentes Estudantes do Ensino Médio", sob responsabilidade da Escola de Enfermagem da Universidade de São Paulo - EEUSP, desde que sejam tomados os devidos cuidados em relação ao Termo de Consentimento Livre e Esclarecido dos pais ou responsáveis dos alunos que participarão da pesquisa.

e consideração.

No ensejo, apresentamos os protestos de estima

Atenciosamente

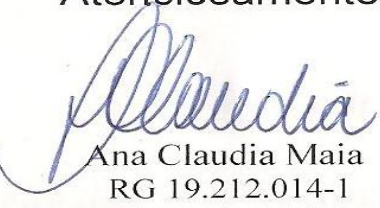

Dirigente Regional de Ensino

IIma. Sra

Christiane Borges do Nascimento

Aluna de Mestrado da USP

São Paulo/SP 